EMERSON BARROS VENCESLAU

\title{
AVALIAÇÃO DE MODELOS E PROPOSTA DE METODOLOGIA PARA PROJETO DE MISTURAS DE SOLVENTES APLICADAS \\ A TINTAS E VERNIZES
}


EMERSON BARROS VENCESLAU

\section{AVALIAÇÃO DE MODELOS E PROPOSTA DE METODOLOGIA PARA PROJETO DE MISTURAS DE SOLVENTES APLICADAS \\ A TINTAS E VERNIZES}

Dissertação apresentada à Escola

Politécnica da Universidade de São

Paulo para obtenção do Título de

Mestre em Engenharia 


\section{AVALIAÇÃO DE MODELOS E PROPOSTA DE METODOLOGIA PARA PROJETO DE MISTURAS DE SOLVENTES APLICADAS A TINTAS E VERNIZES}

Dissertação apresentada à Escola

Politécnica da Universidade de São

Paulo para obtenção do Título de

Mestre em Engenharia

Área de Concentração:

Engenharia Química

Orientador: Prof. Livre-Docente

Galo A. Carrillo Le Roux 
Este exemplar foi revisado e alterado em relação à versão original, sob responsabilidade única do autor e com a anuência de seu orientador.

São Paulo, de junho de 2011.

Assinatura do autor

Assinatura do orientador

FICHA CATALOGRÁFICA

Venceslau, Emerson Barros

Avaliação de modelos e proposta de metodologia para pro-

jeto de misturas de solventes aplicadas a tintas e vernizes / E.B.

Venceslau. -- ed.rev. -- São Paulo, 2011.

$120 \mathrm{p}$.

Dissertação (Mestrado) - Escola Politécnica da Universidade de São Paulo. Departamento de Engenharia Química.

1.Solvente 2.Evaporação 3.Matemática (Modelagem) 4.Otimização não linear I.Universidade de São Paulo. Escola Politécnica. Departamento de Engenharia Química II.t. 
Dedico este trabalho aos meus pais, Deocleciano e Edineide, e ao meu irmão Emmanuel. 


\section{AGRADECIMENTOS}

Ao meu orientador, Prof. Livre-Docente Galo Antonio Carrillo Le Roux, por ter aceitado me orientar, e ter apoiado este projeto.

Ao Prof. Dr. Pedro de Alcântara Pessoa Filho por ter aceitado o desafio de coorientação, e por ter tentando me fazer ver o problema com um olhar diferenciado: a visão termodinâmica.

À minha família e aos meus amigos, que compreenderam a minha ausência, meu distanciamento e minha impaciência em vários momentos.

Aos mestres da Escola Politécnica da Universidade de São Paulo, pelos ensinamentos e ajuda em sala de aula ou fora dela.

Aos gestores da Oxiteno M. Sc. André Luis Conde da Silva, eng ${ }^{a}$ Nádia Andrade Armelin e $\mathrm{eng}^{\circ}$ Marcio Tavares Lauria pela liberação do trabalho para cursar as disciplinas e apoio durante a execução do trabalho.

Aos profissionais e colegas: Celso Ferrari Jr., Cíntia Fávaro, Fábio Rosa, Jaqueline Venâncio, Juliane Pereira Santos, Raphael Rinaldi, Robson Pagani, Renata Pinto, Carlos Tomassini, alguns pela execução de experimentos, outros por informações técnicas e conceituais, e à todos pelo incentivo e amizade ao longo do trabalho.

Ao meu colega de trabalho e amigo Luis Henrique de Freitas por me apresentar o programa de mestrado da Poli/USP e o meu orientador, pelo apoio, amizade e sabedoria compartilhada em todo o tempo.

Aos amigos e colegas Oxiteno e de mestrado Maria Rita Perez de Oliveira e Marcio de Andrade Dias pelo incentivo e apoio durante todo o tempo. Peças-Chave em muitos momentos!

À Oxiteno S.A Indústria e Comércio pela oportunidade. 
À DEUS, por tudo e por muito mais! 
A maior necessidade do mundo é a de homens; homens que não se comprem nem se vendam; homens que no íntimo da alma sejam verdadeiros e honestos; homens que não temam chamar o pecado pelo seu nome exato; homens cuja consciência seja tão fiel ao dever como a bússola o é ao pólo; homens que permaneçam firmes pelo que é reto, ainda que caiam os céus.

Ellen G. White (1827-1915). 


\section{RESUMO}

O mercado de tintas e vernizes é um dos maiores demandantes de solventes. Nos últimos anos, a reformulação de sistemas solventes tem ganhado força, e três são as razões principais para isso: redução de custo, mantendo o desempenho; melhoria do desempenho; e busca por solventes menos agressivos ao homem e à natureza, quer seja voluntariamente ou por imposição de legislação. Dentre as várias propriedades necessárias de um solvente para formulação de tintas e vernizes, a taxa de evaporação e os parâmetros de solubilidade de Hansen são os mais importantes. Em sua grande maioria, os ajustes e substituições de formulação de solventes são realizados pelo método da tentativa e erro, que é caro e demorado. A teoria e modelos sobre os parâmetros de solubilidade já são bastante conhecidos, mas pouco foi explorado sobre modelos para prever a taxa de evaporação de solventes e misturas com base no método do evaporômetro determinado pela ASTM D3539. O objetivo deste trabalho é avaliar os modelos disponíveis em literatura para cálculo da taxa de evaporação de solventes e suas misturas, e por fim, com base em conceitos de otimização e projeto de mistura auxiliado por computador (ComputerAided Mixture/Blend Design), propor uma metodologia para obter misturas de custo otimizado que satisfaçam as restrições de evaporação e solubilidade. Devido às equações das restrições dos modelos das propriedades, este problema de otimização é classificado como programação não-linear (NLP - Non-Linear Programming). Embora os modelos de taxa de evaporação dos solventes e das misturas não apresentem resultados consistentes para todo e qualquer caso, devido a desvios muitas vezes causados pelos solventes de rápida evaporação, estes modelos associados à teoria de solubilidade de Hansen se tornam uma ferramenta de grande importância na formulação de sistemas solventes. Os resultados observados com esta metodologia tem grande concordância com os resultados obtidos experimentalmente.

Palavras-chave: Evaporação de Solventes e Misturas. Projeto de mistura auxiliado por computador - otimização. 


\begin{abstract}
Paint and coatings are one of the most solvent demanding markets. In recent years, reformulation of solvent systems has gained strength, and there are three main reasons: cost reduction maintaining performance, performance improvement, and the search for less aggressive solvents to human and environment, voluntarily or by legislation. Among several properties required for these solvents, evaporation rate and Hansen solubility parameters are the most important ones. Most adjustments and replacements of solvents in formulation are performed by trial and error methods, which are expensive and time consuming. The solubility parameters theory and models are already well known but little was explored about models to predict solvents and mixtures evaporation rate based on the evaporometer method determined by ASTM D3539. The object of this study is to evaluate the available models for calculating the evaporation rate of solvents and their mixtures, and then, based on optimization concepts and computer-aided Mixture/Blend Design, to propose a methodology to obtain cost-optimized mixtures that meet evaporation and solubility constraints. Due to the equations restrictions of properties models, this optimization problem is classified as NLP - Non-Linear Programming. Although evaporation rate models of solvents and mixtures do not show consistent results for every case - most deviations were caused by fast evaporation solvents -, these models associated with the Hansen solubility theory become an important tool in the solvent systems formulation. The results observed with this method have good agreement with experimental results.
\end{abstract}

Keywords: Solvent and Mixture Evaporation. Computer-Aided Mixture/Blend Design - optimization. 


\section{LISTA DE FIGURAS}

Figura 2.1 Gráfico característico dos estágios de secagem (Adaptado de HARDISTY, 1977)

Figura 2.2 Diagrama da evaporação de solventes para a Fase Molhada segundo Sletmoe (1966)

Figura 2.3 Foto do evaporômetro e registrador Falex Thin Film Evaporometer, da Compass Instruments, Inc.

Figura 2.4 Representação das moléculas do líquido que evaporam dentro do vaso e são arrastadas pelo ar que se move através da boca do vaso acima da altura S. Baseado em Gilbert (1971).

Figura 4.1 Gráficos comparativos entre as taxas de evaporação relativas (TER) experimentais e teóricas para todos os solventes da tabela 4.2, calculadas pelas equações: a) Modelo de De Heen; b) Modelos de Gardner; c) Modelo de Gilbert; d) Modelo de Gilbert modificado; e) Modelo de Hardisty

Figura 4.2 Gráficos comparativos entre as taxas de evaporação relativas (TER) experimentais e teóricas para os solventes da tabela 4.2 com pressão de vapor entre $0,136 \mathrm{mmHg}$ e $28,456 \mathrm{mmHg}$, calculadas pelas equações: a) Modelo de De Heen; b) Modelos de Gardner; c) Modelo de Gilbert; d) Modelo de Gilbert modificado; e) Modelo de Hardisty

Figura 4.3 a) Curva de evaporação da mistura 6; b) Curva de composição predita para a evaporação da mistura. Adaptado de Venceslau, Pessoa Filho e Le Roux (2010)

Figura 4.4 Curvas de evaporação experimental e calculadas pelos modelos Ideal/WE e UNIQUAC/DS para a mistura 4.1

Figura 4.5 Curvas de evaporação experimental para a mistura 4.5 sob diferentes umidades relativas: a) $\mathrm{RH}=15 \%$; b) $\mathrm{RH}=40 \%$; c) $\mathrm{RH}=$ $65 \%$ 


\section{LISTA DE TABELAS}

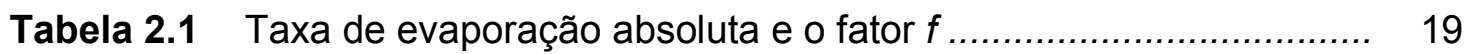

Tabela 2.2 Temperatura de evaporação de solventes obtida de acordo com o método determinado pela ASTM D 3539

Tabela 2.3 Coeficientes de velocidade para água e acetato de n-butila

Tabela 3.1 Solventes utilizados em mistura para estudo dos modelos de evaporação deste trabalho

Tabela 4.2 Solventes e suas propriedades para avaliação dos Modelos de TER ordenados em relação à pressão de vapor

Tabela 4.3 Resultados de RMSE calculados para os diferentes modelos de TER com base nos solventes da tabela 4.2

Tabela 4.4 Cálculo do desvio relativo entre o valor experimental e teórico para o modelo de De Heen para os solventes da tabela $4.2 \mathrm{com}$ pressão de vapor entre 0,136 $\mathrm{mmHg}$ e $28,456 \mathrm{mmHg}$

Tabela 4.5 Cálculo do coeficiente de transferência de calor para o método do evaporômetro com base na equação 4.1, admitindo a temperatura do ar (Tar) igual a $25^{\circ} \mathrm{C}$, calor latente de vaporização calculado para a temperatura de evaporação do solvente (Tmin), e área de evaporação de $0,0128 \mathrm{~m}^{2}$

Tabela 4.6 Modelos de evaporação de misturas de solventes escritos na forma diferencial

Tabela 4.7 Resultados obtidos a partir dos dados experimentais das curvas de evaporação para as misturas de solventes 4.1 e 4.2 de acordo com a norma ASTM D3539

Tabela 4.8 Resultados obtidos a partir dos dados calculados das curvas de evaporação para as misturas de solventes 4.1 e 4.2 de acordo com diferentes modelos de misturas e modelos para cálculo do coeficiente de atividade

Tabela 4.9 Resultados obtidos a partir dos dados experimentais das curvas de evaporação para as misturas de solventes 4.3 e 4.5 de acordo com a norma ASTM D3539

Tabela 4.10 Tempo e desvio padrão para diferentes percentuais de evaporação das misturas 4.1 e 4.2

Tabela 4.11 Resultados obtidos a partir dos dados calculados das curvas de evaporação para as misturas de solventes 4.3 a 4.5 de acordo 
com diferentes modelos de misturas e modelos para cálculo do coeficiente de atividade

Tabela 4.12 Resultados do tempo de evaporação obtidos a partir dos dados experimentais da curva de evaporação para a mistura de solventes 4.5, sob diferentes condições de umidade relativa no evaporômetro

Tabela 4.13 Resultados de RMSE obtidos a partir dos dados de composição e desvio relativo para o tempo de evaporação em $70 \%$ da mistura evaporada, calculados da curva de evaporação para a mistura de solventes 4.5 de acordo com diferentes modelos de evaporação de misturas e modelos para cálculo do coeficiente de atividade

Tabela 4.14 Resultados obtidos a partir dos dados experimentais das curvas de evaporação para as misturas de solventes 4.6 a 4.11 de acordo com a norma ASTM D3539

Tabela 4.15 Resultados obtidos a partir dos dados calculados das curvas de evaporação para as misturas de solventes 4.6 a 4.11 de acordo com diferentes modelos de misturas para cálculo do coeficiente de atividade

Tabela 4.16 Resultados obtidos a partir dos dados experimentais das curvas de evaporação para as misturas de solventes 4.12 e 4.18 de acordo com a norma ASTM D3539

Tabela 4.17 Informações sobre as condições de determinação dos parâmetros binários dos modelos UNIQUAC e de Wilson para cálculo do coeficiente de atividade de acordo com a base de dados DECHEMA

Tabela 4.18 Resultados obtidos a partir dos dados calculados das curvas de evaporação para as misturas de solventes 4.12 a 4.18 de acordo com diferentes modelos de misturas e para cálculo do coeficiente de atividade

Tabela 4.19 Resultados obtidos a partir dos dados calculados das curvas de evaporação para a mistura de solvente 4.15 de acordo com diferentes modelos de misturas e para cálculo do coeficiente de atividade, variando os parâmetros binários obtidos sob diferentes condições

Tabela 4.20 Mistura de Solventes Original para ser subtituída

Tabela 4.21 Solventes e seus preços disponíveis para otimização da mistura Original

Tabela 4.22 Solventes e seus preços disponíveis para otimização da mistura Original 
Tabela 4.23 Resultados obtidos para as Alternativas 1 e 2

Tabela 4.24 Taxa de evaporação experimental para a mistura original e as Alternativas 1 e 2

Tabela 4.25 Resultados obtidos para otimização da mistura original mantendo os mesmos componentes da mistura 


\section{LISTA DE ABREVIATURAS E SIGLAS}

ASOG Analytical Solution of Groups - modelo de coeficiente de atividade

ASTM American Society for Testing Materials (Sociedade Americana para Ensaio de Materiais)

CAM $^{\mathrm{b} D} \quad$ Computer-Aided Mixture/Blend Design (Projeto de mistura auxiliado por computador)

CAMD Computer-Aided Molecular Design (Projeto molecular auxiliado por computador)

CAPD Computer-Aided Product Design (Projeto de Produto Químico Auxliado por Computador)

CPD Chemical Product Design (Projeto de Produto Químico)

$\mathrm{CRH} \quad$ Critical Relative Humidity (Umidade Crítica Relativa)

DS Modelo de evaporação de misturas de Dillon e Stratta

MINLP Mixed-Integer Nonlinear Programming (Programação Não-Linear Inteira Mista)

NLP Nonlinear Programming (Programação Não-Linear)

NRTL Non-Random Two Liquid - modelo de coeficiente de atividade

RB Modelo de evaporação de misturas de Rocklin e Bonner

RBM Modelo de evaporação de misturas de Rocklin e Bonner Modificado

$\mathrm{RH} \quad$ Relative Humidity (Umidade Relativa)

RMSE Root Mean Square Error (Raiz Quadrada do Erro Médio Quadrático)

TER Taxa de Evaporação Relativa

UNIFAC UNIversal Functional Activity Coefficient - modelo de coeficiente de atividade

UNIQUAC UNIversal QUasiChemical - modelo de coeficiente de atividade

VOC Volatile Organic Compound (Composto Orgânico Volátil)

WE Modelo de evaporação de misturas de Walsham e Edwards 


\section{LISTA DE SÍMBOLOS}

A

$A_{i}^{T}$

$a_{i}$

$B$

$B_{i}^{T}$

$C_{i}$

$C_{p_{a r}}$

$\underline{C}^{T}$

$\overline{c_{1}}$

$D$

$d$

$d^{25^{\circ} \mathrm{C}}$

$E_{a}$

$E_{m}$

$f$

$f(x)$

$h$

$h_{\text {malha }}$

$h_{\text {rev }}$

$J_{A B}, J_{B C}, J_{C D}$

$K$

Área superficial $\left(\mathrm{m}^{2}\right)$

Primeiro coeficiente de velocidade do $\operatorname{ar}\left(\min . \mathrm{m}^{2} . \mathrm{g}^{-1}\right)$ para a taxa de transferência de massa do componente $i$ para uma dada temperatura

Atividade do solvente na resina a esta concentração

Constante de resistência à difusão oferecida pela superfície do filme da resina

Segundo coeficiente de velocidade do ar $\left(\min . \mathrm{m}^{2} \cdot \mathrm{mph} \cdot \mathrm{g}^{-1}\right)$ para a taxa de transferência de massa do componente $i$ para uma dada temperatura

Concentração do solvente líquido, tendo como base os voláteis totais, $\%$ volume

Capacidade calorífica $\left(\mathrm{J} . \mathrm{kg}^{-1} \cdot \mathrm{K}^{-1}\right)$

Vetor linha dos custos/preços

Velocidade unidirecional das moléculas na fase vapor $\left(\mathrm{m} . \mathrm{s}^{-1}\right)$

Difusividade do solvente no $\operatorname{ar}\left(\mathrm{m}^{2} . \mathrm{s}^{-1}\right)$

densidade $\left(\mathrm{g} . \mathrm{cm}^{-3}\right)$

densidade a $25^{\circ} \mathrm{C}\left(\mathrm{g} . \mathrm{cm}^{-3}\right)$

Taxa de evaporação absoluta $\left(\mathrm{kg} \cdot \mathrm{m}^{-2} \cdot \mathrm{s}^{-1}\right)$

Taxa de evaporação máxima $\left(\mathrm{kg} \cdot \mathrm{m}^{-2} \cdot \mathrm{s}^{-1}\right)$

Fator relacionado com as condições atmosféricas

Função objetivo

Coeficiente de transferência de calor superficial $\left(\mathrm{W} \cdot \mathrm{m}^{-2} \cdot \mathrm{K}^{-1}\right)$

Coeficiente de transferência de calor do lado da malha $\left(\mathrm{W} \cdot \mathrm{m}^{-2} \cdot \mathrm{K}^{-1}\right)$

Coeficiente de transferência de calor do lado do revestimento (W.m${ }^{2} \cdot \mathrm{K}^{-1}$ )

Fluxo Mássico

Coeficiente de transmissão, que varia de 0 a 1; constante de proporcionalidade da taxa de evaporação relativa $\left(\mathrm{mol} . \mathrm{s} . \mathrm{g}^{-1} . \mathrm{cm}^{-}\right.$ ${ }^{2} \cdot \mathrm{mmHg}^{-1}$ ) 


\begin{tabular}{|c|c|}
\hline$K_{A B}, K_{B C}, K_{C D}$ & Coeficiente de transferência de massa \\
\hline K & Condutividade térmica $\left(\mathrm{W} \cdot \mathrm{m}^{-1} \cdot \mathrm{K}^{-1}\right)$ \\
\hline$k_{m}$ & Coeficiente de transferência de massa $\left(\mathrm{m} \cdot \mathrm{s}^{-1}\right)$ \\
\hline$k_{m_{i}}^{V}$ & $\begin{array}{l}\text { Coeficiente de transferência de massa do componente } i\left(\mathrm{~m}^{-1} \mathrm{~s}^{-1}\right) \text { para } \\
\text { uma dada velocidade do ar }\end{array}$ \\
\hline Le & Número de Lewis \\
\hline$M$ & Peso molecular do líquido $\left(\mathrm{kg} \cdot \mathrm{mol}^{-1}\right)$ \\
\hline$M_{A}$ & Peso molecular do ar $\left(\mathrm{g} \cdot \mathrm{mol}^{-1}\right)$ \\
\hline$M_{B}$ & Peso molecular do solvente $\left(\mathrm{g} \cdot \mathrm{mol}^{-1}\right)$ \\
\hline$\underline{m}$ & Vetor coluna das massas dos solventes da mistura \\
\hline$m_{i}$ & Massa do componente $i(\mathrm{~g})$ \\
\hline$m_{T}$ & Somatório das massas de todos os componentes da mistura ( $\mathrm{g}$ ) \\
\hline$N_{0}$ & Número inicial de moléculas existentes na fase líquida \\
\hline$N_{x}$ & Número de moléculas de vapor por volume \\
\hline$n$ & Número de amostras \\
\hline$n_{i}$ & Número de mols do componente $i(\mathrm{~mol})$ \\
\hline$P$ & Pressão atmosférica (mmHg, Torr, Pa) \\
\hline$P_{A}, P_{B}, P_{C}$ & Pressão (mmHg, Torr, Pa) \\
\hline$P_{a r}$ & Pressão de vapor do ar nas condições do ponto de orvalho $(\mathrm{Pa})$ \\
\hline$P^{0}$ & Pressão de vapor a $25^{\circ} \mathrm{C}(\mathrm{mmHg}$, Torr, $\mathrm{Pa})$ \\
\hline$P_{v}$ & Pressão de vapor do líquido a ser evaporado $(\mathrm{Pa})$ \\
\hline$P_{v_{i}}^{T}$ & $\begin{array}{l}\text { Pressão de vapor do componente puro } i(\mathrm{mmHg} \text {, Torr, Pa) a uma } \\
\text { dada temperatura }\end{array}$ \\
\hline$P_{s}$ & Pressão de vapor do solvente na superfície $(\mathrm{Pa})$ \\
\hline$\% p$ & Porcentagem mássica \\
\hline$p_{A_{1}}$ & Pressão de vapor do líquido evaporado (atm) \\
\hline$p_{A_{2}}$ & $\begin{array}{l}\text { Pressão parcial de vapor no lado da corrente de ar do filme de ar } \\
\text { (atm) }\end{array}$ \\
\hline$p_{B_{M}}$ & Média logarítimica da pressão parcial do ar através do filme (atm) \\
\hline$p_{B_{1}}$ & Pressão parcial do ar na interface do filme líquido-ar (atm) \\
\hline$p_{B_{2}}$ & Pressão parcial do ar no lado da corrente de ar do filme de ar (atm) \\
\hline$P_{\mathrm{H}_{2} \mathrm{O}}$ & Pressão parcial de vapor de água do ar \\
\hline
\end{tabular}




\begin{tabular}{|c|c|}
\hline$P_{H_{2} \mathrm{O}}^{\mathrm{sat}, T}$ & Pressão de vapor de saturação da água a uma dada temperatura \\
\hline$q_{i}$ & Parâmetro de área UNIQUAC da espécie $i$ \\
\hline$R$ & Constante dos gases ideais $\left(8,314 \mathrm{~m}^{3} \cdot \mathrm{Pa} \cdot \mathrm{K}^{-1} \cdot \mathrm{mol}^{-1}\right)$ \\
\hline$R H$ & $\begin{array}{l}\text { Umidade relativa do ar ambiente em volta da mistura em } \\
\text { evaporação }\end{array}$ \\
\hline$R_{i}$ & $\begin{array}{l}\text { Taxa de evaporação do solvente } i \text { de um filme em um dado instante } \\
\left(\mathrm{g} . \mathrm{s}^{-1}\right)\end{array}$ \\
\hline$R^{i j k}$ & $\begin{array}{l}\text { Distância da mistura de solventes do centro da esfera de } \\
\text { solubilidade do polímero }\left(\mathrm{MPa}^{1 / 2}\right) \text {. }\end{array}$ \\
\hline$r(t)$ & Taxa total de evaporação $\left(\mathrm{g} \cdot \mathrm{s}^{-1}\right)$ da mistura para um dado instante \\
\hline$r_{1}^{0}, r_{2}^{0}, \ldots, r_{n}^{0}$ & $\begin{array}{l}\text { Taxa de evaporação }\left(\mathrm{g} \cdot \mathrm{s}^{-1}\right) \text { dos diversos componentes da mistura, } \\
\text { sob as condições dadas pela ASTM D3539. }\end{array}$ \\
\hline$r_{i}$ & Parâmetro de volume UNIQUAC da espécie $i$ \\
\hline$r_{i}^{0}$ & Taxa de evaporação de um solvente puro $\left(\mathrm{g} \cdot \mathrm{s}^{-1}\right)$ \\
\hline$r_{i}^{0}$ & $\begin{array}{l}\text { Taxa de evaporação }\left(\mathrm{g} . \mathrm{s}^{-1}\right) \text { do componente } i \text { puro, sob as condições } \\
\text { dadas pela ASTM D3539 }\end{array}$ \\
\hline$r_{H_{2} \mathrm{O}}(t)$ & $\begin{array}{l}\text { Taxa correspondente da componente água }\left(\mathrm{g} \cdot \mathrm{s}^{-1}\right) \text { para um dado } \\
\text { instante }\end{array}$ \\
\hline$r_{i}^{V, T}$ & $\begin{array}{l}\text { Taxa de evaporação do componente } i\left(\mathrm{~g} \cdot \mathrm{s}^{-1}\right) \text { para dada condição de } \\
\text { temperatura e velocidade do ar }\end{array}$ \\
\hline$S$ & $\begin{array}{l}\text { Altura da superfície do líquido até a boca do cilindro, coluna de } \\
\text { vapor }\end{array}$ \\
\hline$T$ & eratura $\left({ }^{\circ} \mathrm{C}\right.$ ou $\left.\mathrm{K}\right)$ \\
\hline$T_{a r}$ & Temperatura do $\operatorname{ar}\left({ }^{\circ} \mathrm{C}\right.$ ou $\left.\mathrm{K}\right)$ \\
\hline$T_{\text {ar,malha }}$ & $\begin{array}{l}\text { Temperatura de bulbo seco, ou temperatura do ar do lado da malha } \\
(\mathrm{K})\end{array}$ \\
\hline$T_{a r, r e v}$ & $\begin{array}{l}\text { Temperatura de bulbo seco, ou temperatura do ar do lado do } \\
\text { revestimento }(\mathrm{K})\end{array}$ \\
\hline TER & Taxa de evaporação relativa \\
\hline$T_{\min }$ & $\begin{array}{l}\text { Temperatura de bulbo úmido, ou temperatura mínima de } \\
\text { evaporação da água ou do solvente }(\mathrm{K})\end{array}$ \\
\hline$T_{\min , 0}$ & Temperatura inicial da malha $\left({ }^{\circ} \mathrm{C}\right.$ ou $\left.\mathrm{K}\right)$ \\
\hline$T_{\min }$ & Eemperatura real de evaporação do componente $i(\mathrm{~K})$ \\
\hline
\end{tabular}




\begin{tabular}{|c|c|}
\hline$T_{s}$ & Temperatura da superfície da tinta ou solvente $\left({ }^{\circ} \mathrm{C}\right.$ ou $\left.\mathrm{K}\right)$ \\
\hline$T_{\text {sol }}$ & Temperatura real de evaporação da mistura (K) \\
\hline$t$ & Tempo (s) \\
\hline$t_{90 \%}$ & Tempo necessário para evaporar $90 \%$ da massa de solvente (s) \\
\hline$t_{90 \%, m}$ & $\begin{array}{l}\text { Tempo necessário para evaporar } 90 \% \text { da massa de solvente (s) em } \\
\text { base-massa }\end{array}$ \\
\hline$t_{90 \%, v o l}$ & $\begin{array}{l}\text { Tempo necessário para evaporar } 90 \% \text { da massa de solvente (s) em } \\
\text { base-volume }\end{array}$ \\
\hline$t_{90 \%, i}$ & Tempo necessário para evaporar $90 \%$ p do componente $i$ \\
\hline$\left(t_{90 \%}\right)_{A A B}$ & $\begin{array}{l}\text { Tempo necessário para evaporar } 90 \% \text { da massa do padrão acetato } \\
\text { de n-butila (s) }\end{array}$ \\
\hline$u_{i j} e u_{j j}$ & Parâmetro de interação energética média das espécies $i$ e $j$ \\
\hline$u b e l b$ & $\begin{array}{l}\text { Respectivamente, limites mínimos e máximos para a inequação de } \\
\text { variável contínua }\end{array}$ \\
\hline$V$ & Velocidade do ar (mph) \\
\hline$v_{A}$ & Volume molar do ar $\left(\mathrm{cm}^{3} \cdot \mathrm{mol}^{-1}\right)$ \\
\hline$v_{B}$ & Volume molar do solvente $\left(\mathrm{cm}^{3} \cdot \mathrm{mol}^{-1}\right)$ \\
\hline$v_{i}$ & Volume molar líquido $\left(\mathrm{cm}^{3} \cdot \mathrm{mol}^{-1}\right)$ da espécie $i$ \\
\hline$w_{i}$ & Massa de solvente evaporado por unidade de área do substrato \\
\hline$w_{1}, w_{2}, \ldots, w_{n}$ & Fração mássica dos diversos componentes da mistura \\
\hline$X$ & Espessura do filme de ar efetivo acima da superfície de líquido (m) \\
\hline$X$ & $\begin{array}{l}\text { Distância em direção da difusão de ar através do filme estagnado } \\
(\mathrm{cm})\end{array}$ \\
\hline$x$ & Representa a variável continua de dimensão $n$ \\
\hline$x_{i}$ & fração molar do componente $i$ \\
\hline$x_{i}(t)$ & fração molar do componente $i$ na mistura em um dado instante \\
\hline$Y$ & Caminho livre médio das moléculas de vapor misturadas com o ar \\
\hline$\hat{y}_{i}$ & valor predito para a propriedade da amostra $i$ \\
\hline$y_{i}$ & valor experimental da propriedade da amostra $i$ \\
\hline$z$ & 0 \\
\hline
\end{tabular}




\section{Símbolos Gregos}

\begin{tabular}{|c|c|}
\hline$\alpha$ & Fator de proporcionalidade ; difusividade térmica do $\operatorname{ar}\left(\mathrm{m}^{2} \cdot \mathrm{s}^{-1}\right)$ \\
\hline$\alpha_{i}$ & Primeiro parâmetro da velocidade do ar $\left(\min \cdot \mathrm{m}^{2} \cdot \mathrm{K}^{1 / 2} \cdot \mathrm{mmHg} \cdot \mathrm{g}^{-1}\right)$ \\
\hline$\beta_{i}$ & $\begin{array}{l}\text { Segundo parâmetro da velocidade do ar }\left(\min \cdot \mathrm{m}^{2} \cdot \mathrm{K}^{1 / 2} \cdot \mathrm{mmHg} \cdot \mathrm{mph} \text {. }\right. \\
\left.\mathrm{g}^{-1}\right)\end{array}$ \\
\hline$\delta_{i}$ & $\begin{array}{l}\text { Componente difusiva dos parâmetros de solubilidade de Hansen da } \\
\text { espécie } i\left(\mathrm{~Pa}^{1 / 2}\right)\end{array}$ \\
\hline$\delta_{D}^{k}, \delta_{P}^{k}, \delta_{H}^{k}$ & Parâmetros de solubilidade de Hansen do soluto $\left(\mathrm{Pa}^{1 / 2}\right)$ \\
\hline$\delta_{D}^{i j}, \delta_{P}^{i j}, \delta_{H}^{i j}$ & $\begin{array}{l}\text { Parâmetros de solubilidade de Hansen da mistura de solventes } \\
\left(\mathrm{Pa}^{1 / 2}\right)\end{array}$ \\
\hline$\phi_{i}$ & Fração volumétrica da espécie $i$ \\
\hline$\gamma_{1}, \gamma_{2}, \ldots, \gamma_{n}$ & coeficiente de atividade dos diversos componentes da mistura \\
\hline$\gamma_{i}$ & coeficiente de atividade do componente $i$ na fase líquida \\
\hline$\gamma_{i}\left(t, T_{\text {sol }}\right)$ & $\begin{array}{l}\text { coeficiente de atividade do componente } i \text { em um dados instante e } \\
\text { para a temperatura real de evaporação da mistura }\end{array}$ \\
\hline$\lambda$ & calor latente de vaporização $\left(\mathrm{J} . \mathrm{kg}^{-1}\right)$ \\
\hline$\theta_{i}$ & fração superficial da espécie $i$ \\
\hline$\rho$ & densidade da malha $\left(\mathrm{kg} \cdot \mathrm{m}^{-3}\right)$ \\
\hline$\rho_{\text {ar }}$ & densidade do ar $\left(\mathrm{kg} \cdot \mathrm{m}^{-3}\right)$ \\
\hline$\rho_{s}$ & densidade do solvente na fase vapor $\left(\mathrm{kg} \cdot \mathrm{m}^{-3}\right)$ \\
\hline$\rho_{i}$ & aturação relativa do vapor do componente $i$. \\
\hline
\end{tabular}




\section{SUMÁRIO}

1 INTRODUÇÃO

2 REVISÃO BIBLIOGRÁFICA...................................................... 9

2.1 Processo de formação de um Filme ………………………………...... 9

2.2 Método experimental - Evaporômetro …………............................... 13

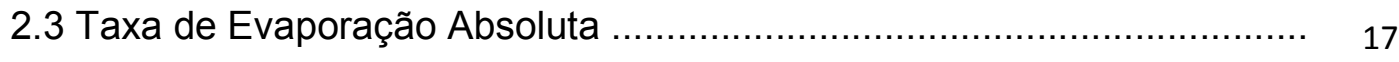

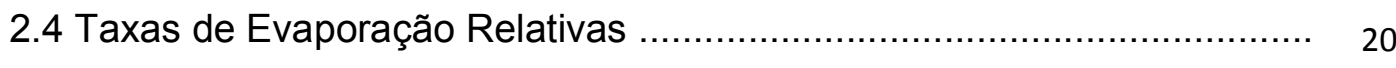

2.4.1 Modelo de De Heen ........................................................... 22

2.4.2 Modelo de Gardner ....................................................... 22

2.4.3 Modelo de Gilbert ........................................................... 25

2.4.4 Modelo de Hardisty …….................................................... 26

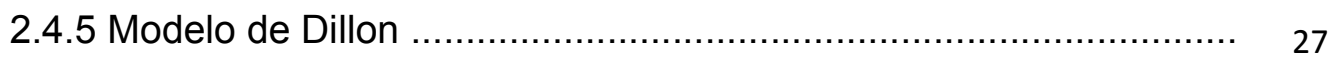

2.5 Modelos de Evaporação para misturas ………................................... 27

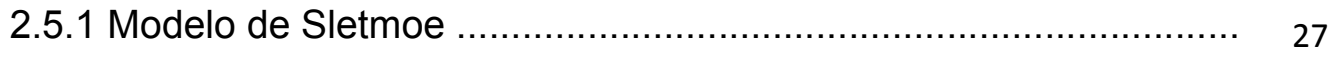

2.5.2 Modelo de Walsham e Edwards (WE) ……............................. 28

2.5.3 Modelo de Rocklin e Bonner (RB) ......................................... 30

2.5.4 Modelo de Dillon e Stratta (DS) ............................................. 33

2.6 Modelos de Evaporação e a teoria da Transferência de Massa e Calor . 37

2.6.1 Modelo de Hardisty ............................................................... 38

2.6.2 Modelo de Cary e Gutoff ......................................................... 41

2.7 Projeto de Produto Químico e Otimização ......................................... 44

3 MATERIAIS E MÉTODOS ...................................................... 47

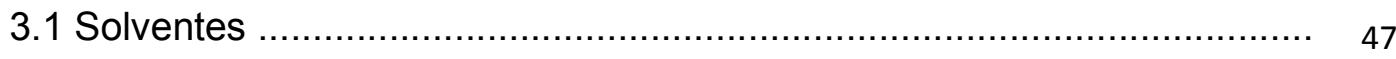

3.2 Misturas de Solventes .............................................................. 47

3.3 Curva de Evaporação Experimental ............................................... 48

3.4 Conversão de Taxas de Evaporação Relativas em Absolutas ................ 49

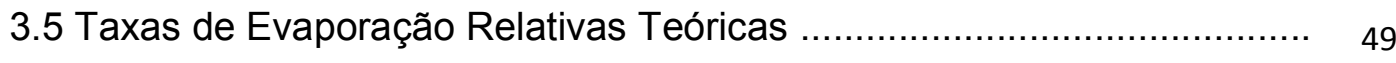

3.6 Taxas Teóricas de Evaporação de Misturas .......................................... $\quad 50$

3.6.1 Modelos de Coeficiente de Atividade ……….............................. 51

3.6.1.1 Solução Regular ......................................................... 52

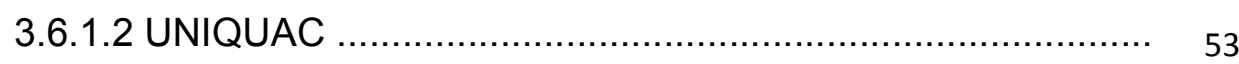




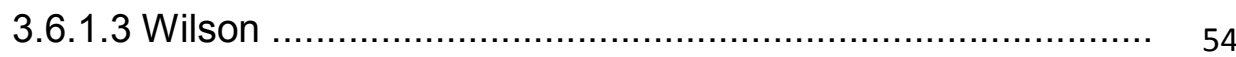

3.6.1.3 Testes de Consistência Termodinâmica ........................... 54

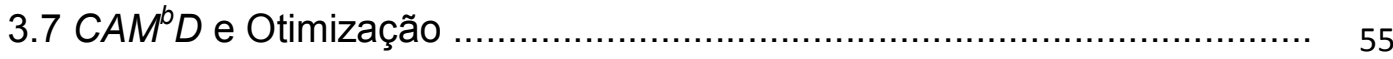

3.7.1 Parâmetros de Solubilidade ………………........................... 56

3.7.2 Programação Não-Linear ...................................................... 57

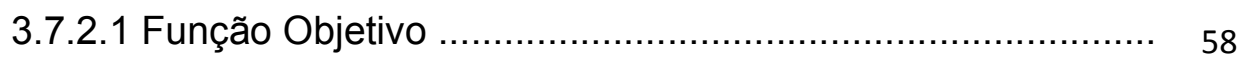

3.7.2.2 Equações de restrição .................................................... 58

3.7.2.3 Inequações de restrição ............................................... 58

4 RESULTADOS E DISCUSSÃO ................................................. 60

4.1 Avaliação de modelos de Evaporação para um componente ................. 60

4.2 Modelos de Evaporação para Misturas de Solventes …………............ 68

4.2.1 Influência do Fator de Correção de Temperatura ……………...... 72

4.2.2 Influência do Fator de Correção de Umidade .............................. 76

4.2.3 Influência dos Diferentes Modelos e parâmetros dos Coeficientes de Atividade ............................................................... 84

4.2.4 Influência das Variações nos Parâmetros Binários ……………… 92

4.3 Chemical Product Design e Otimização ……………………….......... 93

4.4 Metodologia para Otimização de Misturas de Solventes ………............ 100

5 CONCLUSÕES E SUGESTÕES …............................................... 102

6 REFERÊNCIAS BIBLIOGRÁFICAS ............................... 105

APÊNDICE A - Artigo publicado no XVIII Congresso Brasileiro de Engenharia Química ........................................ 


\section{INTRODUÇÃO}

Solventes podem ser definidos como compostos que possuem a capacidade de dissolver outros compostos, resultando em uma mistura homogênea. Acredita-se que o uso dos primeiros solventes data da época das civilizações gregas e romanas. Porém, alguns historiadores apresentam indício de uso ainda anteriores a estas. Já na nossa era, segundo Garbelotto et al. (2007), o crescimento no uso e a produção em larga escala dos solventes foi impulsionado com o fim da $1^{\text {a }}$. Guerra Mundial, em 1918. Hoje, o consumo dos solventes cresce em média nas mesmas taxas do PIB mundial. $\mathrm{O}$ consumo dos solventes oxigenados cresce a taxas duas vezes maiores do que o PIB, e os chamados "verdes", quatro vezes. Entre os anos de 2005 e 2007, a demanda global de solventes foi da ordem de 20 milhões de toneladas por ano, tendo a América do Norte e Europa como líderes no consumo (cerca de 4-5 milhões de toneladas por ano, cada), seguido por China (4 milhões de toneladas) e Japão (2 milhões de toneladas) (LINAK, 2006). Estas quantidades apresentadas são apenas uma estimativa do mercado, tendo em vista a magnitude e pulverização desta indústria, que possui diversos produtos, produtores e usuários. Dentre os produtores, as multinacionais respondem por mais de $50 \%$ em volume da produção mundial de solventes (LINAK, 2006). Dos solventes produzidos mundialmente, $70 \%$ são oxigenados.

Embora este seja um mercado que se mostra crescente, de forma contraditória o mesmo apresenta uma tendência à redução, explicada pela pressão das regulamentações para redução das emissões. A maioria dos solventes é considerada como composto orgânico volátil ( $\mathrm{VOC}$ - volatile organic compound), que contribui para formação da névoa atmosférica mais baixa (smog) em áreas urbanas. Além de muitos deles serem potenciais causadores de problemas de saúde, se não manipulados corretamente. Com isso, tem-se estudado novas moléculas que sejam consideradas "verdes" - solventes "verdes", para substituição dos tradicionais solventes. Ainda assim, atualmente $99 \%$ do mercado de solventes tem sua origem no petróleo (LINAK, 2006). 
Do ponto de vista molecular, os solventes podem ser classificados em quatro grupos:

- Solventes oxigenados: alcoóis, cetonas, glicóis, ésteres, éteres glicólicos e seus acetatos (série E e $\mathrm{P}$, etoxilados e propoxilados, respectivamente);

- Hidrocarbônicos, os quais incluem aromáticos, alifáticos e solventes parafínicos;

- Solventes halogenados, principalmente os solventes clorados;

- Solventes variados, incluindo compostos que contêm Nitrogênio.

Ao se escolher os solventes entre as diversas categorias ou dentro da mesma categoria, algumas propriedades físico-químicas precisam ser levadas em consideração para as suas várias aplicações. Recentemente a preocupação com o meio ambiente e com a saúde ocupacional levou à criação de novos critérios de escolha: toxicidade inerente, flamabilidade, explosividade, degradação do ozônio estratosférico, produção de ozônio atmosférico, potencial de causar aquecimento global (LINAK, 2006). Assim, ao buscar um solvente para determinada aplicação, o usuário busca as seguintes qualidades: aparência límpida e incolor, volatilização sem deixar resíduos, boa resistência química, quimicamente inerte, odor leve ou agradável, baixo teor de água, propriedades físicas constantes, baixa toxicidade e biodegradabilidade (GARBELOTTO et al., 2007).

Segundo Linak (2006), cerca de $40-50 \%$ do mercado de solventes é utilizado na formulação de tintas e vernizes (Paintings and Coatings). Há ainda outros mercados também importantes, mas que correspondem a menos de $10 \%$ cada: adesivos, tintas de impressão, produtos farmacêuticos, processos químicos, produtos de limpeza, produtos de higiene pessoal, lavagem/limpeza a seco, limpeza de metais e agroquímicos. Para cada um desses mercados, algumas propriedades são mais essenciais que outras.

As tintas líquidas geralmente são constituídas de cinco partes: resinas, diluentes, aditivos, pigmentos e cargas (GARBELOTTO et al., 2007). Já os vernizes apresentam a ausência de pigmentos em sua formulação como a principal diferença com as tintas. No mercado de tintas e vernizes, há dois grandes grupos de produtos: 
base-água e base-solvente, ou seja, o principal diluente de uma tinta ou verniz pode ser a água, ou outro solvente qualquer.

$\mathrm{Na}$ aplicação em tintas e vernizes base-solvente, os solventes apresentam algumas funções específicas (LINAK, 2006):

- Solubilização da resina ou do polímero formando a fase contínua do revestimento. Subseqüentemente, pigmentos e aditivos são dispersos na solução;

- Molhabilidade do pigmento, que possibilita o revestimento das partículas de pigmento pela resina;

- Redução e ajuste da viscosidade para facilitar a aplicação e fornecimento;

- Controle do processo de secagem por meio da evaporação e auxilio na formação do filme (alastramento). O solvente evapora logo após a atomização do material do revestimento e continua durante o processo de formação do filme;

- Promoção de adesão. O solvente suaviza o revestimento previamente aplicado, melhorando a adesão entre revestimentos;

- Realce de brilho. Freqüentemente um solvente de mais baixa evaporação é adicionado à formulação, para que melhore o desenvolvimento de brilho e suavidade do filme do revestimento.

As tintas e vernizes base-água também possuem solventes orgânicos em sua formulação, pois estes desenvolvem algumas funções importantes: coalescência - o solvente age como um plastificante temporário promovendo a deformação e fluxo, para então evaporar após a formação do filme; estabilidade - permite que o produto resista ao congelamento durante a estocagem sob baixas temperaturas.

Como são muitas as propriedades a serem consideradas na escolha de um solvente ou de uma mistura de solventes, geralmente a escolha é feita com base na taxa de evaporação e na capacidade de dissolver a resina, que pode ser verificada teoricamente a partir dos parâmetros de solubilidade. 
Nos últimos anos, a reformulação de sistemas solventes tem ganhado força, e três são as razões principais para isso: redução de custo, mantendo o desempenho; melhoria do desempenho; e busca por solventes menos agressivos ao homem e à natureza, quer seja voluntariamente ou por imposição de legislação. O problema é que o trabalho experimental por tentativa e erro para determinar um solvente ou uma mistura adequada é exaustivo, e uma ferramenta (software) que pudesse reduzir tempo e custo de trabalho seria de fundamental importância.

Hoje já existem programas computacionais que se propõem a estimar qual o melhor solvente ou mistura para formulação de uma tinta ou verniz, com base nos parâmetros de solubilidade e taxa de evaporação separadamente, levando em consideração as propriedades não-ideais da mistura. Porém, o foco destes programas sempre tem sido os parâmetros de solubilidade. Pouco se sabe sobre a teoria envolvendo a taxa de evaporação e validação dos modelos utilizados.

Walsham et al. (1971) alertam para o fato de que, quando uma mistura de solventes é formulada, não apenas se quer obter uma taxa de evaporação adequada, mas também os parâmetros de solubilidade e viscosidade que atendam à aplicação para a qual a formulação original era utilizada, evitando assim mudanças no tempo de secagem da tinta e no método de aplicação.

A teoria dos parâmetros de solubilidade tem sido amplamente estudada e difundida (HANSEN, 2004), e esta está relacionada com a propriedade do solvente dissolver sólidos, como as resinas. Porém pouco se tem discutido e apresentado de teoria sobre a taxa de evaporação.

A capacidade de evaporação de um solvente, ou de uma mistura, é de extrema importância para o balanceamento correto da formulação das tintas e vernizes, garantindo um bom aspecto do filme no final. Da evaporação depende a velocidade de secagem, determinando o ponto de equilíbrio para evitar o escorrimento. Além disso, pode-se evitar o esbranquiçamento da superfície da tinta, conhecido como blushing, que é causado pela absorção de água, devido ao resfriamento pronunciado de solventes mais voláteis, levando a temperaturas abaixo do ponto de orvalho. Finalmente, conhecer como se dá a evaporação da mistura ao longo do 
tempo e a relação que esta tem com a solvência pode também evitar imperfeições no filme final. Além dos problemas citados acima, podem-se evitar outros, tais como: efeito casca de laranja, crateras, etc.

Este processo de evaporação depende de uma série de propriedades: pressão de vapor à temperatura do processamento; calor específico; entalpia de vaporização; grau de associação molecular; velocidade de fornecimento de calor; tensão superficial; massa molecular do solvente; turbulência atmosférica; umidade atmosférica.

Por depender de tantos fatores, torna-se muito difícil prever teoricamente a taxa de evaporação. A taxa de evaporação relativa (TER) é determinada experimentalmente de acordo com a norma ASTM D 3539, que utiliza o acetato de n-butila como solvente de referência. A utilização desta norma não é complexa, porém, para cada determinação da curva de evaporação, é necessário um longo período de preparação para a utilização de um equipamento específico, chamado de evaporômetro, e depois o tratamento dos dados obtidos. Além disso, no uso de misturas de solventes se obtém apenas a curva de evaporação total, de toda a mistura, desconhecendo a concentração dos componentes da mistura ao longo do período de evaporação.

Assim, para químicos e engenheiros que trabalham com formulações e aplicação de tintas e vernizes, é essencial conhecer um pouco mais a teoria por trás da taxa de evaporação, bem como ter em mãos uma ferramenta que ajude na seleção de solventes com base na taxa de evaporação e parâmetros de solubilidade concomitantemente.

Este trabalho avaliou os diversos modelos de evaporação para os solventes puros e suas misturas, e diferentes modelos para o cálculo do coeficiente de atividade, como medida do desvio da idealidade das misturas de solventes, comparando com os dados experimentais obtidos de acordo com a norma ASTM D3539 pelo método do evaporômetro. Avaliou também a influência de fatores, como a temperatura de evaporação dos solventes e a umidade relativa. 
Uma vez avaliados os modelos de evaporação das misturas, foi realizada uma etapa de otimização. Esta teve por objetivo a minimização do custo das misturas dos solventes, levando em conta os modelos de evaporação estudados, e o modelo de solubilidade com base nos parâmetros de solubilidade de Hansen, de acordo com as especificações desejadas. Devido à presença de variáveis contínuas e como as restrições são não lineares, a programação matemática utilizada foi a Programação Não-Linear (NLP - Nonlinear Programming). 


\section{REVISÃO BIBLIOGRÁFICA}

\subsection{Processo de formação de um Filme}

A aparência final de uma tinta ou verniz é resultado do processo de formação de filme, que por sua vez sofre influência direta da taxa de evaporação do solvente ou da mistura de solventes.

O processo de formação de um filme leva em consideração três etapas fundamentais (GARBELOTTO et al., 2007):

Etapa 1: Aplicação: nesta etapa o solvente regula a viscosidade da solução de resina, que determina o tipo de aplicação a ser empregada;

Etapa 2: Fixação: o solvente possui a função de garantir uma boa aderência da resina na superfície e também a formação de uma camada uniforme;

Etapa 3: Secagem: é nesta etapa que a taxa de evaporação parece ter um dos papéis mais importantes. O solvente precisa evaporar completamente após a solubilização da resina de tal forma que as cadeias poliméricas formem uma camada homogênea, uniforme e durável, garantindo a formação de um filme de boa aparência.

Havendo solvente suficiente, a etapa de secagem ocorre em dois estágios (GARBELOTTO et al., 2007; SAARY; GOFF, 1973):

Estágio 1: Inicialmente, a perda de solvente do filme ocorre devido à pressão parcial de vapor do solvente. Neste caso, a resistência à evaporação se deve à difusão das moléculas de solventes através de uma fina camada de ar acima da superfície do filme. Assim, a taxa de evaporação nesta etapa é controlada pelo que é conhecido de mecanismo de barreira de 
superfície, Surface Barrier (SLETMOE, 1970). Nesta etapa a taxa de evaporação ou secagem é constante e pode ser predita por parâmetros externos ao tipo de tinta ou verniz (CARY; GUTOFF, 1991), ou seja, é controlada inteiramente pelo estado dinâmico do ar de secagem (HARDISTY, 1977). Stratta et al. (1978) chamaram este estágio de Fase Molhada ou Úmida;

Estágio 2: No segundo estágio, quando a concentração da resina é maior, a taxa de evaporação é dependente do tipo de tinta ou verniz em questão (CARY; GUTOFF, 1991), portanto, controlada pela taxa de difusão das moléculas do solvente através do filme polimérico, até a superfície, e é conhecida como taxa de evaporação decrescente. Este estágio é considerado como o mais lento, e muitos autores afirmam que se inicia quando cerca de $80 \%$ do solvente foi evaporado. Para Sletmoe (1970), os efeitos da resina se tornam importantes, ou seja, a difusão através do filme da resina, durante a evaporação dos últimos $10 \%$ de solvente. Stratta et al. (1978) chamaram este estágio de Fase Seca.

O processo de secagem ou de evaporação pode então ser representado de forma gráfica, de acordo com a figura 2.1.

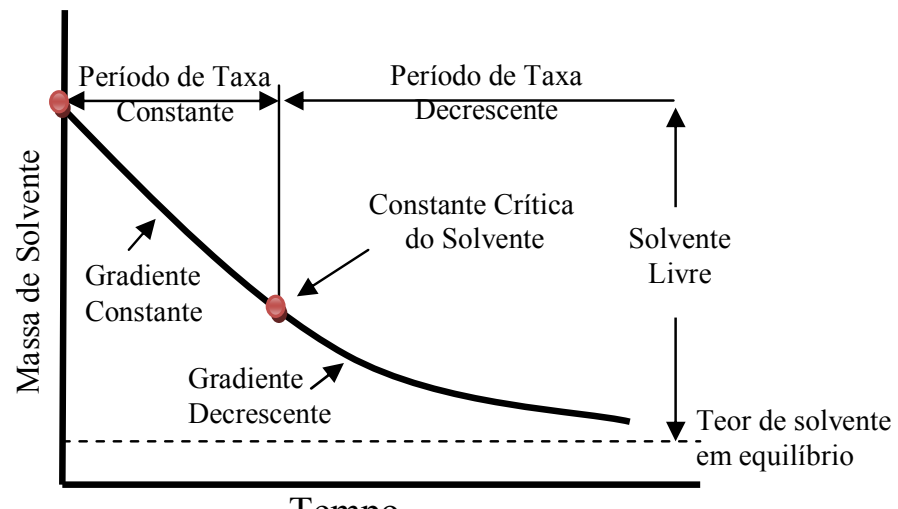

Tempo

Figura 2.1 - Gráfico característico dos estágios de secagem (Adaptado de HARDISTY, 1977)

No estudo da evaporação de um solvente puro, o fenômeno é função basicamente da pressão de vapor, e o primeiro estágio da secagem é o mais pronunciado, enquanto que, quando uma resina está presente, o segundo estágio passa a ser o 
principal. Neste estágio, segundo Garbelotto et al.(2007), a predição dos coeficientes de difusão é muito mais difícil, e por isso os modelos de evaporação geralmente desconsideram este estágio numa primeira aproximação.

Sletmoe (1966) apresentou um diagrama bastante interessante (figura 2.2), facilitando o entendimento das teorias apresentadas acima para a Fase Molhada, mas simplificando apenas para misturas de solventes, sem levar em consideração os demais componentes da formulação de uma tinta, como por exemplo, a resina.

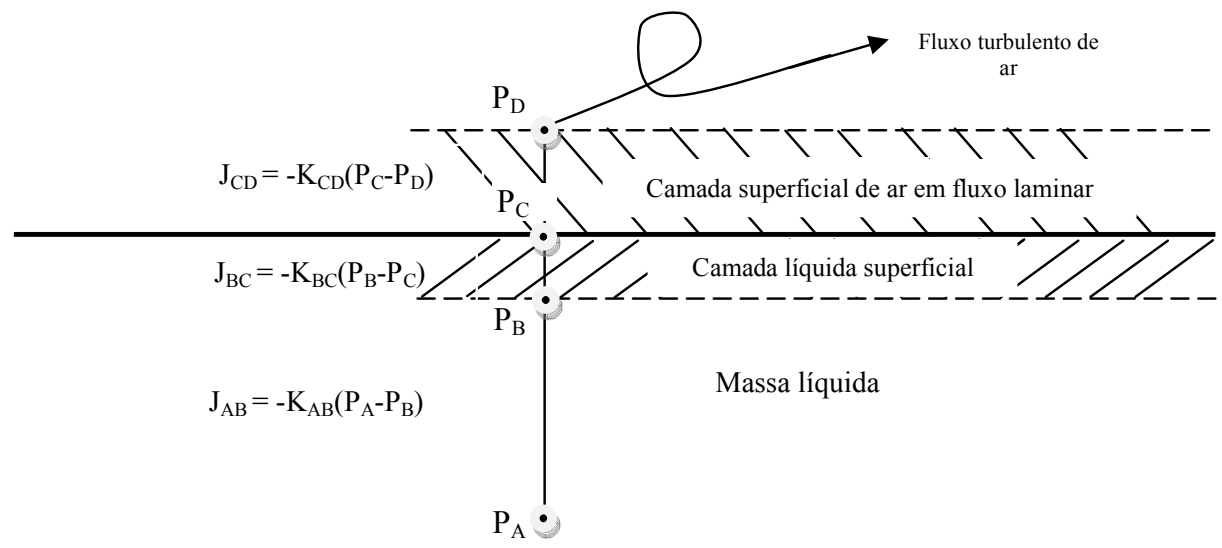

Figura 2.2 - Diagrama da evaporação de solventes para a Fase Molhada segundo Sletmoe (1966)

Conforme Sletmoe (1966) o solvente deveria difundir através de três meios estacionários:

1. Através da massa líquida (A para $B)$;

2. Através do filme superficial líquido (B para $C$ );

3. Através do filme de ar estagnado adjacente à superfície líquida (C para $D)$;

Finalmente, o solvente alcança e segue pela região de ar turbulento. A passagem do estado líquido para vapor ocorre no ponto $\mathrm{C}$, e de forma relativamente rápida em comparação aos efeitos difusionais.

Os potenciais químicos em cada um dos pontos $A, B, C$ e $D$ são dados em termos das pressões parciais. Os fluxos de massa $\left(J_{A B}\right)$ são apresentados com sinal negativo, denotando a difusão na direção da menor pressão parcial. Os coeficientes de transferência de massa para cada interface, representados pela letra $\mathrm{K}$ são 
específicos para o caso de difusão através de um meio estacionário, e conseqüentemente dependentes da concentração dos solventes. Considerando que em dado momento se obtêm condições de estado pseudo-estacionário, $J_{A B}=J_{B C}=$ $J_{C D}$, e, portanto:

$K_{A B^{*}}\left(P_{A^{-}} P_{B}\right)=K_{B C^{\cdot}}\left(P_{B^{-}} P_{C}\right)=K_{C D^{*}}\left(P_{C^{-}} P_{D}\right)$

Com base nessa teoria, resta saber qual das etapas apresentadas é a limitante.

1. Etapa limitante: Difusão Gasosa

Aqui se considera que a difusão através da massa líquida ( $A$ para $B$ ) e a difusão de sua superfície (B para $C$ ) são ambas relativamente muito rápidas em relação à difusão gasosa (C para D). Logo, $K_{A B}$ e $K_{B C} \gg K_{C D}$ e $P_{A} \cong P_{B} \cong$ $P_{C}$. Sendo assim, as quedas de pressão $\left(P_{A^{-}} P_{B}\right)$ e $\left(P_{B}-P_{C}\right)$ devem ser bem pequenas, limitadas pela difusão gasosa. Logo, a taxa de transferência de massa para esta etapa pode ser escrita como:

$J_{C D}=-K_{C D} \cdot\left(P_{C}-P_{D}\right)=-K_{C D} \cdot\left(P_{A}-P_{D}\right)$

Considerando-se que a concentração de vapor no ponto $D$ está sob ação de um fluxo turbulento, e por isso é pequena em comparação à concentração no ponto C. Logo:

$J_{C D}=-K_{C D} \cdot\left(P_{A}\right)$

2. Etapa limitante: Difusão através da superfície líquida

Neste caso, a etapa limitante seria a difusão através do filme líquido superficial (B para $\mathrm{C})$. Semelhantemente à etapa anterior:

$J_{B C}=-K_{B C} \cdot\left(P_{B}-P_{C}\right)=-K_{B C} \cdot\left(P_{A}-P_{D}\right)=-K_{B C} \cdot P_{A}$

3. Etapa limitante: Difusão através da massa líquida 
Quando esta etapa é a limitante, a difusão através da superfície líquida e através da camada de ar é bastante rápida, portanto:

$$
J_{A B}=-K_{A B^{\prime}}\left(P_{A^{-}} P_{B}\right)=-K_{A B^{\prime}} \cdot P_{A}
$$

Do ponto de vista da transferência de massa e de calor, parâmetros como a temperatura, a umidade e o fluxo de ar desempenham um papel importante na determinação da taxa de evaporação (SHERWOOD, 1929).

\subsection{Método experimental - Evaporômetro}

Durante os primeiros estudos de evaporação de solventes para aplicação em Tintas e Vernizes ainda não havia um método padronizado de análise. De acordo com os equipamentos disponíveis, os químicos desenvolviam sua própria metodologia, o que causava certa confusão na comparação de dados gerados por diferentes pessoas. Várias técnicas foram desenvolvidas e estudadas: gravimetria, cromatografia gasosa (CASTELLS; CASELLA, 1987; CASTELLS et al., 1989), infravermelho, método do evaporômetro, método do Evapocorder (SAARY; GOFF, 1973), entre outras.

Atualmente, a taxa de evaporação experimental é normatizada pela ASTM D3539. O método apresentado na ASTM D3539 faz uso do equipamento conhecido como evaporômetro ou ainda Shell Thin Film Evaporometer (figura 2.3). O evaporômetro consiste em um sistema de duas cabines, interna e externa, para determinação da curva de evaporação. 


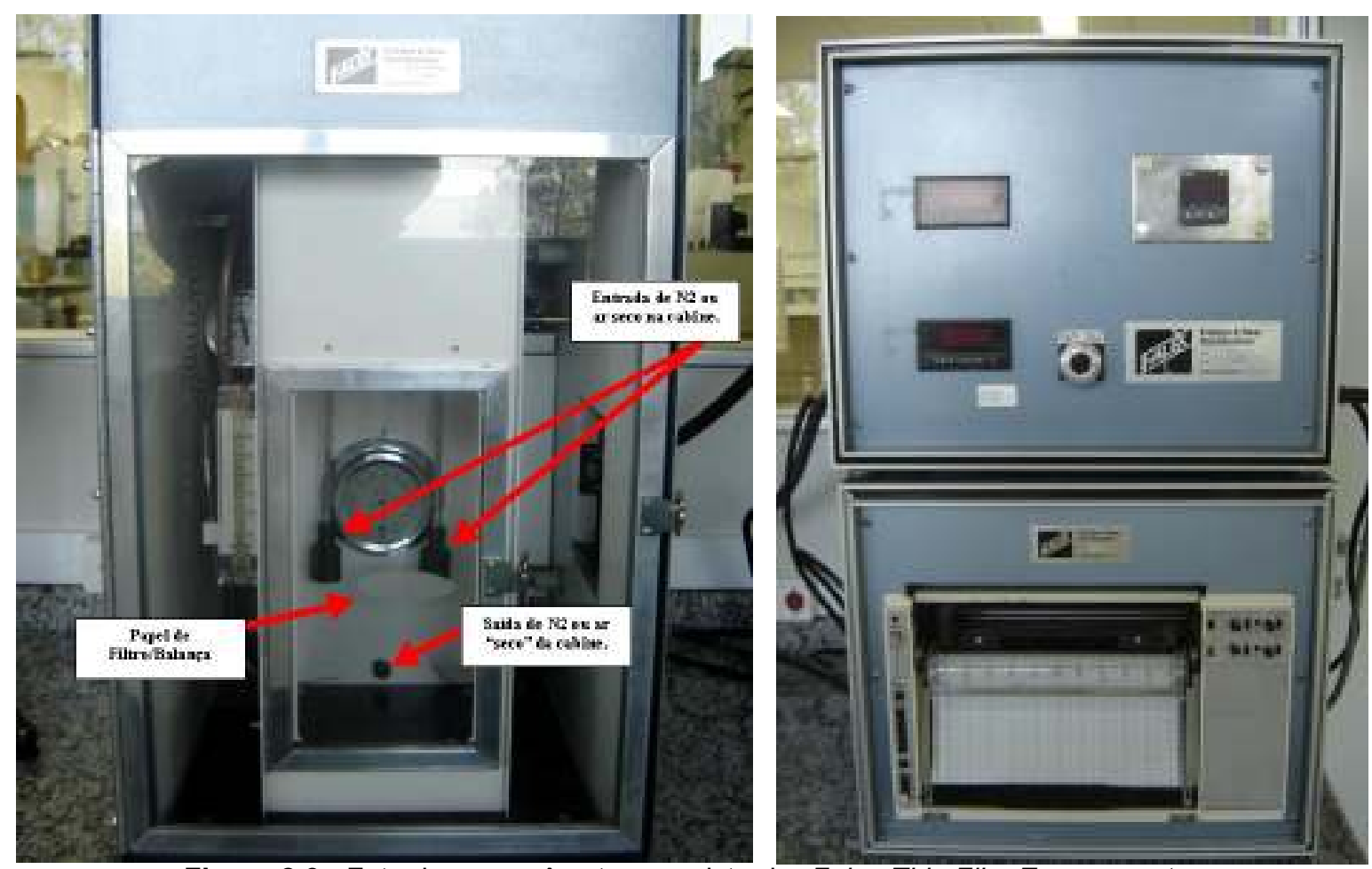

Figura 2.3 - Foto do evaporômetro e registrador Falex Thin Film Evaporometer, da Compass Instruments, Inc.

A norma determina que o evaporômetro seja calibrado de maneira que, quando $90 \%$ do acetato n-butila for evaporado, o tempo de evaporação seja de $470 \pm 10 \mathrm{~s}$, sob as condições de $25^{\circ} \mathrm{C}$, pressão atmosférica, umidade relativa menor que $5 \%$ e fluxo de ar de 21 L. $\mathrm{min}^{-1}$. Sletmoe (1970) em seus experimentos obtinha o tempo de evaporação de 456 segundos.

São encontrados alguns trabalhos em literatura que mostram o efeito da umidade relativa, temperatura e fluxo de ar na taxa de evaporação.

Rocklin (1978) estudou o efeito da umidade relativa em misturas de solventes orgânicos e água, e apresentou as seguintes conclusões:

- O aumento na umidade relativa do sistema não só prolonga o tempo de secagem em sistemas solventes que contenham água em sua composição, como distorce a ordem de evaporação dos solventes;

- Em situações de baixa umidade relativa, os solventes orgânicos tendem a evaporar mais lentamente que a água, e sob alta umidade relativa, estes 
mesmos solventes tendem a evaporar mais rapidamente, enriquecendo a mistura em água;

- Assim, para uso, substituição ou adaptação de sistemas solventes, é necessário conhecer a umidade relativa à qual este sistema será exposto para que se possa fazer o correto balanceamento do sistema com solventes de baixa ou alta taxa de evaporação.

Stratta et al. (1978) também estudaram o efeito da umidade relativa e observaram que, para cada mistura de solventes que contenha água, existe uma umidade relativa necessária para permitir que a evaporação ocorra de maneira que a concentração dos solventes orgânicos na água permaneça constante durante todo o processo de evaporação. Com base nesta observação, eles definiram o conceito de Umidade Crítica Relativa ( $\mathrm{CRH}$ - Critical Relative Humidity). Para evaporações de misturas abaixo da sua $\mathrm{CRH}$, há um aumento na concentração dos solventes orgânicos, enquanto que, para condições de umidade relativa acima da $\mathrm{CRH}$ da mistura, há uma redução no teor dos solventes orgânicos, conforme também observado por Rocklin (1978).

Dillon (1977), Stratta et al. (1978) também mostraram a dependência da taxa de evaporação com a temperatura e a velocidade do ar. Com respeito a esta última, Stratta et al. (1978) alerta para o fato de que não só a velocidade do ar por si só, mas também a natureza e intensidade da turbulência do ar podem influenciar profundamente as constantes das taxas de evaporação dos modelos desenvolvidos, e que serão apresentados mais adiante.

Além do solvente, das condições do ambiente - umidade, temperatura e fluxo de ar, outro fator é importante para a taxa de evaporação: o substrato, ou seja, a superfície de onde se evapora o líquido em questão. De acordo com um trabalho apresentado por Sletmoe (1966), para um determinado grupo de solventes estudado, a taxa de evaporação média foi $6 \%$ mais rápida quando determinada a partir de uma superfície metálica em relação àquela determinada a partir de um papel de filtro.

Rocklin (1976) também estudou o efeito do substrato sobre a taxa de evaporação, e fez este estudo para o evaporômetro com base na norma ASTM D3539. A sua 
justificativa para este trabalho era a preocupação de que, quando as tintas e vernizes fossem aplicados sobre superfícies metálicas, uma superfície lisa e plana, as taxas de evaporação dos solventes poderiam não coincidir com os valores obtidos no teste do evaporômetro a partir do papel de filtro, que é uma superfície porosa. Rocklin calibrou o evaporômetro com o acetato de n-butila utilizando o papel de filtro, de maneira a obter $468 \pm 3$ segundos em 90\% evaporado. Em seguida, realizou-se apenas a troca do papel de filtro pelo disco de alumínio. Após 10 determinações, foi obtido o tempo de $2902 \pm 25$ segundos em $90 \%$ evaporado.

Com base nos experimentos e dados obtidos, Rocklin fez as seguintes observações:

- Para hidrocarbonetos, o tempo de evaporação em superfície lisa metálica (disco metálico) é cerca de seis vezes maior, ou seja, seis vezes mais lento que a evaporação no papel de filtro;

- A ordem de evaporação com base na taxa de evaporação relativa nem sempre é mantida quando se altera o tipo de substrato;

- Embora a taxa de evaporação relativa dos hidrocarbonetos aumente com o aumento da pressão de vapor, para a evaporação a partir do papel de filtro a relação não é linear. A partir de uma superfície metálica, lisa, essa relação se aproxima da linearidade;

- Com exceção da água e dos alcoóis, os demais solventes se comportam de maneira similar aos hidrocarbonetos;

- Em se tratando da água e dos alcoóis, não se observa nenhuma linearidade entre a taxa de evaporação e a pressão de vapor dos mesmos para nenhum dos dois tipos de evaporação, mostrando que a água e esta classe de solventes são diferentes dos demais. A água e os alcoóis apresentam taxa de evaporação muito mais lenta que os outros compostos com a mesma pressão de vapor, em ambos os tipos de substrato. Acredita-se que esta diferença seja atribuída à interação do substrato celulósico com os alcoóis e a água;

- Rocklin conclui que, com base nas diferenças observadas, o tempo de secagem e o balanço de solventes ao longo da evaporação podem ser bastante diferentes dependendo do tipo de superfície a que se submete a evaporação. Dessa forma, assumir uma taxa de evaporação com base no 
papel de filtro para aplicação em uma superfície metálica pode levar a erros significativos.

\subsection{Taxa de Evaporação Absoluta}

Uma das primeiras equações apresentadas para determinar a taxa de evaporação é conhecida como a equação de Langmuir-Knudsen (SLETMOE, 1966; GILBERT, 1971; SAARY; GOFF, 1973). Esta é chamada taxa de evaporação máxima $\left(E_{m}\right)$, pois, por ter sido desenvolvida para a evaporação que ocorreria sob condição de vácuo, não tem a influência da pressão atmosférica - que retarda a evaporação. Se sob a influência da atmosfera, o mais imóvel possível, sem influência de correntes de ar, a evaporação se daria de forma muito lenta.

$$
E_{m}=K \cdot P_{v} \cdot\left[\frac{M}{2 \cdot \pi \cdot R \cdot T}\right]^{1 / 2}
$$

em que:

$E_{m}$ - taxa de evaporação máxima $\left(\mathrm{kg} \cdot \mathrm{m}^{-2} \cdot \mathrm{s}^{-1}\right)$;

$P_{V}$ - pressão de vapor do líquido a ser evaporado $(\mathrm{Pa})$;

$M$ - peso molecular do líquido $\left(\mathrm{kg} \cdot \mathrm{mol}^{-1}\right)$;

$R$ - constante dos gases ideais $\left(8,314 \mathrm{~m}^{3} \cdot \mathrm{Pa} \cdot \mathrm{K}^{-1} \cdot \mathrm{mol}^{-1}\right)$;

$T$ - temperatura (K);

$K$ - coeficiente de transmissão, que varia de 0 a 1.

A equação acima cobre a evaporação de solventes puros quando a difusão na superfície líquida é a etapa limitante, segundo a teoria de Sletmoe (1966). A Equação de Langmuir-Knudsen foi derivada da teoria cinética dos gases. Segundo Lagmuir (GILBERT, 1971), a equação acima só seria válida quando a pressão de vapor do líquido não excedesse a pressão de $1,0 \mathrm{mmHg}$.

Semelhante à equação de Langmuir-Knudsen, mas levando em consideração a presença do ar, outra equação foi descrita também a partir da teoria cinética dos 
gases. Supondo-se que há vários líquidos repousando em cilindros separados, a altura da superfície do líquido até a boca do cilindro é a mesma em cada caso, e definida como S. De acordo com a teoria cinética dos gases, o número de moléculas de vapor por volume $\left(N_{x}\right)$ na altura $S$ é dado por:

$N_{x}=N_{0} \cdot e^{-S / Y}$

em que:

$N_{0}$ - número inicial de moléculas existentes na fase líquida;

$Y$ - caminho livre médio das moléculas de vapor misturadas com o ar;

$S$ - altura da superfície do líquido até a boca do cilindro, coluna de vapor;

Assumindo que as moléculas estão organizadas em camadas, à medida que o ar passa por sobre a boca do cilindro, este arrasta a camada mais externa de moléculas na fase vapor que está acima da altura $S$. O número de moléculas na fase vapor que cruzam um centímetro quadrado da seção transversal por segundo é obtido pela multiplicação $N_{x}$ por $\overline{c_{1}}$ (velocidade unidirecional das moléculas na fase vapor). Assim, a taxa de evaporação de um líquido é função do número de moléculas na fase vapor a uma determinada altura $S$ acima da superfície da fase líquida.

A figura 2.4 a seguir é uma representação esquemática utilizada por Gilbert (1971) para mostrar que cada molécula na fase vapor sofrerá alguns choques no seu caminho para cima.

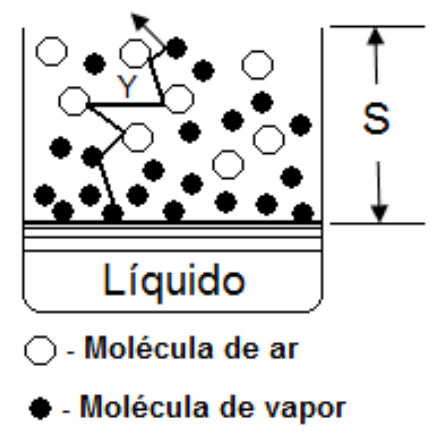

Figura 2.4 - Representação das moléculas do líquido que evaporam dentro do vaso e são arrastadas pelo ar que se move através da boca do vaso acima da altura S. Baseado em Gilbert (1971). 
$S=f \cdot Y$

em que:

$f$ - fator relacionado com as condições atmosféricas.

Se a altura do cilindro aumenta, aumentam também $S$ e $f$. Se o movimento da atmosfera aumenta, $Y$ aumenta e, conseqüentemente, $f$ diminui.

Fazendo uma correlação da equação 2.7 com a equação 2.6, o autor apresenta a equação 2.9 para a taxa de evaporação absoluta partir da taxa de evaporação máxima.

$E_{a}=e^{-f} \cdot P_{v} \cdot\left[\frac{M}{2 \cdot \pi \cdot R \cdot T}\right]^{1 / 2}$

A equação acima mostra que a taxa de evaporação está relacionada com a taxa de colisão das moléculas dada pela teoria cinética dos gases, $P_{v} \sqrt{\frac{M}{2 \pi R T}}$.

Com base em dados experimentais e na equação acima, o autor determinou o valor de $f$ para sete solventes, de acordo com a tabela 2.1.

Tabela 2.1 - Taxa de evaporação absoluta e o fator $f$

\begin{tabular}{lcc}
\hline Solvente & $\mathbf{E}_{\mathrm{a}}, \mathbf{g . c \mathbf { c m } ^ { - 2 } \cdot \mathbf { s } ^ { - 1 }}$ & $\boldsymbol{f}$ \\
\hline Acetato de n-butila & $1,74 \times 10^{-5}$ & 13,52 \\
n-Propanol & $2,38 \times 10^{-5}$ & 13,49 \\
Metanol & $9,69 \times 10^{-5}$ & 13,58 \\
Ciclohexano & $10,40 \times 10^{-5}$ & 13,63 \\
Benzeno & $9,47 \times 10^{-5}$ & 13,76 \\
Tolueno & $3,60 \times 10^{-5}$ & 13,60 \\
n-Heptano & $7,43 \times 10^{-5}$ & 13,63 \\
\hline
\end{tabular}

Assim, o autor observou que os valores de $f$ apresentam uma variação muito pequena entre os solventes. Todavia, o autor comenta que a equação acima pode apresentar melhores resultados para solventes de baixa pressão de vapor, ou que o 
valor de $f$ tende a apresentar maior variação para os solventes de maior pressão de vapor do que para os solventes de baixa pressão de vapor.

Sletmoe (1970) apresentou uma equação mais simples para a taxa de evaporação de compostos puros, que não se aplica para os solventes que ele considerou de rápida evaporação.

$$
E_{a}=\left(6,4 \times 10^{-4}\right) \cdot \frac{P^{0} \cdot M}{d}
$$

em que:

$P^{0}$ - pressão de vapor a $25^{\circ} \mathrm{C}$ (torr);

$M$ - peso molecular (g.mol $\left.{ }^{-1}\right)$;

$d$ - densidade $\left(\mathrm{g} \cdot \mathrm{cm}^{-3}\right)$.

Com base na teoria da difusão, Gardner também desenvolveu uma equação para a taxa de evaporação controlada pela difusão do vapor através da camada estagnada de ar acima do líquido (SLETMOE, 1966):

$$
E_{a}=\frac{B \cdot M \cdot D \cdot P_{v}}{R \cdot T \cdot P \cdot X}
$$

em que:

$B$ - constante;

$M$ - peso molecular (g.mol $\left.{ }^{-1}\right)$;

$D$ - coeficiente de difusão do líquido a ser evaporado $\left(\mathrm{m}^{2} \cdot \mathrm{s}^{-1}\right)$;

$P_{V}$ - pressão de vapor do componente a ser evaporado $(\mathrm{Pa})$;

$R$ - constante dos gases ideais $\left(8,314 \mathrm{~m}^{3} \cdot \mathrm{Pa} \cdot \mathrm{K}^{-1} \cdot \mathrm{mol}^{-1}\right)$;

$T$ - temperatura do líquido a ser evaporado $(\mathrm{K})$;

$P$ - pressão atmosférica $(\mathrm{Pa})$;

$X$ - espessura do filme de ar efetivo acima da superfície de líquido (m).

\subsection{Taxas de Evaporação Relativas}


Como os fatores que influenciam a taxa de evaporação no ar são muitos, vários autores consideram que as relações para calcular as taxas de evaporação relativas são mais apropriadas.

Grande parte das taxas de evaporação relativas foi elaborada de forma que o acetato de n-butila, escolhido arbitrariamente, possua o valor de 1 ou 100. Assim, um solvente que tenha taxa de evaporação relativa igual a 2 ou 200, dependendo da escala adotada, evapora duas vezes mais rápido que o acetato de n-butila.

A taxa de evaporação relativa (TER) é calculada por:

$T E R=\frac{\left(t_{90 \%}\right)_{A A B}}{\left(t_{90 \%}\right)}$

ou

$T E R=\frac{\left(t_{90 \%}\right)_{A A B}}{\left(t_{90 \%}\right)} \cdot 100$

A taxa de evaporação relativa geralmente é calculada com base no tempo necessário para evaporar $90 \%$ da massa injetada ( $\left.t_{90 \%}\right)$, que sempre deve corresponder a $0,7 \mathrm{ml}$ de solvente conforme a norma ASTM D 3539. Com base nesse tempo, calcula-se a TER pelas equações 2.12 ou 2.13 , sendo a TER padrão do acetato de n-butila igual a 1 e 100, respectivamente.

Embora não seja comum, a taxa de evaporação pode ser calculada em base mássica, ou seja, injeta-se uma massa definida e fixa para todos os solventes, a partir de então se calcula a taxa de evaporação relativa. Rocklin (1976) sugeriu uma equação que transforma a taxa de evaporação relativa base-volume em basemassa: 


$$
\begin{aligned}
& t_{90 \%, m}=\frac{t_{90 \%, v o l}}{d^{25^{\circ} \mathrm{C}}} \\
& T E R=\frac{\left(t_{90 \%, m}\right)_{A A B}}{\left(t_{90 \%, m}\right)}=\frac{\left(t_{90 \%, m}\right)_{A A B}}{\left(t_{90 \%, m}\right)} \cdot \frac{\left(d^{25^{\circ} \mathrm{C}}\right)}{\left(d^{25^{\circ} \mathrm{C}}\right)_{A A B}}
\end{aligned}
$$

em que:

$d^{25^{\circ} \mathrm{C}}$ - densidade a $25^{\circ} \mathrm{C}\left(\mathrm{g} \cdot \mathrm{cm}^{-3}\right)$;

$t_{90 \%, m}$ - tempo necessário para evaporar $90 \%$ da massa de solvente (s) em basemassa;

$t_{90 \%, v o l}$ - tempo necessário para evaporar $90 \%$ da massa de solvente (s) em basevolume.

Muitos autores também tentaram determinar correlações para as taxas de evaporação relativas. A seguir são apresentados os diversos modelos encontradas em literatura.

\subsubsection{Modelo de De Heen}

De Heen (1913) foi o primeiro a apresentar uma equação para a taxa de evaporação relativa de líquidos:

$$
T E R=\frac{M \cdot P_{v}}{\left(M \cdot P_{v}\right)_{A A B}}
$$

Gilbert (1971) comenta que esta equação, embora simples, apresenta resultados notadamente coincidentes com os valores experimentais para um grande número de solventes, com algumas exceções, como o caso do metanol.

\subsubsection{Modelo de Gardner}


Em 1940, Gardner comentou sobre a dificuldade que havia na interpretação do fenômeno de evaporação e na determinação da taxa de evaporação relativa a partir de uma constante física. Segundo ele, em anos anteriores a evaporação era avaliada com base na faixa de ebulição, mas que esta abordagem havia sido substituída pela avaliação a partir da pressão de vapor.

Gardner estudou um pouco mais o fenômeno e apresentou uma equação para a taxa de evaporação relativa de solventes derivada a partir da equação de MaxwellStefan, para o caso da difusão de vapor através de um filme de ar.

A partir da superfície líquida se obtém:

$$
N_{A}=\frac{D \cdot P}{R \cdot T \cdot x} \cdot \ln \frac{p_{B_{2}}}{p_{B_{1}}}
$$

em que:

$D$ - coeficiente de difusão ou difusividade $\left(\mathrm{cm}^{2} \mathrm{~s}^{-1}\right)$;

$P$ - pressão total (atm);

$T$ - temperatura $(\mathrm{K})$;

$p_{B_{1}}$ - pressão parcial do ar na interface do filme líquido-ar (atm);

$p_{B_{2}}$ - pressão parcial do ar no lado da corrente de ar do filme de ar (atm);

$x$ - distância em direção da difusão de ar através do filme estagnado $(\mathrm{cm})$.

Substituindo $D$ por $D_{1} / P$, onde $D_{1}$ é o coeficiente de difusão sob a pressão de $1 \mathrm{~atm}$ :

$$
N_{A}=\frac{D_{1}}{R \cdot T \cdot x} \cdot \ln \frac{p_{B_{2}}}{p_{B_{1}}}
$$

Ou, se a taxa de evaporação é desejada em termos da massa líquida evaporada,

$$
N_{A}=\frac{D_{1} \cdot M}{R \cdot T \cdot x} \cdot \ln \frac{p_{B_{2}}}{p_{B_{1}}}=\frac{D_{1} \cdot M}{R \cdot T \cdot x} \cdot \frac{\left(p_{A_{1}}-p_{A_{2}}\right)}{p_{B_{M}}}
$$


em que:

$p_{A_{1}}$ - pressão de vapor do líquido evaporado (atm);

$p_{A_{2}}$ - pressão parcial de vapor no lado da corrente de ar do filme de ar (atm);

$p_{B_{M}}$ - média logarítimica da pressão parcial do ar através do filme (atm).

Oautor observa que, para processos industriais, o termo $\frac{\left(p_{A_{1}}-p_{A_{2}}\right)}{p_{B_{M}}}$ pode ser substituído por $\frac{p_{A_{1}}}{P}$, pois $p_{A_{2}} \ll p_{A_{1}}$ e $p_{B_{M}} \approx P$. Dessa forma, a equação 2.19 se torna:

$E_{a}=\frac{\alpha}{R \cdot T \cdot P \cdot x} \cdot\left(D_{1} \cdot M \cdot p_{A_{1}}\right)$

em que:

$\alpha$ - fator de proporcionalidade;

Se as condições de temperatura, pressão e fluxo de ar forem mantidas constantes:

$T E R=K \cdot\left(D_{1} \cdot M \cdot p_{A 1}\right)=K \cdot D \cdot M \cdot P_{v}$

O autor chama então o produto $D \cdot M \cdot P_{v}$ de índice evaporativo.

A variável $K$ passa a ser constante de proporcionalidade e $D$ é o coeficiente de difusão $\left(\mathrm{cm}^{2} . \mathrm{s}^{-1}\right)$, este último calculado de acordo com a equação de Gilliland (1934):

$D=\frac{0,0043 \cdot T^{3 / 2} \cdot\left[\frac{M_{A}+M_{B}}{M_{A} \cdot M_{B}}\right]^{1 / 2}}{P \cdot\left[\left(v_{A}\right)^{1 / 3}+\left(v_{B}\right)^{1 / 3}\right]^{2}}$

em que: 
$M_{A}$ - Peso molecular do ar $\left(\mathrm{g} \cdot \mathrm{mol}^{-1}\right)$;

$M_{B}$ - Peso molecular do solvente $\left(\mathrm{g} \cdot \mathrm{mol}^{-1}\right)$;

$v_{A}$ - volume molar do $\operatorname{ar}\left(\mathrm{cm}^{3} \cdot \mathrm{mol}^{-1}\right)$;

$v_{B}$ - volume molar do solvente $\left(\mathrm{cm}^{3} \cdot \mathrm{mol}^{-1}\right)$.

Esta equação de difusividade é conveniente, pois necessita apenas de dados simples de serem obtidos, como a temperatura, pressão, peso molecular do vapor e os volumes molares do ar e do vapor.

Para determinar a taxa de evaporação experimental, Gardner desenvolveu um aparato que consistia em uma câmara equipada com um banho térmico, onde $20 \mathrm{ml}$ do solvente eram colocados sobre um prato metálico. As condições de operação eram: fluxo de ar seco de 1 litro por minuto, pressão de $760 \mathrm{mmHg}$, e temperatura do líquido e do ar de $50^{\circ} \mathrm{C}$.

Os resultados obtidos mostraram boa concordância com os valores experimentais. Mas vale a ressalva de que o índice evaporativo utilizado neste artigo foi comparado às taxas de evaporação determinadas sob as mesmas condições.

No artigo publicado por Gardner (1940), não há menção alguma sobre o valor da constante de proporcionalidade $K$. Porém, Gilbert (1971) apresenta $K=1,143 \times 10^{-2}$ mol.s. $\mathrm{g}^{-1} \cdot \mathrm{cm}^{-2} \cdot \mathrm{mmHg}^{-1}$, sendo a TER do acetato de n-butila igual a 100 , enquanto que, Saary e Goff (1973) apresentaram $K=0,143 \times 10^{2} \mathrm{~mol} . \mathrm{s} . \mathrm{g}^{-1} \cdot \mathrm{cm}^{-2} \cdot \mathrm{mmHg}^{-1}$.

\subsubsection{Modelo de Gilbert}

Gilbert (1971) apresentou uma equação para calcular a taxa de evaporação absoluta a partir da teoria cinética dos gases. Com base na taxa de evaporação do acetato de n-butila, obteve-se a equação 2.23 para calcular a taxa de evaporação relativa:

$T E R=0,8215 \cdot \sqrt{M} \cdot P_{v}$ 
Gilbert comenta que seus resultados experimentais apresentam diferenças quando comparados aos resultados obtidos por outros autores, devido à pureza dos solventes utilizados $e$, principalmente, às condições experimentais utilizadas. A principal diferença nos testes experimentais de ambos está relacionada com a natureza do recipiente utilizado para a evaporação. Enquanto Gilbert utilizou um recipiente com paredes, algo como um pequeno pote, Doolittle utilizou tampas de latas de tintas, eliminando assim o efeito das paredes sobre a evaporação. Gilbert comenta que estas diferenças são um bom motivo para haver, naquela época, uma padronização na definição da taxa de evaporação relativa.

Com base na equação 2.22, Gilbert mostrou que o termo $P\left(v_{a}+v_{b}\right)^{2}$ é quase constante. Assim, considerando o peso molecular do ar de 29, e combinando as equações 2.21 e 2.22, obtém-se:

$T E R=0,0667 \cdot \sqrt{M^{2}+29 \cdot M} \cdot P_{v}$

Esta equação 2.24 é obtida a partir da equação de De Heen, equação 2.16.

\subsubsection{Modelo de Hardisty}

Partindo da equação que explica a transferência de massa e a analogia de ChiltonColburn, Hardisty (1977) apresentou a equação 2.25 para calcular a taxa de evaporação.

$T E R=D^{2 / 3} \cdot P_{v} \cdot M$

Esta equação é consistente com o índice evaporativo de Gardner, que foi baseado na hipótese do filme estagnado. $O$ coeficiente de difusão $D$ foi determinado utilizando a fórmula de Fuller, Schettler e Giddings (1966). 


$$
D=\frac{1,00 \times 10^{-3} \cdot T^{1,75} \cdot\left[\frac{1}{M_{A}}+\frac{1}{M_{B}}\right]^{1 / 2}}{P \cdot\left[\left(v_{A}\right)^{1 / 3}+\left(v_{B}\right)^{1 / 3}\right]^{2}}
$$

\subsubsection{Modelo de Dillon}

Dillon (1977) também apresentou uma equação para cálculo da taxa de evaporação relativa. Esta equação é bastante semelhante à equação 2.23 de Gilbert, com uma pequena variação na constante de proporcionalidade:

$T E R=0,8217 \cdot \sqrt{M} \cdot P_{v}$

\subsection{Modelos de Evaporação para misturas}

\subsubsection{Modelo de Sletmoe}

Para se chegar à taxa de evaporação para uma mistura, Sletmoe (1966; 1970) apresentou uma correlação que explica o mecanismo do tipo Barreira de Superfície para um solvente puro:

$\frac{R_{i}}{r_{i}^{0}}=a_{i}-B$

em que:

$R_{i}$ - taxa de evaporação do solvente de um filme em um dado instante $\left(\mathrm{g} \mathrm{s}^{-1}\right)$;

$r_{i}^{0}$ - taxa correspondente do solvente puro $\left(\mathrm{g} \mathrm{s}^{-1}\right)$;

$a_{\mathrm{i}}$ - atividade do solvente na resina a esta concentração;

$B$ - resistência à difusão oferecida pela superfície do filme da resina. 
Assim, para uma determinada quantidade de solvente, quando não há a presença de uma resina, ou esta não oferece nenhuma resistência à difusão, B pode ser considerado zero, e se obtém a primeira aproximação:

$\frac{R_{1}}{r_{i}^{0}} \approx a_{i} \rightarrow R_{i}=a_{i} \cdot r_{i}^{0}$

em que:

$$
a_{1}=\gamma_{1} \cdot C_{1}
$$

Logo,

$$
R_{i}=\gamma_{i} \cdot C_{i} \cdot r_{i}^{0}
$$

em que:

$C_{i}$ - concentração do solvente líquido, tendo como base os voláteis totais, \% volume.

Para se obter a taxa de evaporação da mistura, seria simplesmente necessário somar as taxas dos componentes individuais, o que leva a equação 2.32 :

$r=C_{1} \cdot \gamma_{1} \cdot r_{1}^{0}+C_{2} \cdot \gamma_{2} \cdot r_{2}^{0}+\cdots+C_{n} \cdot \gamma_{n} \cdot r_{n}^{0}$

Em misturas nas quais as espécies químicas são semelhantes, o coeficiente de fugacidade ou atividade acaba não tendo função alguma, porém, em aplicações onde as misturas tendem à não-idealidade, ele possui uma importante função. Segundo Sletmoe (1970), quanto mais diferentes forem os tipos dos compostos químicos na mistura, maior será o coeficiente de fugacidade para cada componente, que varia também de acordo com a concentração de cada componente. Neste artigo (SLETMOE, 1970), os coeficientes foram determinados através de dados experimentais e calculados pelo método de Pierotti, Deal e Derr (1959) para diluição infinita.

\subsubsection{Modelo de Walsham e Edwards (WE)}


Segundo Walsham e Edwards (1971), para a maioria dos solventes puros a evaporação ocorre a uma taxa constante ao longo de quase todo o tempo de evaporação. Contudo, para misturas de solventes pode haver variação na taxa ao longo do processo de evaporação. Considerando que, a evaporação de um solvente puro apresenta linearidade nos $90 \%$ iniciais de massa evaporada, a taxa de evaporação $\left(r_{i}\right)$ é constante e é dada como:

$r_{i}=\frac{w_{i}}{t_{90 \%, i}}$

em que:

$w_{i}$ - massa de solvente evaporado por unidade de área do substrato;

$t_{90 \%, i}$ - tempo necessário para evaporar $90 \%$ p do componente $i$.

Para misturas de solventes, a taxa de evaporação total é igual à soma das taxas de evaporação dos componentes individuais, conforme apresentado por Sletmoe (1966). Todavia, para mistura de solventes não se observa um comportamento ideal, linear, apenas em caso onde os componentes da mistura sejam similares em tamanho molecular e estrutura. Assim, a taxa de evaporação para uma mistura de $n$ componentes quer seja ideal ou não é definida da mesma forma que a equação 2.32:

$r=\gamma_{1} \cdot w_{1} \cdot r_{1}^{0}+\gamma_{2} \cdot w_{2} \cdot r_{2}^{0}+\cdots+\gamma_{n} \cdot w_{n} \cdot r_{n}^{0}$

em que:

$\gamma_{1}, \gamma_{2}, \ldots, \gamma_{n}$ - coeficiente de atividade dos diversos componentes da mistura;

$w_{1}, w_{2}, \ldots, w_{n}$ - fração mássica dos diversos componentes da mistura;

$r_{1}^{0}, r_{2}^{0}, \ldots, r_{n}^{0}$ - taxa de evaporação dos diversos componentes da mistura, sob as condições dadas pela ASTM D3539.

A equação 2.34 foi prevista inicialmente pelos autores utilizando a fração molar no lugar da fração mássica, porém segundo eles esta substituição tinha o intuito de 
aumentar efetivamente o termo de concentração para os solventes de maior peso molecular, e assim corrigir as discrepâncias que surgiam nos cálculos dos coeficientes de atividade pelo modelo por eles utilizado.

Para calcular os coeficientes de atividade, Walsham e Edwards (1971) utilizaram a extensão multicomponente da equação de Van Laar.

Os resultados de Walsham e Edwards (1971) mostraram uma boa correlação entre os valores experimentais e preditos.

\subsubsection{Modelo de Rocklin e Bonner (RB)}

Rocklin e Bonner (1980), e Rocklin (1982) publicaram seus trabalhos para a predição do comportamento de evaporação para sistemas de solventes onde a água estivesse presente como um componente, e onde a umidade fosse levada em consideração, pois em trabalhos anteriores já se falava da sua relevância. Segundo eles, o trabalho apresentado por Walsham e Edwards (1970) foi bem sucedido para misturas de solventes orgânicos, mas não para misturas aquosas. Partindo deste trabalho, Rocklin e Bonner (1980) utilizaram o método UNIFAC para calcular os coeficientes de atividades, e também levaram em consideração o efeito de resfriamento evaporativo dos solventes.

Eles apresentaram uma variação da equação 2.34 para a taxa de evaporação de misturas, inserindo alguns termos de correção.

$r(t)=\sum_{i=1}^{n} x_{i}(t) \cdot \gamma_{i}\left(t, T_{s o l}\right) \cdot r_{i}^{0} \cdot\left(\frac{T_{s o l}}{T_{\min _{i}}}\right)^{1 / 2}$

em que:

$r(t)$ - taxa total de evaporação $\left(\mathrm{g} \cdot \mathrm{s}^{-1}\right)$ da mistura no tempo $t$;

$x_{i}(t)$ - fração molar do componente $i$ na mistura no tempo $t$; 
$\gamma_{i}\left(t, T_{\text {sol }}\right)$ - coeficiente de atividade do componente $i$ no tempo $t$, na temperatura real de evaporação da mistura;

$T_{\text {sol }}$ - temperatura real de evaporação da mistura $(\mathrm{K})$;

$T_{\min _{i}}$ - temperatura real de evaporação do componente $i(\mathrm{~K})$;

$r_{i}^{0}$ - taxa de evaporação $(\mathrm{g} / \mathrm{s})$ do componente $i$ puro, sob as condições dadas pela ASTM D3539.

Vale ressaltar que o trabalho feito por Rocklin e Bonner (1980) faz uso de taxas de evaporação para solventes puros determinadas respeitando as condições de umidade, temperatura e fluxo de ar definidas na ASTM D 3539. Segundo eles, foram evaporados $90 \%$ de acetato de n-butila em 468 segundos, respeitando os limites impostos pela norma para o seu padrão.

Na equação acima, o termo $\left(\frac{T_{s o l}}{T_{\min _{i}}}\right)^{1 / 2}$ é de um fator de correção de temperatura, devido ao fato de que cada solvente evapora à temperatura de solução $\left(T_{\text {sol }}\right)$ e não à temperatura de evaporação do componente puro $\left(T_{\min }\right)$, que é conhecida como a temperatura de bulbo úmido. A temperatura $T_{\min }$ pode ser medida acoplando um termopar ao papel de filtro utilizado na determinação da taxa de evaporação para um componente puro. A tabela 2.2 apresenta os valores medidos para alguns solventes segundo os autores. A temperatura $T_{\text {sol }}$ pode ser calculada de acordo com a equação 2.36. Esta equação foi determinada com base em um balanço de energia, feito sob algumas simplificações, nas quais se considera que o calor de mistura é pequeno quando comparado com a perda de calor por evaporação; as capacidades caloríficas permanecem constantes durante a evaporação e a temperatura da solução cai instantaneamente atingindo um estado estacionário, alcançando a

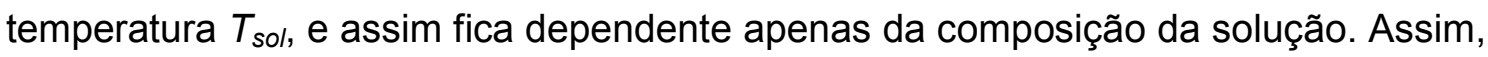
o balanço pode ser escrito como sendo o calor necessário para evaporar a mistura, que é igual a soma do calor necessário para evaporar cada uma das substâncias puras individualmente.

$\sum_{i=1}^{n} n_{i} \cdot C_{p_{i}} \cdot\left(298,15-T_{\text {sol }}\right)=\sum_{i=1}^{n} n_{i} \cdot C_{p_{i}} \cdot\left(298,15-T_{\min _{i}}\right)$ 
em que:

$n_{i}$ - número de mols do componente $i$;

$C_{p_{i}}$ - capacidade calorífica do componente $i$.

Considera-se que para cada solvente, $C p_{i}$ permanece constante, calculada para $298,15 K$, e $n_{i}$ é o número de mols do componente i na solução. Rearranjando a equação (2.36):

$T_{\text {sol }}=298,15-\frac{\sum_{i=1}^{n} n_{i} \cdot C_{p_{i}} \cdot\left(298,15-T_{\min _{i}}\right)}{\sum_{i=1}^{n} n_{i} \cdot C_{p_{i}}}$

Esta temperatura é calculada a cada iteração, sendo também levada em consideração nos cálculos dos coeficientes de atividade.

Tabela 2.2 - Temperatura de evaporação de solventes obtida de acordo com o método determinado pela ASTM D 3539

\begin{tabular}{lc}
\hline Solvente & $\mathbf{T}_{\min }\left({ }^{\circ} \mathbf{C}\right)$ \\
\hline Água & 15,6 \\
Acetona & 0,0 \\
Metiletilcetona & 10,0 \\
Etanol & 12,2 \\
Isopropanol & 14,7 \\
Tolueno & 18,4 \\
sec-Butanol & 18,6 \\
Metilisobutilcetona & 20,0 \\
n-Butanol & 20,8 \\
2-Etoxietanol & 21,3 \\
(Etilglicol) & 22,0 \\
Acetato de n-butila & 22,5 \\
Xileno & \\
\hline
\end{tabular}

Para misturas aquosas de solventes, ou seja, quando há água presente na mistura, o termo da taxa de evaporação é multiplicado por um fator de correção linear com base na umidade:

$r_{\mathrm{H}_{2} \mathrm{O}}(t)=\left(1-\frac{R H}{100}\right) \cdot x_{\mathrm{H}_{2} \mathrm{O}}(t) \cdot \gamma_{i} \mathrm{H}_{2} \mathrm{O}\left(t, T_{\text {sol }}\right) \cdot r_{\mathrm{H}_{2} \mathrm{O}}^{0} \cdot\left(\frac{T_{\text {sol }}}{T_{\min _{\mathrm{H}_{2} \mathrm{O}}}}\right)^{1 / 2}$ 
em que:

$R H$ - umidade relativa (Relative Humidity) do ar ambiente em volta da mistura em evaporação.

Este termo, $\left(1-\frac{R H}{100}\right)$, é aplicado exclusivamente para a água, porque segundo Rocklin e Bonner (1980), ela é a única componente cuja taxa de evaporação é afetada significativamente pela umidade. Umidades elevadas tendem a reduzir a evaporação da água, que indiretamente reduz a evaporação dos demais solventes, porque prolonga o tempo que a água permanecerá na solução, como diluente.

O modelo apresentado não é exclusivo para sistemas aquosos, como já foi mostrado, mas a influência da umidade só pode ser avaliada quando água estiver presente na mistura.

\subsubsection{Modelo de Dillon e Stratta (DS)}

O modelo apresentado por Dillon (1977) e Stratta et al. (1978) é bastante semelhante aos que já haviam sido apresentados por Sletmoe $(1966,1970)$ e por Walsham e Edwards (1971). A taxa de evaporação é apresentada na forma de uma equação diferencial, e é dada como uma cinética de primeira ordem, apenas com uma modificação para o fator de correção da umidade relativa (saturação de vapor relativa).

$\frac{d m_{i}}{d t}=-A \cdot r_{i}^{V, T} \cdot\left(\gamma_{i} \cdot x_{i}-\rho_{i}\right)$

em que:

$m_{i}$ - massa do componente $i(\mathrm{~g})$;

$A$ - área interfacial líquido/vapor da mistura de solventes $\left(\mathrm{m}^{2}\right)$;

$r_{i}^{V, T}$ - taxa de evaporação do componente $i\left(\mathrm{~g} \cdot \mathrm{m}^{-2} \cdot \mathrm{s}^{-1}\right)$ para dada condição de temperatura e velocidade do ar; 
$\gamma_{i}$ - coeficiente de atividade do componente $i$ na fase líquida;

$x_{i}$ - fração molar do componente $i$;

$\rho_{i}$ - saturação relativa do vapor do componente $i$.

A saturação relativa do vapor, $\rho_{i}$, é a fração do vapor do componente $i$ sobre a superfície líquida. Considerando que esta fração é muito pequena (levando em consideração que há uma corrente de ar que arrasta os vapores gerados), assumese que $\rho_{i}=0$. Porém, em se tratando da água como componente de uma mistura:

$\rho_{i}=\frac{R H}{100}$

Por definição, a umidade relativa do ar é:

$R H=100 \cdot \frac{P_{\mathrm{H}_{2} \mathrm{O}}}{P_{\mathrm{H}_{2} \mathrm{O}}^{\text {Sat }}}$

em que:

$P_{\mathrm{H}_{2} \mathrm{O}}$ - pressão parcial de vapor de água do ar;

$P_{H_{2} \mathrm{O}}^{\mathrm{sat}, T}$ - pressão de vapor de saturação da água a uma dada temperatura.

Segundo Oliveira (1992), a razão das pressões na equação 2.41 confere à umidade relativa o significado termodinâmico de atividade da água na fase vapor e, portanto ela pode ser subtraída diretamente do termo $\gamma_{i} \cdot x_{i}$. Esta é uma abordagem diferente da apresentada no modelo de Rocklin e Bonner (1980) que apresenta a umidade relativa apenas como um fator numérico.

Dillon (1977) ainda apresenta a dependência da taxa de evaporação com a temperatura a partir da equação de Gardner:

$r_{i}^{V, T}=k_{m_{i}}^{V} \cdot T^{1 / 2} \cdot P_{v_{i}}^{T}$ 
em que:

$k_{m_{i}}^{V}$ - coeficiente de transferência de massa do componente $i$

$\left(g \cdot \mathrm{min}^{-1} \cdot \mathrm{m}^{-2} \cdot \mathrm{K}^{-1 / 2} \cdot \mathrm{mmHg}^{-1}\right)$;

$\mathrm{T}$ - temperatura $(\mathrm{K})$;

$P_{v_{i}}^{T}$ - pressão de vapor do componente puro $i(\mathrm{mmHg})$ a uma dada temperatura $\mathrm{T}$.

Dillon (1977) e Stratta et al. (1978) mostraram que a velocidade do ar possui uma grande influência na taxa de evaporação. Em um túnel de vento em miniatura, com velocidades na faixa de 0 a 5,0 mph, provendo um fluxo laminar, água foi evaporada à $23,5^{\circ} \mathrm{C}$ e umidade relativa de $50 \%$. Sob as mesmas condições, acetato de n-butila foi evaporado a $23,5^{\circ} \mathrm{C}$ e umidade relativa de $0 \%$. Os resultados foram corrigidos para $25^{\circ} \mathrm{C}$ através da equação 2.42. A partir destes experimentos, a dependência do coeficiente de transferência de massa com a velocidade do ar foi determinada empiricamente, de forma que a taxa de evaporação $\left(25^{\circ} \mathrm{C}\right.$, umidade relativa de $\left.0 \%\right)$ pudesse ser correlacionada com a velocidade do ar:

$r_{i}^{V}=r_{i}^{0}+\frac{V}{A_{i}^{T} \cdot V+B_{i}^{T}}$

em que:

$V$ - velocidade do ar (mph);

$A_{i}^{T}-1^{\circ}$ coeficiente de velocidade do ar $\left(\min . \mathrm{m}^{2} \cdot \mathrm{g}^{-1}\right)$ para a taxa de transferência de massa do componente $i$ para uma dada temperatura $T$;

$B_{i}^{T}-2^{\circ}$ coeficiente de velocidade do ar $\left(\min . \mathrm{m}^{2} \cdot \mathrm{mph} . \mathrm{g}^{-1}\right)$ para a taxa de transferência de massa do componente $i$ para uma dada temperatura $T$.

Na tabela 2.3 são apresentados os valores obtidos a partir dos mínimos quadrados para os fatores de ajuste, os coeficientes $A_{i}^{T}$ e $B_{i}^{T}$.

Tabela 2.3 - Coeficientes de velocidade para água e acetato de n-butila

\begin{tabular}{lccc}
\hline Líquido & $\boldsymbol{r}_{\boldsymbol{i}}^{\mathbf{0 , 2 5}} \mathbf{C}$ & $\boldsymbol{A}_{\boldsymbol{i}}^{\mathbf{2 5}^{\circ} \mathbf{C}}$ & $\boldsymbol{B}_{\boldsymbol{i}}^{\mathbf{2 5}} \mathbf{C}$ \\
\hline Água & 2,58 & 0,0579 & 0,0746 \\
Acetato de n-butila & 1,86 & 0,0155 & 0,0706 \\
\hline \multicolumn{2}{l}{ Fonte: Stratta et al., 1978}
\end{tabular}


Stratta et al.(1978) mostraram ainda que há uma boa concordância, geralmente de até $5 \%$, entre as constantes das taxas de evaporação predita e medida com a velocidade do ar a 2,0 mph para a maioria dos co-solventes testados

Dillon (1977) e Stratta et al. (1978) também demonstraram que os coeficientes $A$ e $B$ são também dependentes da temperatura, partindo-se da equação de Gardner:

$r_{i}^{0, T}=k_{m_{i}}^{0} \cdot T^{1 / 2} \cdot P_{v_{i}}^{T}$

$k_{m_{i}}^{V} \cdot T^{1 / 2} \cdot P_{v_{i}}^{T}=k_{m_{i}}^{0} \cdot T^{1 / 2} \cdot P_{v_{i}}^{T}+\frac{V}{A \cdot V+B}$

Dividindo-se a equação 2.45 por $T^{1 / 2} \cdot P_{v_{i}}^{T}$ :

$k_{m_{i}}^{V}=k_{m_{i}}^{0}+\frac{V}{(A \cdot V+B) \cdot T^{1 / 2} \cdot P_{v_{i}}^{T}}$

em que:

$\alpha_{i}=A \cdot T^{1 / 2} \cdot P_{v_{i}}^{T}$

$\beta_{i}=B \cdot T^{1 / 2} \cdot P_{v_{i}}^{T}$

Logo,

$k_{m_{i}}^{V}=k_{m_{i}}^{0}+\frac{V}{\alpha_{i} \cdot V+\beta_{i}}$

em que:

$\mathrm{V}$ - velocidade do ar (mph);

$\alpha_{i}-1^{\circ}$ parâmetro da velocidade do ar $\left(\min \cdot \mathrm{m}^{2} \cdot \mathrm{K}^{1 / 2} \cdot \mathrm{mmHg} \cdot \mathrm{g}^{-1}\right)$;

$\beta_{i}-2^{\circ}$ parâmetro da velocidade do ar $\left(\min \cdot \mathrm{m}^{2} \cdot \mathrm{K}^{1 / 2} \cdot \mathrm{mmHg} \cdot \mathrm{mph} \cdot \mathrm{g}^{-1}\right)$.

A dependência da pressão de vapor com a temperatura pode ser expressa de acordo com a conhecida expressão de Antoine e suas constantes: 
$\log _{10} P_{v_{i}}^{T}=a_{i}-\frac{b_{i}}{T+C_{i}}$

Nos estudos apresentados por Stratta et al. (1978) foram utilizados os parâmetros de Wilson para cálculo dos coeficientes de atividade.

\subsection{Modelos de Evaporação e a teoria da Transferência de Massa e Calor}

A teoria de evaporação e secagem trata basicamente de um processo simultâneo de transferência de calor e massa, no qual a energia e a evaporação de um líquido e de um sólido podem ser facilmente caracterizadas.

No período em que a taxa de evaporação se mantém constante, o solvente passa rapidamente através dos componentes não voláteis do sistema, mantendo sempre a superfície em condições saturadas. Neste período a taxa depende apenas da velocidade, temperatura e teor de solvente do ar. Se estas condições externas não variarem significativamente, a taxa se manterá constante.

Embora seja pouco prático para determinação da taxa de evaporação dos solventes devido à necessidade de conhecer muitos parâmetros, a teoria de transferência de massa e transferência calor é completa na explicação e modelagem do processo de secagem e evaporação.

Abaixo seguem algumas abordagens encontradas para a etapa em que a taxa de evaporação se mantém constante. O foco dado por muitos autores nesta abordagem envolve o cálculo da temperatura de bulbo úmido, que é a temperatura mínima que o solvente em questão evapora, e depois segue com a elaboração da equação para cálculo da taxa de evaporação. 


\subsubsection{Modelo de Hardisty}

Hardisty descreveu em 1977 o processo de secagem evaporativa em termos do processo de transferência de massa e calor. Devido à diferença de temperatura existente entre o ar de secagem, mais quente, e a superfície contendo a tinta ou apenas solvente, calor é transferido para a superfície para suprir a energia (calor latente, $\lambda$ ) necessária para evaporar o solvente. Da mesma maneira, a diferença de concentração que existe entre a condição de vapor saturado na superfície livre e a baixa concentração de vapor no ar de secagem é a força motriz para a transferência de massa (solvente) para longe da superfície livre. Assim, calor é transferido numa direção, enquanto massa é transferida na direção oposta. Contanto que o líquido passe através do sólido rapidamente de modo a manter uma condição de equilíbrio na superfície livre, o líquido evaporará desta superfície a uma taxa constante. A evaporação então ocorre como se um líquido livre e sua superfície estivessem à temperatura de bulbo úmido. Nesta situação, a taxa de evaporação de um solvente particular é altamente dependente dos valores dos coeficientes de transferência de massa e calor da superfície.

A teoria da mecânica dos fluidos explica então a formação do filme de ar estagnado sobre a superfície do líquido. Quando um fluido em movimento turbulento passa sobre uma superfície sólida, o fluido próximo à parede é retardado por um arraste viscoso e turbulento, e na parede a velocidade do fluido é zero. Esta camada de fluido retardado é chamada de camada limite. Como calor deve ser transferido através desta camada inteiramente por condução molecular, a mesma é encarada como a principal resistência à transferência de calor. Como o autor apresenta, de fato é útil conceitualmente definir o fluido adjacente à superfície como um filme estagnado do qual sua espessura "efetiva" é tal que oferece a mesma resistência à transferência de calor que a camada limite real.

A taxa de transferência de calor $(\mathrm{Q})$ em estado estacionário através de uma camada limite turbulenta até uma superfície sólida pode ser expressa pela equação 2.51: 
$\dot{Q}=h \cdot A \cdot\left(T_{a r}-T_{s}\right)$

em que:

$h$ - coeficiente de transferência de calor superficial (W.m $\left.{ }^{-2} . K\right)$;

$A$ - área superficial $\left(\mathrm{m}^{2}\right)$;

$T_{a r}$ - temperatura do ar $\left({ }^{\circ} \mathrm{C}\right.$ ou $\left.\mathrm{K}\right)$;

$T_{s}$ - temperatura da superfície da tinta ou solvente $\left({ }^{\circ} \mathrm{C}\right.$ ou $\left.\mathrm{K}\right)$;

Para uma dada diferença de temperatura, $h$ é dependente tanto da espessura efetiva quanto das propriedades térmicas do filme estagnado.

$h=f\left(v, x, \rho, \mu, C_{p}, k\right.$, formato da superfície $)$

Geralmente é necessário recorrer a experimentos para determinar os valores de $h$.

Analogamente, a taxa de transferência de massa pode ser determinada de acordo com a equação 2.53:

$\dot{m}=k_{m} \cdot A \cdot\left(\rho_{s}-\rho_{a r}\right)$

em que:

$k_{m}$ - coeficiente de transferência de massa $(\mathrm{m} / \mathrm{s})$;

$A$ - área superficial $\left(\mathrm{m}^{2}\right)$;

$\rho_{s}$ - densidade do solvente na fase vapor $\left(\mathrm{kg} / \mathrm{m}^{3}\right)$;

$\rho_{\text {ar }}$ - densidade do ar $\left(\mathrm{kg} / \mathrm{m}^{3}\right)$.

No equilíbrio, a superfície se encontra à temperatura de bulbo úmido e a equação de balanço de energia é satisfeita:

$h \cdot A \cdot\left(T_{a r}-T_{s}\right)=k_{m} \cdot A \cdot\left(\rho_{s}-\rho_{a r}\right) \cdot \lambda$

em que:

$\lambda$ - calor latente de vaporização (J.kg). 
Considerando que $\rho_{\text {ar }}=0$, a equação 2.54 se torna:

$T_{a r}-T_{s}=\frac{k_{m}}{h} \cdot \rho_{s} \cdot \lambda$

Por meio da analogia de Chilton-Colburn, a equação 2.55 pode ser reescrita em função do número de Lewis.

$\frac{h}{\rho_{a r} \cdot C_{p_{a r}} \cdot k_{m}}=\left(\frac{k /\left(\rho_{a r} \cdot C_{p}\right)}{D}\right)^{2 / 3}=\left(\frac{\alpha}{D}\right)^{2 / 3}=L e^{2 / 3}$

em que:

$h$ - coeficiente de transferência de calor $\left(\mathrm{W} \cdot \mathrm{m}^{-2} \cdot \mathrm{K}^{-1}\right)$;

$\rho_{\text {ar }}$ - densidade do ar $\left(\mathrm{kg} / \mathrm{m}^{3}\right)$;

$C_{p_{a r}}$ - capacidade calorífica $\left(\mathrm{J} . \mathrm{kg}^{-1} \cdot \mathrm{K}^{-1}\right)$;

$k_{m}$ - coeficiente de transferência de massa $\left(\mathrm{m} \cdot \mathrm{s}^{-1}\right)$;

$k$ - condutividade térmica $\left(\mathrm{W} \cdot \mathrm{m}^{-1} \cdot \mathrm{K}^{-1}\right)$;

$D$ - Difusividade do solvente no $\operatorname{ar}\left(\mathrm{m}^{2} \cdot \mathrm{s}^{-1}\right)$;

$\alpha$ - Difusividade térmica do ar $\left(\mathrm{m}^{2} . \mathrm{s}^{-1}\right)$;

Le - número de Lewis.

Assim,

$T_{a r}-T_{s}=\frac{1}{\rho_{a r} \cdot C_{p_{a r}}} \cdot L e^{-2 / 3} \cdot \rho_{s} \cdot \lambda$

É com base no desenvolvimento acima que Hardisty (1977) chega à equação 2.25 para calcular a taxa de evaporação relativa.

Saary e Goff (1973) determinaram experimentalmente a temperatura $T_{s}$ para alguns solventes, e chegaram a algumas conclusões: 
1. A temperatura do filme líquido e do substrato diminui tão logo a evaporação comece a ocorrer. Quanto mais rápido o solvente evapora, maior a redução de temperatura;

2. Quando solventes rápidos tais como acetona e hexano evaporam, a temperatura do substrato cai até que $70-80 \%$ do solvente tenha evaporado;

3. Quando solventes mais lentos evaporam, há também uma queda de temperatura, mas apenas durante os $30 \%$ iniciais de evaporação. O restante evapora quase que à temperatura constante até $85 \%$ do mesmo tenha evaporado.

Para ambos os tipos de solventes, a evaporação e o efeito de resfriamento diminuem até que cerca de $85 \%$ do solvente tenha evaporado.

\subsubsection{Modelo de Cary e Gutoff}

Cary e Gutoff (1991) e Gutoff (1994) apresentaram seus estudos para modelar o processo de secagem de tintas em materiais flexíveis, como tecido, papel, e outros, que por meio de rolos atravessassem zonas de secagem, o que é chamado de Continuous Web, e será chamado aqui de malha contínua.

Como Hardisty havia descrito, para calcular a taxa de secagem ou taxa de evaporação, é necessário conhecer as fontes de calor, os coeficientes de transferência de calor entre $o$ ar e a superfície, a temperatura da superfície e as propriedades do ar (CARY; GUTOFF, 1991).

Cary e Gutoff (1991) propuseram um balanço de energia considerando que a quantidade de calor transferido do ar para a superfície deve ser igual à taxa de transferência de massa da superfície multiplicado pelo calor latente de vaporização.

$Q+h \cdot\left(T_{a r}-T_{\min }\right)=\lambda \cdot k_{m} \cdot\left(\rho_{s}-\rho_{a r}\right)$ 
Segundo os autores, quando a secagem ocorre através do contato com o ar seco por apenas um lado da malha, Q será igual a zero, e neste caso, a superfície do revestimento será a temperatura de bulbo úmido do ar com respeito ao solvente em particular. Se o processo de secagem ocorrer em ambos os lados, admitindo que apenas um dos lados possua revestimento (tinta ou verniz), $Q$ será igual ao outro termo do lado esquerdo da mesma equação, e a temperatura da malha será um pouco mais alta que a temperatura de bulbo úmido do ar. Logo:

$h_{\text {rev }} \cdot\left(T_{\text {ar }, \text { rev }}-T_{\text {min }}\right)+h_{\text {malha }} \cdot\left(T_{\text {ar }, \text { malha }}-T_{\text {min }}\right)=\lambda \cdot k_{m} \cdot\left(\rho_{s}-\rho_{a r}\right)$

em que:

$h_{\text {rev }}$ - coeficiente de transferência de calor do lado do revestimento (W. $\left.\mathrm{m}^{-2} \cdot \mathrm{K}^{-1}\right)$;

$h_{\text {malha }}$ - coeficiente de transferência de calor do lado da malha (W. $\left.\mathrm{m}^{-2} \cdot \mathrm{K}^{-1}\right)$;

$T_{\text {ar,rev }}$ - temperatura de bulbo seco, ou temperatura do ar do lado do revestimento $(\mathrm{K})$;

$T_{\text {ar,malha }}$ - temperatura de bulbo seco, ou temperatura do ar do lado da malha (K);

$T_{\min }$ - temperatura de bulbo úmido, ou temperatura mínima de evaporação da água ou do solvente $(\mathrm{K})$;

$k_{m}$ - coeficiente de transferência de massa $\left(\mathrm{m} . \mathrm{s}^{-1}\right)$;

$\rho_{s}$ - densidade do solvente na fase vapor $\left(\mathrm{kg} / \mathrm{m}^{3}\right)$;

Considerando a lei de gás ideal, a equação 2.59 se torna:

$h_{r e v} \cdot\left(T_{a r, r e v}-T_{\min }+\frac{h_{\text {malha }}}{h_{r e v}} \cdot\left(T_{a r, \text { malha }}-T_{\min }\right)\right)=\frac{\lambda \cdot k_{m} \cdot M}{1000 \cdot R} \cdot\left(\frac{P_{s}}{T_{\min }}-\frac{P_{a r}}{T_{a r, r e v}}\right)$

em que:

$P_{s}$ - pressão de vapor do solvente na superfície $(\mathrm{Pa})$;

$P_{a r}$ - pressão de vapor do ar nas condições do ponto de orvalho (Pa);

É possível ainda desenvolver a equação 2.60 para se chegar a uma equação implícita para cálculo da temperatura mínima de evaporação do solvente. A partir 
disso, segundo Cary e Gutoff (1991), o período que a taxa de evaporação ou secagem é constante pode ser determinado pela equação 2.61 :

$E_{a}=\frac{h_{r e v} \cdot\left(T_{a r, r e v}-T_{\text {min }}\right)+h_{\text {malha }} \cdot\left(T_{a r, \text { malha }}-T_{\text {min }}\right)}{\lambda}$

Esta equação foi obtida a partir do balanço do estado estacionário em que o calor latente de vaporização é igual ao calor transferido ao solvente na superfície, mantendo as temperaturas constantes.

Gutoff (1994) ressalta que para utilizar a equação 2.61 é necessário conhecer o coeficiente de transferência de calor sob uma velocidade de ar ou pressão referência.

Cary e Gutoff (1991) alertam para o fato de que é difícil calcular o coeficiente de transferência de calor. De qualquer forma, Gutoff (1994) apresenta uma forma de obtê-lo a partir do perfil de temperatura no evaporador. O cálculo é baseado no balanço de calor do estado não-estacionário sobre a malha: se uma seção de uma malha sem revestimento (tinta, ou verniz) é aquecido por um ar quente em ambos os lados, a taxa de acúmulo de energia na malha é igual à taxa na qual a energia flui para dentro da malha. Baseado neste balanço de energia se obtém a equação 2.62:

$h_{r e v}+h_{\text {malha }}=\frac{x \cdot \rho \cdot C_{p}}{t} \cdot \ln \left(\frac{T_{a r}-T_{\text {min }, 0}}{T_{a r}-T_{\text {min }}}\right)$

em que:

$T_{\min , 0}$ - Temperatura inicial da malha ( ${ }^{\circ} \mathrm{C}$ ou $\left.\mathrm{K}\right)$;

$\rho$ - densidade da malha $\left(\mathrm{kg} / \mathrm{m}^{3}\right)$;

$t$ - tempo (s).

O coeficiente de transferência de calor apresenta alguns valores típicos (AVCl; CAN, 1999):

- Convecção livre: 5-30 W.m $\mathrm{m}^{-2} \cdot \mathrm{K}^{-1}$; 
- Circulação cruzada convencional: $30-140 \mathrm{~W} \cdot \mathrm{m}^{-2} \cdot \mathrm{K}^{-1}$;

- Sob influências de jatos diretos de ar: até $550 \mathrm{~W} \cdot \mathrm{m}^{-2} \cdot \mathrm{K}^{-1}$.

O coeficiente de transferência de calor está diretamente relacionado com a teoria da camada limite. Por isso, se a velocidade do ar de secagem aumenta, haverá uma redução da espessura da camada limite, portanto um aumento no valor de $h$.

Avci e Can (1999), Avci, Can e Etemoglu (2001), Etemolglu, Can e Pulat (2004) apresentaram uma abordagem bastante semelhante à apresentada por Cary e Gutoff para calcular a taxa de evaporação da água ou outros solventes, porém ainda mais complexa.

\subsection{Projeto de Produto Químico e Otimização}

A busca pela substituição de solventes é geralmente devida à necessidade de solventes que possam causar nenhum dano ao meio ambiente e ao homem, às mudanças de legislação ambiental, à necessidade de novos requisitos de aplicação e processo, e à resposta de demandas de mercado (ACHENIE; SINHA, 2002). O processo de substituição de solventes ocorre através de experimentos baseados na tentativa e erro, embora já existam várias técnicas para auxiliar neste desenvolvimento.

Segundo Cussler e Moggridge (2001), o projeto de produto químico, ou Chemical Product Design (CPD) como é mais conhecido, é um procedimento que consiste na definição do que se necessita, gerando resultados que vão ao encontro das necessidades, selecionando as melhores idéias, e finalmente decidindo o aspecto e como deve ser produzido o produto. Inúmeras técnicas computacionais estão disponíveis, e quando associadas ao $C P D$, são conhecidas como Computer-Aided Product Design (CAPD), por natureza um processo iterativo (GANI, 2004a).

O CAPD pode ser dividido em duas categorias (GANI, 2004a): 
- CAMD: Projeto molecular auxiliado por computador (Computer-Aided Molecular Design), com base em programação matemática e métodos híbridos que, através de modelos de contribuição de grupos, possibilitam projetar moléculas que atendam às necessidades;

- $\mathrm{CAM}^{\mathrm{b}} \mathrm{D}$ : Projeto de mistura auxiliado por computador (Computer-Aided Mixture/Blend Design), também baseado em programação matemática, métodos híbridos, e neste caso modelos de mistura para as diferentes propriedades avaliadas.

Ambos os casos tratam a predição de propriedades de forma reversa, pois dado um conjunto de propriedades, busca-se identificar uma estrutura molecular ou conjunto de moléculas que as possua. Gani (2004b) descreve que a maior vantagem desta abordagem é o fato de que se uma solução viável for encontrada, pelo menos as propriedades desejadas serão determinadas dentro dos limites das incertezas experimentais. Devido a isso, é necessário que os modelos das propriedades utilizados apresentem uma precisão razoável. Ou seja, as limitações desse tipo de técnica estão diretamente relacionadas às limitações do modelo que está sendo utilizado.

Segundo Gani (2004), os problemas de $C A M^{b} D$ podem ser definidos como a necessidade de definir a mistura ótima (componentes e composição), a partir de um dado conjunto de produtos químicos e um conjunto de restrições de propriedades. Como exemplo o autor cita a necessidade de se substituir solventes por misturas otimizadas que consigam atender as propriedades necessárias (solubilização, taxa de evaporação, etc.) e ainda apresentar menor custo. Wu, Klein e Gani (1992) propuseram um algoritmo de otimização que determina a identidade e a composição de misturas de solventes com propriedades desejadas, e também classifica as misturas de acordo com o custo. Este trabalho foi feito integrando algoritmos de otimização com CAMD, para resolução de um sistema que possui o custo como função objetivo, e diferentes propriedades termodinâmicas (ponto de ebulição, densidade e parâmetros de solubilidade) como restrições lineares e não-lineares.

Problemas de otimização de CAPD geralmente são descritos por programação nãolinear inteira mista (MINLP - Mixed-Integer Nonlinear Programming). Achenie e 
Sinha (2003) comentam que este tipo de formulação pode ser de difícil solução, principalmente se o número de variáveis binárias for elevado. Como a variável binária tem a função de reforçar as condições lógicas (GANI, 2004a), em alguns casos pode ser possível suprimi-las da formulação, reduzindo o problema acima para uma programação não-linear (NLP - Nonlinear Programming). 


\section{MATERIAIS E MÉTODOS}

\subsection{Solventes}

Para o desenvolvimento deste trabalho foram escolhidos solventes produzidos pela Oxiteno (grau industrial) e solventes comerciais (grau PA), de pureza mínima de $99 \%$.

Tabela 3.1 - Solventes utilizados em mistura para estudo dos modelos de evaporação deste trabalho

\begin{tabular}{lcc}
\hline \multicolumn{1}{c}{ Solvente } & Pureza (\%) & TER \\
\hline Acetato de Isopentila & 99,0 & 53,0 \\
Acetato de n-Butila & 99,0 & 100,0 \\
Acetato de sec-Butila & 99,5 & 195,0 \\
Acetona & 99,8 & 560,0 \\
Água & 100 & 33,0 \\
Butilglicol & 99,0 & 7,0 \\
Ciclohexano & 99,5 & 460,0 \\
Etanol & 99,8 & 165,0 \\
Etilglicol & 99,5 & 35,0 \\
Isopropanol & 99,7 & 150,0 \\
Metiletilcetona & 99,7 & 390,0 \\
Metilisobutilcetona & 99,0 & 165,0 \\
Metilpropilenoglicol & 99,5 & 71,0 \\
n-Butanol & 99,8 & 46,0 \\
sec-Butanol & 99,0 & 89,7 \\
Tolueno & 99,5 & 200,0 \\
Xilenos & 98,5 & 77,0 \\
\hline
\end{tabular}

\subsection{Misturas de Solventes}

As misturas de solventes utilizadas neste estudo representam misturas de interesse industrial e misturas citadas em referências bibliográficas, importantes para avaliação de algum aspecto dos modelos estudados. As misturas foram preparadas 
com base na composição mássica apresentadas no capítulo de Resultados e Discussões.

\subsection{Curva de Evaporação Experimental}

Para determinação das curvas de evaporação dos solventes puros e das misturas foi utilizado o Evaporômetro, Falex Thin Film Evaporometer, da Compass Instruments, Inc. A metodologia utilizada está de acordo com a metodologia recomendada pela ASTM D3539.

O evaporômetro consiste de um sistema de duas cabines, interna e externa, para a determinação da curva de evaporação. Esta estrutura visa proporcionar o controle das variáveis: temperatura $-25,0 \pm 0,5^{\circ} \mathrm{C}$, umidade $-0-5 \%$, e fluxo de ar (fluxo de

nitrogênio ou ar seco) - 21 L. $\min ^{-1}$. A amostra de solvente ou mistura de solventes é aplicada sobre um papel de filtro de $90 \mathrm{~mm}$ de diâmetro, que fica suspenso em uma estrutura de arame preso a uma balança. Depois de atingidas as condições determinadas pelo método, $0,7 \mathrm{~mL}$ de amostra (condicionada a $25 \pm 0,50^{\circ} \mathrm{C}$ ) é aplicada com auxílio de uma seringa sobre o papel de filtro, através de um orifício de borracha na lateral direita do equipamento. A perda de massa é então medida e registrada para posterior avaliação e tratamento dos dados.

Antes de qualquer medição, o evaporômetro precisa ser padronizado com acetato de n-butila (99\%), e este deve apresentar uma taxa de evaporação em $90 \%$ de $470 \pm$ 10 seg. Se o tempo de evaporação estiver fora desta faixa, alguns ajustes podem ser feitos no fluxo de ar. O resultado final deste teste é apresentado em um gráfico onde se apresenta a perda de massa líquida em relação ao tempo. A taxa de evaporação relativa (TER) é calculada pela razão entre o tempo necessário para evaporar $90 \%$ do acetato de n-butila e o tempo necessário para evaporar $90 \%$ do solvente em avaliação, multiplicado por 100 (equação 2.13). Desta forma, o acetato de n-butila possui taxa de evaporação relativa de 100 , enquanto que os mais voláteis possuem valores maiores que 100 , e os menos voláteis, valores menores que 100. As curvas de evaporação foram todas realizadas ao menos em triplicata. 


\subsection{Conversão de Taxas de Evaporação Relativas em Absolutas}

Os resultados das curvas de evaporação são geralmente apresentados em termos da taxa de evaporação relativa, embora os modelos de evaporação façam uso da taxa de evaporação absoluta.

A taxa de evaporação relativa pode ser facilmente convertida na taxa de evaporação absoluta, e vice-versa. Partindo do princípio do método do evaporômetro, onde são injetados sempre $0,7 \mathrm{ml}$ de amostra, e que apenas $90 \%$ da massa dessa amostra é evaporada e contabilizada para a taxa de evaporação:

$$
E_{a}=\frac{m_{0,7 m l}}{t_{90 \%}}=\frac{0,9 \cdot 0,7 \cdot d^{25^{\circ} \mathrm{C}}}{\frac{470 \cdot 100}{T E R}}=\frac{0,63 \cdot d^{25^{\circ} \mathrm{C}} \cdot T E R}{47000}
$$

Logo,

$$
E_{a}=1,34 \times 10^{-4} \cdot d^{25^{\circ} \mathrm{C}} \cdot T E R
$$

Alguns autores apresentam uma correlação direta da taxa de evaporação absoluta com a taxa de evaporação relativa. Stratta et al. (1978) a partir de seus estudos apresentaram uma taxa absoluta proporcional à taxa relativa dada por:

$E_{a}=0,0186 \cdot T E R$

Segundo o autor, a constante de proporcionalidade $(0,0186)$ foi obtida pela razão entre taxa de evaporação absoluta do acetato de butila e sua TER, corrigida para $25^{\circ} \mathrm{C}$.

\subsection{Taxas de Evaporação Relativas Teóricas}


Para avaliação dos modelos de taxa de evaporação relativa, foram necessárias algumas propriedades dos solventes selecionados: densidade, peso molecular e pressão de vapor. Estas propriedades foram encontradas em literatura (BARTON, 1983; DEAN, 1985; WEAST, 1983-1984; YAWS, 1999).

As taxas de evaporação relativa dos solventes foram cedidas pela Oxiteno S/A Indústria e Comércio, a partir do seu banco de dados experimentais, determinadas de acordo com a ASTM D3539.

Os resultados teóricos foram comparados com os dados experimentais por meio da raiz quadrada do erro médio quadrático (RMSE - Root Mean Square Error), que mede o ajuste do modelo aos dados experimentais, e também o desvio relativo.

$R M S E=\sqrt{\frac{\sum_{i=1}^{n}\left(\hat{y}_{i}-y_{i}\right)^{2}}{n}}$

$\operatorname{Desvia}(\%)=\frac{y_{i}-\hat{y}_{i}}{y_{i}} \cdot 100$

em que:

$\hat{y}_{i}$ - valor predito para a propriedade da amostra $i$;

$y_{i}$ - valor experimental da propriedade da amostra $i$;

$n$ - número de amostras.

\subsection{Taxas Teóricas de Evaporação de Misturas}

As curvas de evaporação teóricas das misturas foram calculadas de acordo com os diversos modelos apresentados na revisão bibliográfica. As taxas de evaporação de 
cada componente da mistura foram determinadas de acordo com o método citado na ASTM D3539.

A programação para os cálculos das curvas de evaporação foi feita em Matlab R2007b, da Mathworks, Inc.

A base do algoritmo de cálculo consiste na resolução de um balanço de massa diferencial, de acordo com as equações 2.34, 2.35 e 2.39, a partir das quais se calcula a perda de massa da mistura e de seus componentes. Estas equações diferenciais são solucionadas no Matlab com a função ODE45 ou ODE15S. O cálculo é finalizado quando $90 \%$ da mistura de solventes foram evaporados. São calculadas as composições da mistura cada intervalo de 1 segundo.

De forma geral, é necessário "alimentar" o algoritmo com as seguintes informações:

1. Mistura:
a. Número de Componentes;
b. Composição;
c. Temperatura ambiente;
d. Umidade relativa;

2. Componentes:
a. Taxa de evaporação absoluta ou relativa;
b. Peso molecular;
c. Densidade;
d. Parâmetros dos modelos para o cálculo do coeficiente de atividade;
e. Temperatura mínima de evaporação;
f. Capacidade Calorífica.

Os resultados obtidos para os modelos de evaporação das misturas também foram avaliados e comparados com base no desvio relativo e em função do RMSE.

\subsubsection{Modelos de Coeficiente de Atividade}


Os modelos para cálculo da curva de evaporação de misturas de solventes utilizam o coeficiente de atividade $\left(\gamma_{i}\right)$ como a medida da não idealidade da mistura. Para o caso de uma mistura ideal, o valor do coeficiente de atividade é um. A teoria termodinâmica referente ao coeficiente de atividade e seus diferentes modelos é bastante extensa, e este trabalho não tem por objetivo se aprofundar no assunto.

Existem diferentes modelos para cálculo do coeficiente de atividade, mas neste trabalho foram avaliadas apenas os modelos de solução regular, UNIQUAC e WILSON.

\subsubsection{Solução Regular}

Um dos modelos mais simples é conhecido como Solução Regular e foi desenvolvido por Hildebrand e Scatchard a partir da teoria de soluções de Van Laar (PRAUSNITZ; LICHTENTHALER; AZEVEDO, 1999). O coeficiente de atividade é definido de acordo com a equação 3.6.

$$
\begin{aligned}
& R \cdot T \cdot \ln \left(\gamma_{i}\right)=v_{i} \cdot\left(\delta_{i}-\sum_{j=1}^{m} \phi_{j} \cdot \delta_{j}\right) \\
& \phi_{j}=\frac{x_{j} \cdot v_{j}}{\sum_{i=1}^{m} x_{i} \cdot v_{i}}
\end{aligned}
$$

em que:

$v_{i}$ - Volume molar líquido $\left(\mathrm{cm}^{3} \cdot \mathrm{mol}^{-1}\right)$ da espécie $i$;

$\delta_{i}$ - Componente difusiva dos parâmetros de solubilidade de Hansen da espécie $i$;

$\phi_{j}$ - Fração volumétrica da espécie $j$;

Este é um modelo bastante interessante para se estudar devido à sua simplicidade, já que depende apenas de parâmetros que estão amplamente disponíveis para os mais diversos solventes: parâmetro de solubilidade, volume molar, fração volumétrica e molar. 


\subsubsection{UNIQUAC}

O modelo UNIQUAC (UNIversal QUasiChemical) desenvolvida por Abrams e Prausnitz (SANDLER, 1999) baseados na teoria mecânica estatística, permite determinar a composição local, e conseqüentemente o coeficiente de atividade de uma mistura multicomponente a partir das diferenças de tamanho e energia entre as moléculas da mistura. O modelo UNIQUAC é bastante utilizado para calcular o equilíbrio líquido-líquido e líquido-vapor.

A equação do coeficiente de atividade (equação 3.8) possui uma componente combinatória (equação 3.9) e uma componente residual (equação 3.10).

$$
\begin{aligned}
& \ln \left(\gamma_{i}\right)=\ln \gamma_{i}^{C}+\ln \gamma_{i}^{R} \\
& \ln \gamma_{i}^{C}=\ln \left(\frac{\phi_{i}}{x_{i}}\right)+\frac{z}{2} \cdot q_{i} \cdot \ln \left(\frac{\theta_{i}}{\phi_{i}}\right)+l_{i}-\frac{\phi_{i}}{x_{i}} \cdot \sum_{j} x_{j} \cdot l_{j} \\
& \ln \gamma_{i}^{R}=q_{i} \cdot\left[1-\ln \left(\sum_{j} \theta_{j} \cdot \tau_{j i}\right)-\sum_{j} \frac{\theta_{j} \cdot \tau_{i j}}{\sum_{k} \theta_{k} \cdot \tau_{k j}}\right]
\end{aligned}
$$

em que:

$r_{i}$ - parâmetro de volume da espécie $i$;

$q_{i}$ - parâmetro de área da espécie $i$;

$\theta_{i}=\frac{x_{i} \cdot q_{i}}{\sum_{j} x_{j} \cdot q_{j}}-$ fração superficial da espécie $i$

$\phi_{i}=\frac{x_{i} \cdot r_{i}}{\sum_{j} x_{j} \cdot r_{j}}$ - segmento ou fração volumétrica da espécie $i$;

$$
\ln \left(\tau_{i j}\right)=\frac{u_{i j}-u_{i j}}{R \cdot T} ;
$$

$u_{i j}$ e $u_{j j}$ - parâmetro de interação energética média das espécies $i$ e $j$;

$z$ - número médio de coordenação, geralmente utilizado no valor de 10,0. 
Todos os parâmetros necessários para calcular o coeficiente de atividades das misturas de acordo com o modelo UNIQUAC e de Wilson foram obtidos no Software de Simulação ASPEN PLUS 7.1, ou no Vapor-Liquid Equilibrium Data Collection (1979-), coleção de dados bastante conhecido pelo nome de sua editora, Dechema, ou pelo nome de um de seus principais autores, Jürgen Gmehling.

O Dechema utiliza a notação AlJ para representar os parâmetros de interação energética $\left(u_{i j}-u_{j j}\right)$ nas equações do modelo UNIQUAC, e $\left(\lambda_{i j}-\lambda_{i i}\right)$ nas equações dos modelos de Wilson. Neste trabalho serão utilizadas as notações $A_{i j}$ e $B_{i j}$ para as equações dos modelos de UNIQUAC e Wilson, respectivamente.

\subsubsection{Wilson}

Embora não seja aplicável ao cálculo do equilíbrio líquido-líquido, o modelo de Wilson é matematicamente mais simples que o modelo UNIQUAC, e possivelmente o mais útil para misturas binárias fortemente não-ideais (REID; PRAUSNITZ: POLING, 1987), especialmente em situações próximas à miscibilidade parcial, mas nas quais não haja separação de duas fases líquidas.

$\ln \gamma_{i}=1-\ln \left(\sum_{j} x_{j} \cdot \Lambda_{i j}\right)-\sum_{j} \frac{x_{j} \cdot \Lambda_{j i}}{\sum_{k} x_{k} \cdot \Lambda_{j k}}$

em que:

$$
\begin{aligned}
& \Lambda_{i j}=\frac{v_{j}}{v_{i}} \cdot \exp \left[-\frac{\left(\lambda_{i j}-\lambda_{i i}\right)}{R \cdot T}\right] \\
& \Lambda_{i i}=\Lambda_{j j}=1
\end{aligned}
$$

\subsubsection{Testes de Consistência Termodinâmica}


Os parâmetros binários de interação apresentados pelos modelos UNIQUAC e de Wilson são determinados, principalmente, a partir de dados experimentais geralmente apresentados na forma de curvas isotérmicas ou isobáricas. Entretanto, é possível que os dados disponíveis em literatura muitas vezes não representem com exatidão o comportamento real. Uma forma de avaliar a qualidade dos dados experimentais é aplicar os chamados testes de consistência termodinâmica, que visam comparar as relações termodinâmicas existente com os dados experimentais.

Quando possível, é importante conhecer e selecionar os parâmetros dos diferentes modelos para cálculo do coeficiente de atividade de acordo com os resultados destes testes de consistência.

São dois os principais testes de consistência termodinâmica, o primeiro, chamado de teste de área, e o segundo, chamado de teste de ponto. A teoria envolvida no cálculo destes testes está discutida em Gmehling et al. (1979-), e não será aqui apresentada. Grande parte dos parâmetros utilizados nos modelos termodinâmicos foi obtida de dados consistentes.

\section{7 $C A M^{b} D$ e Otimização}

O problema de otimização apresentado neste trabalho envolve duas importantes classes de parâmetros para a formulação de tintas e vernizes: a taxa de evaporação dos solventes e suas misturas e os parâmetros de solubilidade dos solventes, e das resinas ou polímeros que se pretende solubilizar.

As equações para cálculo da taxa de evaporação e solubilidade das misturas são, portanto, importantes para escrever as equações e inequações de restrições no modelo de otimização. Como as equações sobre a taxa de evaporação já foram apresentadas, segue abaixo apenas um breve resumo da teoria envolvendo os parâmetros de solubilidade. 


\subsubsection{Parâmetros de Solubilidade}

De acordo com Hansen (2004), os parâmetros de solubilidade de Hildebrand dos solventes podem ser cindidos em três componentes: $\delta_{\mathrm{D}}$, parâmetro difusivo responsável por descrever as interações atômicas não-polares; $\delta_{\mathrm{P}}$, parâmetro de momento-dipolo, responsável por descrever as interações moleculares dipolares; $\delta_{H}$, parâmetro de ligações de hidrogênio, responsável pelas interações moleculares de hidrogênio. Estes parâmetros ficaram conhecidos como os parâmetros de solubilidade de Hansen.

Por meio destes parâmetros e pela equação da esfera de solubilidade (3.12), é possível prever se um soluto é ou não solúvel em um solvente ou mistura de solventes.

$R^{i j k}=\left[4 \cdot\left(\delta_{D}^{k}-\delta_{D}^{i j}\right)^{2}+\left(\delta_{P}^{k}-\delta_{P}^{i j}\right)^{2}+\left(\delta_{H}^{k}-\delta_{H}^{i j}\right)^{2}\right]^{1 / 2}$

em que:

$\delta_{D}^{k}, \delta_{P}^{k}, \delta_{H}^{k}$ - Parâmetros de solubilidade de Hansen do soluto $\left(\mathrm{Pa}^{1 / 2}\right)$;

$\delta_{D}^{i j}, \delta_{P}^{i j}, \delta_{H}^{i j}$ - Parâmetros de solubilidade de Hansen da mistura de solventes $\left(\mathrm{Pa}^{1 / 2}\right)$;

$R^{i j k}$ - Distância da mistura de solventes do centro da esfera de solubilidade do polímero $\left(\mathrm{MPa}^{1 / 2}\right)$.

Os parâmetros de solubilidade da mistura podem ser calculados a partir dos parâmetros de solubilidade dos solventes e suas frações volumétricas.

$$
\begin{aligned}
& \delta_{D}^{i j}=\sum_{i} \Phi_{i} \cdot \delta_{D}^{i} \\
& \delta_{P}^{i j}=\sum_{i} \Phi_{i} \cdot \delta_{P}^{i} \\
& \delta_{H}^{i j}=\sum_{i} \Phi_{i} \cdot \delta_{H}^{i}
\end{aligned}
$$


De acordo com Barton (1983), para que um soluto seja solúvel em um determinado solvente ou mistura de solventes, é necessário que o raio da mistura de solventes $\left(R^{i j k}\right)$ centrado na esfera de solubilidade da resina seja menor que o Raio da resina $\left(R^{k}\right)$, ou seja, $R^{i j k} \leq R^{k}$.

Neste trabalho, todos os parâmetros de solubilidade de Hansen foram obtidos do Handbook of Solubility Parameters and Others Cohesion Parameters (BARTON, 1983).

\subsubsection{Programação Não-Linear}

A solução da otimização proposta foi construída com a estrutura de um problema de Programação Não-Linear (NLP - Non-Linear Programming). Problemas de CAPD como este podem ser descritos por meio de representações matemáticas genéricas (ACHENIE; SINHA, 2003):

$\min f(x)$

sujeita a

$$
\begin{aligned}
& h(x)=0 \\
& l b \leq g(x) \leq u b \\
& x \in \mathfrak{R}^{n}
\end{aligned}
$$

em que:

$f(x)$ - função objetivo;

$x$ - representa a variável continua de dimensão $n$;

$u b$ e $l b$ - respectivamente, limites mínimos e máximos para a inequação de variável contínua.

Foi utilizada a função FMINCON do Matlab R2007b para solução deste problema de otimização. 


\subsubsection{Função Objetivo}

A função objetivo foi criada a fim de minimizar o custo da mistura de solventes através de uma função de custo/preço. Assim, a função objetivo assume a forma:

$\min f(\underline{m})=\min \underline{C}^{T} \cdot \frac{\underline{m}}{m_{T}}$

em que:

$\underline{C}^{T}$ - vetor linha dos custos/preços;

$\underline{m}$ - vetor coluna das massas dos solventes da mistura;

$m_{T}-$ somatório das massas de todos os componentes da mistura.

\subsubsection{Equações de restrição}

Como este é um problema de mistura, a soma das frações mássicas deve ser igual a um, e por isso a equação 3.20 representa uma das restrições, relativa à composição:

$h_{1}\left(m_{1}, m_{2} \ldots m_{n}\right)=\sum_{i=1}^{n} \frac{m_{i}}{m_{T}}=1$

O cálculo da taxa de evaporação da mistura é feita com base na massa da mistura de solventes injetada inicialmente, e esta massa deve ser correspondente a 0,7 ml. Por isso, como mais uma forma de controle e restrição, a equação 3.21 representa outra equação de restrição utilizada no modelo.

$h_{2}\left(m_{1}, m_{2} \ldots m_{n}\right)=\sum_{i=1}^{n} \frac{m_{i}}{d_{i}}=0,7$

\subsubsection{Inequações de restrição}


As inequações de restrição estão associadas à taxa de evaporação relativa da mistura de solventes (equação 3.22) e ao raio de solubilidade da mistura e da resina (equação 3.23).

$l b \leq \frac{470}{t_{90 \%}} \cdot 100 \leq u b$

em que:

Ib e $u b$ - limites para a taxa de evaporação da mistura.

$R^{i j k}-R^{k} \leq 0$ 


\section{RESULTADOS E DISCUSSÃO}

Há muita informação sobre evaporação de solventes disponível em literatura para diversas situações e aplicações, mas quando se trata especificamente do fenômeno de evaporação no evaporômetro, a disponibilidade de informações é reduzida.

Os modelos apresentados no capítulo 2 (Revisão Bibliográfica) são aqueles disponíveis em literatura que estão mais relacionados com o principal objetivo deste trabalho.

\subsection{Avaliação de modelos de Evaporação para um componente}

Embora seja dada mais importância nos modelos de evaporação de misturas como substitutos ao método experimental do evaporômetro, ainda existe uma dependência do equipamento para estes modelos, como será visto mais adiante.

Os modelos disponíveis em literatura apresentados no capítulo 2 seguem consolidados na tabela 4.1 .

A equação apresentada por Dillon (1977) se trata da mesma equação apresentada originalmente por Gilbert (1971), com uma diferença apenas na quarta casa decimal da constante. Por isso não será discutida nas considerações abaixo.

A fim de avaliar a validade das equações acima, foram selecionados alguns solventes (tabela 4.2) dos quais são conhecidos os parâmetros necessários para cálculo das equações acima e também suas taxas de evaporação relativa (TER) determinadas experimentalmente. 
Tabela 4.1 - Modelos de Evaporação por Componente

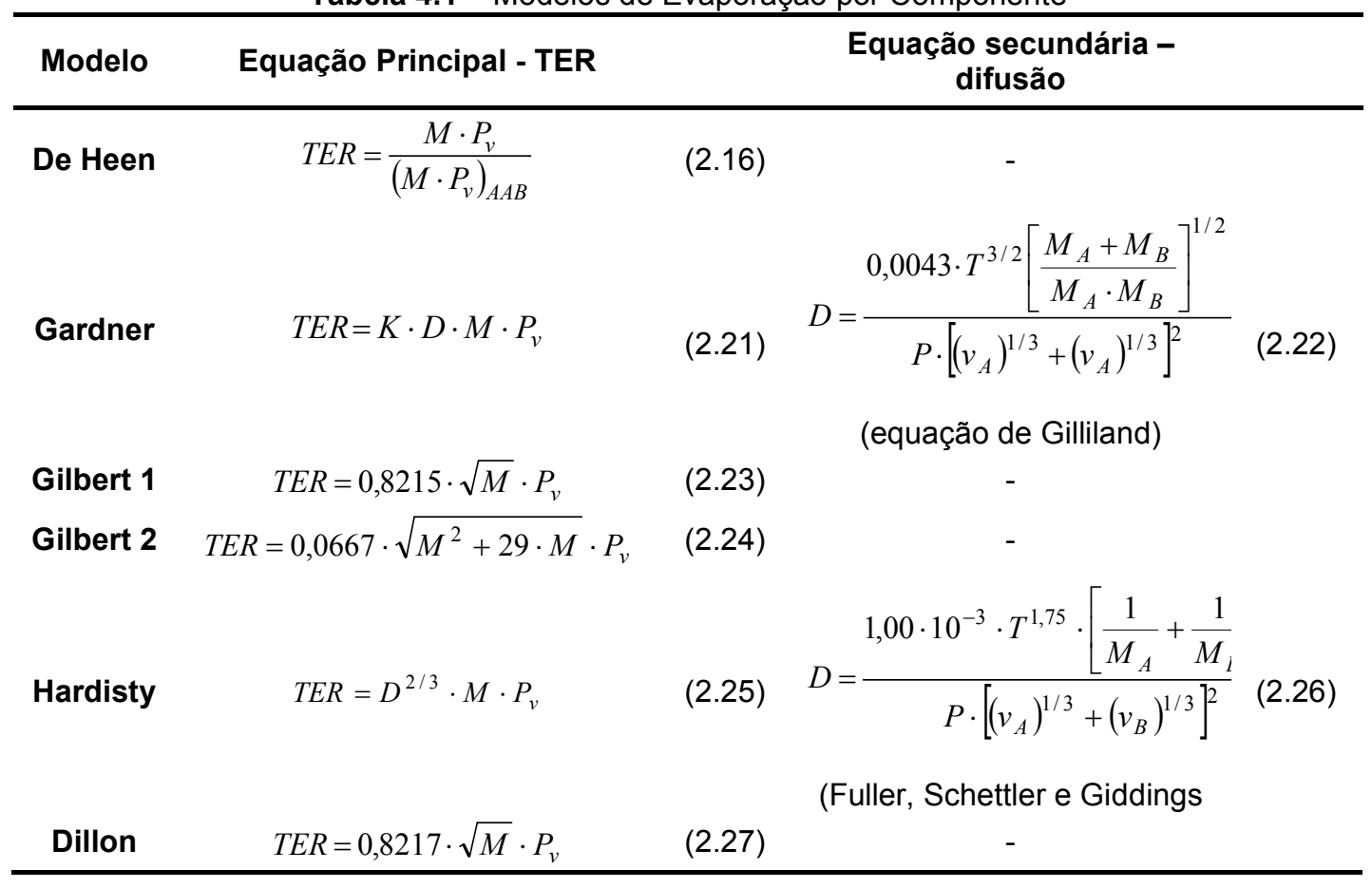

Tabela 4.2 - Solventes e suas propriedades para avaliação dos Modelos de TER ordenados em relação à pressão de vapor

\begin{tabular}{cccc}
\hline Solventes & $\begin{array}{c}\text { Peso } \\
\text { molecular }\end{array}$ & $\begin{array}{c}\mathbf{P v}^{*} \\
(\mathbf{m m H g})\end{array}$ & $\begin{array}{c}\text { TER } \\
\text { Experimental** }\end{array}$ \\
\hline 2-Etil hexanol & 130,23 & 0,136 & 2 \\
Metildiglicol & 120,15 & 0,180 & 2 \\
Acetato de 2-Etilhexila & 172,27 & 0,229 & 3,4 \\
Isoforona & 138,20 & 0,437 & 2 \\
Diacetato de Etilenoglicol & 146,15 & 0,581 & 2,6 \\
Ciclohexanol & 100,16 & 0,755 & 5 \\
Butilglicol & 118,18 & 0,872 & 7 \\
Diisobutilcetona & 142,24 & 1,687 & 19 \\
Diacetona Álcool & 116,16 & 1,709 & 12 \\
Acetato de Etilglicol & 132,16 & 2,342 & 19 \\
Isopentanol & 88,15 & 3,183 & 20 \\
Lactato de Etila & 118,10 & 3,751 & 18 \\
Metilamillcetona & 114,18 & 3,795 & 33 \\
Ciclohexanona & 98,14 & 4,325 & 31 \\
Metilisoamilcetona & 114,18 & 5,203 & 53 \\
Metilisobutilcarbinol & 102,18 & 5,245 & 27 \\
Etilglicol & 90,12 & 5,308 & 35 \\
Acetato de Isopentila & 130,19 & 5,594 & 53 \\
n-Butanol & 74,12 & 7,051 & 46 \\
Metilglicol & 76,09 & 9,002 & 58 \\
& Continua & & \\
& & &
\end{tabular}


Continuação da tabela 4.2

\begin{tabular}{|c|c|c|c|}
\hline Solventes & $\begin{array}{c}\text { Peso } \\
\text { molecular }\end{array}$ & $\begin{array}{c}P_{v}^{*} \\
(\mathrm{mmHg})\end{array}$ & $\begin{array}{c}\text { TER } \\
\text { Experimental** }^{*}\end{array}$ \\
\hline Isobutanol & 74,12 & 10,442 & 62 \\
\hline Óxido de mesitila & 98,14 & 11,030 & 88 \\
\hline Acetato de n-Butila & 116,16 & 11,528 & 100 \\
\hline Acetato de Isobutila & 116,16 & 17,818 & 145 \\
\hline sec-Butanol & 74,12 & 18,322 & 89,7 \\
\hline Metilisobutilcetona & 100,16 & 19,849 & 165 \\
\hline n-Propanol & 60,09 & 20,694 & 89 \\
\hline Acetato de sec-Butila & 116,16 & 22,274 & 195 \\
\hline Água & 18,02 & 23,782 & 33 \\
\hline Tolueno & 92,13 & 28,456 & 200 \\
\hline Acetato de n-Propila & 102,14 & 33,289 & 209 \\
\hline Isopropanol & 60,09 & 45,552 & 150 \\
\hline Heptano & 100,21 & 45,564 & 275 \\
\hline Etanol & 46,07 & 59,222 & 165 \\
\hline Acetato de Isopropila & 102,13 & 60,343 & 340 \\
\hline Acetato de Etila & 88,10 & 93,384 & 400 \\
\hline Metiletilcetona & 72,10 & 95,500 & 390 \\
\hline Ciclohexano & 84,16 & 98,458 & 460 \\
\hline Metanol & 32,04 & 126,067 & 210 \\
\hline Hexano & 86,18 & 152,616 & 765 \\
\hline Acetato de Metila & 74,08 & 214,337 & 520 \\
\hline Acetona & 58,08 & 229,602 & 560 \\
\hline
\end{tabular}

Com base nas equações apresentadas na tabela 4.1, as taxas de evaporação foram calculadas e comparadas graficamente com os valores experimentais (figura 4.1). 


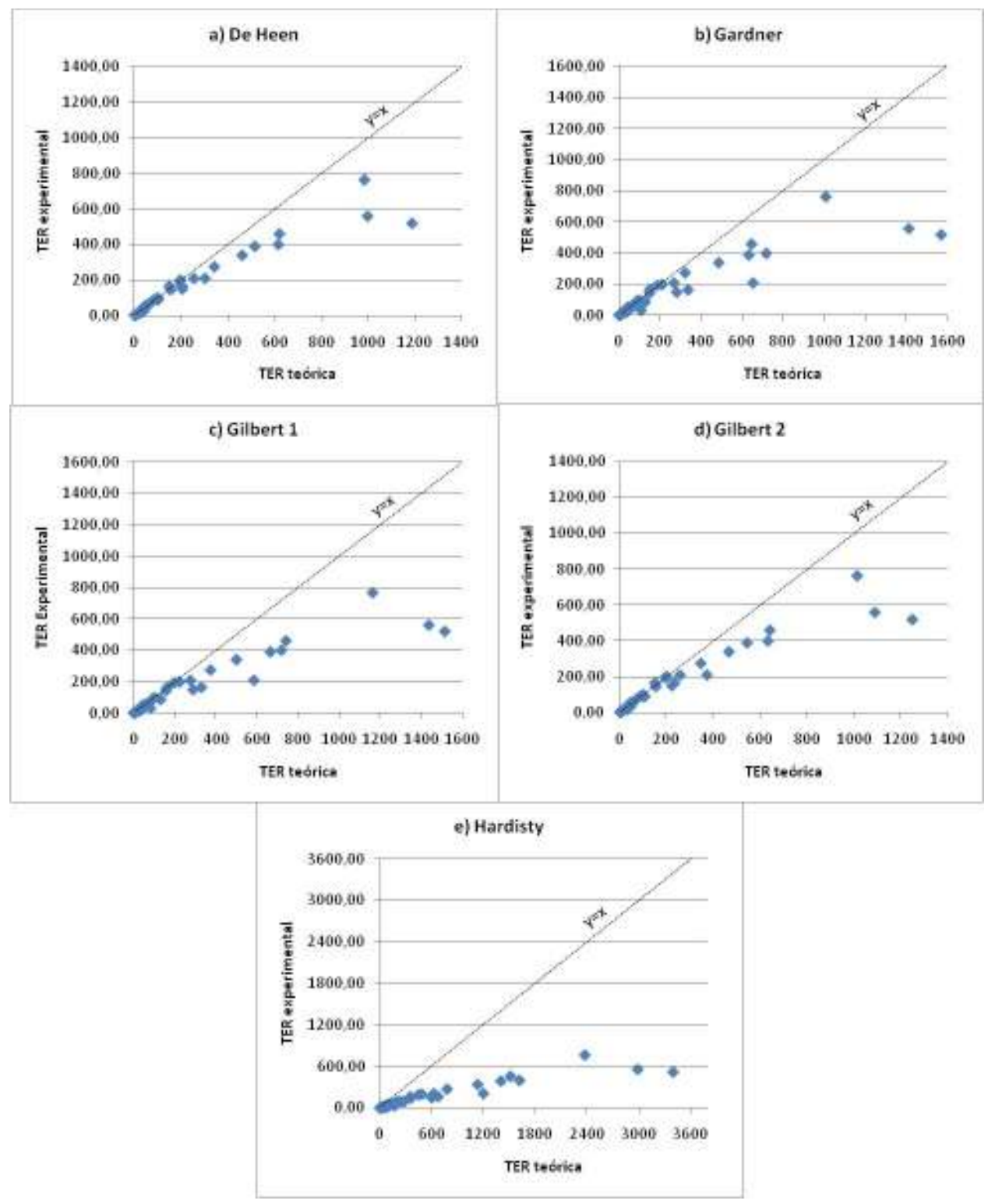

Figura 4.1 - Gráficos comparativos entre as taxas de evaporação relativas (TER) experimentais e teóricas para todos os solventes da tabela 4.2, calculadas pelas equações: a) Modelo de De Heen; b) Modelos de Gardner; c) Modelo de Gilbert; d) Modelo de Gilbert modificado; e) Modelo de Hardisty.

O melhor resultado possível que se poderia esperar seria o caso onde os valores experimentais fossem iguais aos valores teóricos $(y=x)$. Assim, observando a figura 4.1, conclui-se que nenhum modelo apresenta resultado satisfatório. Ainda é possível observar que, quanto maior a TER, maior o desvio da TER teórica em relação a TER experimental. Quanto maior a TER, mais rápida é a evaporação do solvente. Conforme discutido anteriormente, Sletmoe (1970) apresentou uma equação para calcular a taxa de evaporação de componentes puros, mas alertou 
para o fato de que seu modelo não se aplicava aos solventes que ele considerou de rápida evaporação.

Como a TER está diretamente relacionada em todos os modelos com a pressão de vapor, é possível que haja uma faixa onde estes modelos se ajustem melhor aos valores experimentais.

O RMSE foi calculado pela equação 3.4 para todo o conjunto de solventes apresentado na tabela 4.2 para os diferentes modelos de TER. Também se buscou um valor mínimo de RMSE com base na faixa de pressão de vapor dos solventes calculados pelos modelos. Um valor mínimo para o RMSE foi obtido para o modelo de De Heen quando se levou em consideração apenas os 30 primeiros solventes da tabela 4.2 listados por ordem crescente de pressão de vapor, ou seja, com pressão de vapor variando de $0,136 \mathrm{mmHg}$ a $28,456 \mathrm{mmHg}$. A tabela 4.3 apresenta estes resultados.

Tabela 4.3 - Resultados de RMSE calculados para os diferentes modelos
\begin{tabular}{ccc} 
TER com base nos solventes da tabela 4.2. \\
\hline Modelo & $\begin{array}{c}\text { RMSE - Todos } \\
\text { os solventes }\end{array}$ & $\begin{array}{c}\text { RMSE - 30 } \\
\text { primeiros solventes }\end{array}$ \\
\hline De Heen & 138,18 & 6,40 \\
Gardner & 237,03 & 17,72 \\
Gilbert 1 & 239,78 & 15,89 \\
Gilbert 2 & 157,74 & 7,12 \\
Hardisty & 743,66 & 113,96 \\
\hline
\end{tabular}

A figura 4.2 apresenta os resultados comparativos para os primeiros 30 solventes da tabela 4.2 para todos os modelos. 


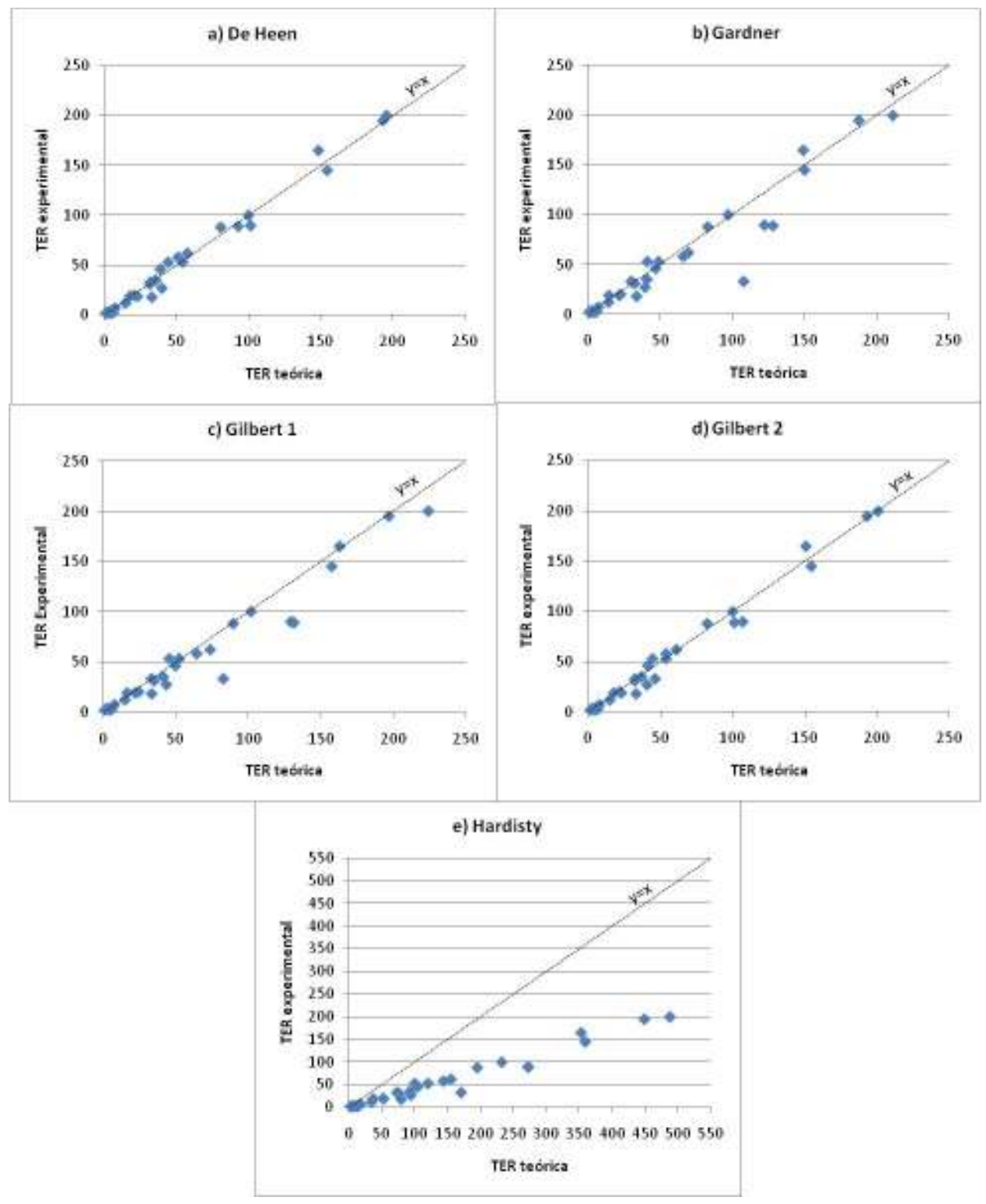

Figura 4.2 - Gráficos comparativos entre as taxas de evaporação relativas (TER) experimentais e teóricas para os solventes da tabela 4.2 com pressão de vapor entre $0,136 \mathrm{mmHg}$ e $28,456 \mathrm{mmHg}$, calculadas pelas equações: a) Modelo de De Heen; b) Modelos de Gardner; c) Modelo de Gilbert; d) Modelo de Gilbert modificado; e) Modelo de Hardisty.

Observando a figura 4.2 e os resultados apresentados na tabela 4.3, mais uma vez se comprova que o modelo de De Heen apresenta os melhores resultados para cálculo da TER com base no conjunto de solventes estudados. Porém, é importante ressaltar que mesmo para tal conjunto de dados, o modelo de De Heen apresenta desvios altos para alguns solventes, de até $144 \%$, como se pode observar na tabela 4.4 . 


\begin{tabular}{|c|c|c|c|c|}
\hline Solventes & $\begin{array}{c}\mathrm{Pv} \\
(\mathrm{mmHg})\end{array}$ & $\begin{array}{c}\text { TER } \\
\text { Experimental } \\
\end{array}$ & $\begin{array}{c}\text { TER } \\
\text { De Heen }\end{array}$ & $\begin{array}{c}\text { Desvio } \\
(\%)\end{array}$ \\
\hline 2-Etil hexanol & 0,136 & 2,0 & 1,3 & $-33,9$ \\
\hline Metildiglicol & 0,180 & 2,0 & 1,6 & $-19,3$ \\
\hline Acetato de 2-Etilhexila & 0,229 & 3,4 & 2,9 & $-13,4$ \\
\hline Isoforona & 0,437 & 2,0 & 4,5 & 125,6 \\
\hline Diacetato de Etilenoglicol & 0,581 & 2,6 & 6,3 & 144,1 \\
\hline Ciclohexanol & 0,755 & 5,0 & 5,6 & 13,0 \\
\hline Butilglicol & 0,872 & 7,0 & 7,7 & 9,9 \\
\hline Diisobutilcetona & 1,687 & 19,0 & 17,9 & $-5,7$ \\
\hline Diacetona Álcool & 1,709 & 12,0 & 14,8 & 23,6 \\
\hline Acetato de Etilglicol & 2,342 & 19,0 & 23,1 & 21,7 \\
\hline Isopentanol & 3,183 & 20,0 & 21,0 & 4,8 \\
\hline Lactato de Etila & 3,751 & 18,0 & 33,1 & 83,8 \\
\hline Metilamillcetona & 3,795 & 33,0 & 32,4 & $-1,9$ \\
\hline Ciclohexanona & 4,325 & 31,0 & 31,7 & 2,3 \\
\hline Metilisoamilcetona & 5,203 & 53,0 & 44,4 & $-16,3$ \\
\hline Metilisobutilcarbinol & 5,245 & 27,0 & 40,0 & 48,2 \\
\hline Etilglicol & 5,308 & 35,0 & 35,7 & 2,1 \\
\hline Acetato de Isopentila & 5,594 & 53,0 & 54,4 & 2,6 \\
\hline n-Butanol & 7,051 & 46,0 & 39,0 & $-15,1$ \\
\hline Metilglicol & 9,002 & 58,0 & 51,2 & $-11,8$ \\
\hline Isobutanol & 10,442 & 62,0 & 57,8 & $-6,8$ \\
\hline Óxido de mesitila & 11,030 & 88,0 & 80,8 & $-8,1$ \\
\hline Acetato de n-Butila & 11,528 & 100,0 & 100,0 & 0,0 \\
\hline Acetato de Isobutila & 17,818 & 145,0 & 154,6 & 6,6 \\
\hline sec-Butanol & 18,322 & 89,7 & 101,4 & 13,1 \\
\hline Metilisobutilcetona & 19,849 & 165,0 & 148,5 & $-10,0$ \\
\hline n-Propanol & 20,694 & 89,0 & 92,9 & 4,3 \\
\hline Acetato de sec-Butila & 22,274 & 195,0 & 193,2 & $-0,9$ \\
\hline Água & 23,782 & 33,0 & 32,0 & $-3,0$ \\
\hline Tolueno & 28,456 & 200,0 & 195,8 & $-2,1$ \\
\hline
\end{tabular}

Ou seja, o melhor dos modelos disponíveis em literatura ainda estão muito aquém de representar satisfatoriamente os resultados esperados para a TER experimental, obtida pelo método do evaporômetro, para todo e qualquer solvente. De acordo com a ASTM D3539 que normatiza o método do evaporômetro, o tempo necessário para se evaporar o padrão acetato de n-butila deve ser de $470 \pm 10$ seg., o que representa um desvio de cerca de $\pm 2 \%$. Os desvios observados estão muito acima deste padrão. 
Para calcular a TER de componentes puros, há ainda o modelo de evaporação apresentado por Cary e Gutoff (1991) e Gutoff (1994). Este modelo apresentado pela equação 2.61 difere dos demais apresentados acima, pois foi estabelecido e desenvolvido para uma condição diferente do método do evaporômetro. O modelo de Cary e Gutoff foi obtido para o caso da evaporação de solventes presentes em materiais como tecido, papel, e outros, que por meio de rolos atravessassem zonas de secagem por ar quente.

Esta equação é interessante se avaliar, pois foi obtida da modelagem do fenômeno de evaporação, levando em consideração o balanço de energia, diferente dos modelos discutidos acima que foram obtidos empiricamente. Este mesmo balanço pode ser facilmente aplicado ao caso do evaporômetro, estabelecendo apenas que a temperatura da corrente de ar é igual em ambos os lados do papel onde ocorre a secagem. Assim, a eq. 2.61 é simplificada para a equação 4.1.

$E=\frac{h \cdot\left(T_{a r}-T_{w}\right)}{\lambda}$

em que:

$E$ - taxa de evaporação $\left(\mathrm{kg} / \mathrm{s} . \mathrm{m}^{2}\right)$

$h$ - coeficiente de transferência de transferência de calor $\left(\mathrm{W} / \mathrm{m}^{2} . \mathrm{K}\right)$

$T_{a r}$ - temperatura do ar $\left(\mathrm{K}\right.$ ou $\left.{ }^{\circ} \mathrm{C}\right)$

$T_{\min }$ - temperatura de evaporação do solvente $\left(\mathrm{K}\right.$ ou $\left.{ }^{\circ} \mathrm{C}\right)$

$\lambda$ - calor latente de vaporização $(\mathrm{J} / \mathrm{kg})$

Seria esperado que, mantidas as mesmas condições do sistema, mudando-se apenas o solvente em evaporação, o valor do coeficiente de transferência de calor se manteria constante. Isto pode ser facilmente observado se fossem conhecidas as demais propriedades da equação 4.1 para diversos solventes. A tabela 4.5 apresenta dados para alguns solventes que foram evaporados sob as condições do método do evaporômetro, e o valor do coeficiente de transferência de calor calculado pela equação 4.1 para cada um deles. 
Tabela 4.5 - Cálculo do coeficiente de transferência de calor para o método do evaporômetro com base na equação 4.1 , admitindo a temperatura do $\operatorname{ar}\left(\mathrm{T}_{\text {ar }}\right)$ igual a $25^{\circ} \mathrm{C}$, calor latente de vaporização calculado para a temperatura de evaporação do solvente $\left(T_{\min }\right)$, e área de evaporação de $0,0128 \mathrm{~m}^{2}$

\begin{tabular}{lcccc}
\hline \multicolumn{1}{c}{ Solventes } & $\begin{array}{c}\boldsymbol{E} \\
\left(\mathbf{k g} / \mathbf{s} \cdot \mathbf{m}^{\mathbf{2}}\right)^{*}\end{array}$ & $\begin{array}{c}\boldsymbol{T}_{\min } \\
\left({ }^{\circ} \mathbf{C}\right)^{* *}\end{array}$ & $\begin{array}{c}\lambda \\
(\mathbf{k J} / \mathbf{m o l})^{\star * *}\end{array}$ & $\begin{array}{c}\boldsymbol{h} \\
\left(\mathbf{W} / \mathbf{m}^{\mathbf{2}} \mathbf{K}\right)\end{array}$ \\
\hline Acetona & 0,4609 & 0,0 & 33,98 & 10,79 \\
Metiletilcetona & 0,3263 & 10,0 & 36,10 & 10,89 \\
Metilisobutilcetona & 0,1375 & 20,0 & 42,76 & 11,74 \\
n-Butanol & 0,0388 & 20,8 & 49,83 & 6,21 \\
Etanol & 0,1360 & 12,2 & 40,47 & 9,33 \\
Isopropanol & 0,1230 & 14,7 & 44,92 & 8,93 \\
sec-Butanol & 0,0756 & 18,6 & 50,34 & 8,02 \\
Acetato de n-Butila & 0,0917 & 22,0 & 43,66 & 11,49 \\
Etilglicol & 0,0339 & 21,3 & 47,90 & 4,87 \\
Tolueno & 0,1812 & 18,4 & 38,66 & 11,52 \\
Xileno & 0,0694 & 22,5 & 44,67 & 11,68 \\
\hline
\end{tabular}

* Taxa de evaporação calculada com base na TER experimental cedida pela Oxiteno S/A.

** Valores determinados experimentalmente por Rocklin e Bonner (1980).

${ }^{* * *}$ Valores calculados com base em Yaws (1999).

Os resultados obtidos para $h$ mostram que não há um valor constante para o coeficiente de transferência de calor que pudesse ser utilizado como padrão para cálculo da taxa de evaporação no método do evaporômetro para qualquer solvente. Como se pode observar para o caso do etilglicol que apresentou o menor valor de $h$. Para este solvente, caso fosse calculada a taxa de evaporação do mesmo pela equação 4.1 com um valor médio de $h$, de 9,59, se observaria uma taxa de evaporação de quase o dobro do valor do que realmente se observa experimentalmente.

\subsection{Modelos de Evaporação para Misturas de Solventes}

Os modelos de misturas apresentados anteriormente foram todos adaptados para a forma diferencial, conforme apresentado na tabela 4.6. 
Tabela 4.6 - Modelos de evaporação de misturas de solventes escritos na forma diferencial.

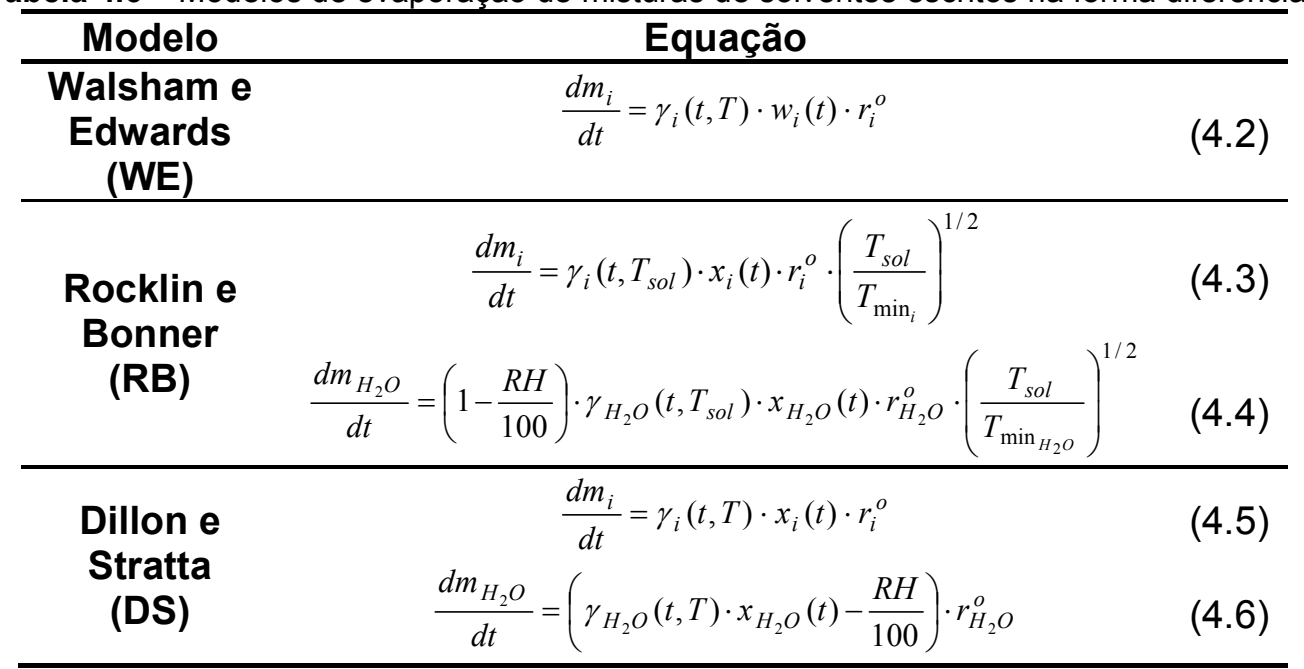

Com estes modelos facilmente se pode calcular a perda de massa total da mistura, bem como sua a composição ao longo do tempo. Conhecer a variação da composição da mistura é uma das principais vantagens deste trabalho, pois pode ajudar a prever melhor o comportamento de secagem e formação de filme de uma tinta. Venceslau, Pessoa Filho e Le Roux (2010) apresentaram alguns resultados obtidos para misturas que tiveram suas taxas de evaporação calculadas pelo modelo de evaporação de misturas WE, e coeficiente de atividade calculado pelo modelo de solução regular. Como exemplo dos resultados que se podem obter com estes modelos de evaporação de misturas, a figura 4.3 apresenta graficamente os resultados teóricos e experimentais de evaporação obtidos para uma determinada mistura. 

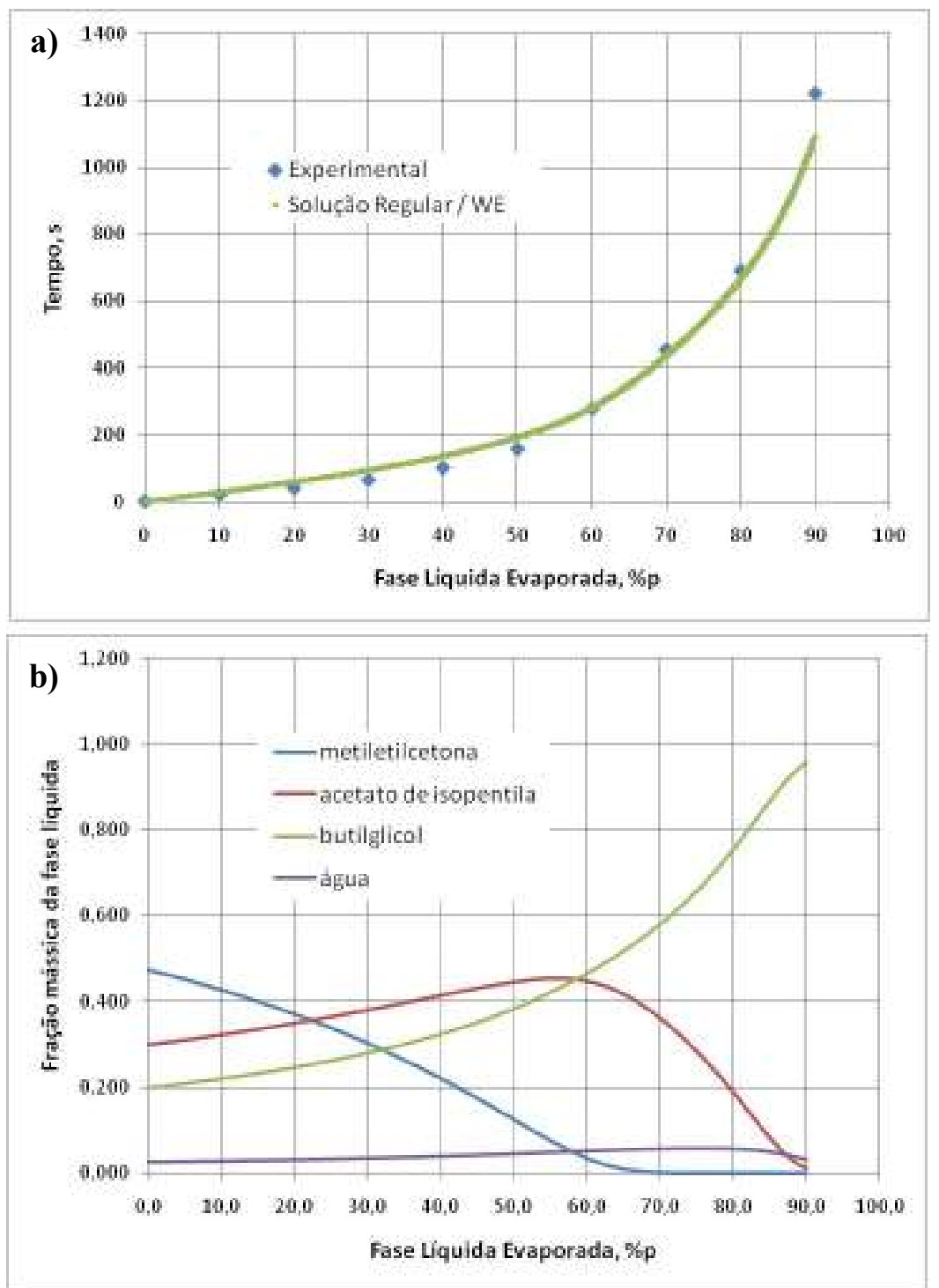

Figura 4.3 - a) Curva de evaporação da mistura 6; b) Curva de composição predita para a evaporação da mistura. Adaptado de Venceslau, Pessoa Filho e Le Roux (2010)

Em geral, todos os modelos são bastante similares, com apenas algumas variações entre eles:

1. Fator de correção de temperatura de evaporação;

2. Fator de correção de umidade relativa para a componente água.

Além dessas duas diferenças, o coeficiente de atividade pode ser calculado por diferentes modelos, e cada modelo pode apresentar variações nos valores de seus parâmetros impactando no resultado final da evaporação da mistura. Também é 
importante observar que o Modelo de Walsham e Edwards foi escrito em função da fração mássica, enquanto que os demais foram escritos em função da fração molar.

Para este trabalho foram escolhidos os modelos de solução regular, Wilson e UNIQUAC para calcular o coeficiente de atividade das misturas. O primeiro modelo foi selecionado pela sua simplicidade, e por necessitar apenas da componente difusiva $\left(\delta_{d}\right)$ dos parâmetros de solubilidade de Hansen. Os outros dois modelos foram escolhidos por não apresentarem grande complexidade algébrica para cálculo do coeficiente de atividade, são amplamente utilizados, necessitam apenas de dois parâmetros para representar dados de equilíbrio binário, e estes parâmetros podem ser encontrados facilmente no Software de Simulação ASPEN PLUS 7.1, e VaporLiquid Equilibrium Data Collection (1979) para uma grande quantidade de binários. Além disso, segundo Wallas (1984), as equações de Wilson geralmente apresentam resultados superiores para o cálculo do coeficiente de atividade de misturas polares e não polares, enquanto que as equações do UNIQUAC são possivelmente representações superiores de misturas de moléculas de diferentes tamanhos moleculares, e ambos são capazes de representar misturas multicomponentes em termos de apenas parâmetros binários.

Wallas (1984) ainda avaliou a freqüência com que se obtinham os melhores ajustes para cinco modelos de cálculo do coeficiente de atividade, com base nos dados publicados no Vapor-Liquid Equilibrium Data Collection e conclui que a equação de Wilson fornece, na maioria das vezes, os resultados mais satisfatórios.

Os modelos de Wilson e UNIQUAC apresentam outra vantagem sobre os demais, eles são as bases para a predição do coeficiente de atividade por contribuição de grupo, respectivamente pelos métodos ASOG e UNIFAC. De acordo com Wallas (1984), o modelo NRTL embora apresente melhor resultados para o primeiro caso, misturas de solventes orgânicos em meio aquoso, ele necessita de três parâmetros, uma desvantagem em relação a Wilson e UNIQUAC. Além disso, os parâmetros do UNIQUAC apresentam pouca dependência da temperatura, e devido a sua variável de concentração primária ser a fração superficial, UNIQUAC pode ser aplicada para soluções contendo moléculas grandes e pequenas, incluindo polímeros (REID; PRAUSNITZ; POLING, 1987). 


\subsubsection{Influência do Fator de Correção de Temperatura}

A temperatura mínima em que se evapora um solvente $\left(t_{\min }\right)$ é determinada experimentalmente, e não é uma determinação simples como a determinação da taxa de evaporação no evaporômetro. Para isso, é necessário adaptar um sistema de medição de temperatura confiável no papel de filtro dentro do evaporômetro. Embora isto não tenha sido possível determinar neste presente trabalho, Rocklin e Bonner (1980) realizaram esta determinação de $t_{\min }$ para alguns solventes (tabela 2.2 e tabela 4.5$)$.

Com base nestes dados, foram selecionadas duas misturas para se avaliar a influência do fator de correção de temperatura através da comparação dos resultados dos modelos WE e RB. Os modelos foram calculados utilizando os diferentes modelos de coeficiente de atividade citados acima, e para o caso de mistura ideal, quando $\gamma_{i}=1$. Os resultados da curva de evaporação obtidos dos modelos são apresentados como sendo o tempo necessário para evaporar $10 \%$, $20 \%$ e assim por diante, até $90 \%$ da mistura inicial de solventes, sendo o tempo para evaporar $90 \%$ da mistura o mais importante, pois é por meio deste que se calcula a TER da mistura. Os experimentos foram realizados de acordo com a norma ASTM D3539, respeitando as condições de temperatura $\left(25^{\circ} \mathrm{C}\right)$, pressão $(760 \mathrm{mmHg})$, e umidade relativa (menor que $5 \%$ ). Os parâmetros binários para cálculo dos coeficientes de atividade UNIQUAC e Wilson foram obtidos do banco de dados do ASPEN PLUS 7.1. A tabela 4.7 apresenta os resultados obtidos a partir dos dados experimentais. 
Tabela 4.7 - Resultados obtidos a partir dos dados experimentais das curvas de evaporação para as misturas de solventes 4.1 e 4.2 de acordo com a norma ASTM D3539.

\begin{tabular}{|c|c|c|c|c|c|c|c|}
\hline Mistura & Componentes & Composição & $\begin{array}{l}\text { Número de } \\
\text { Repetições }\end{array}$ & $\begin{array}{c}t_{90 \%} \text { médio } \\
\text { experimental } \\
(s)\end{array}$ & $\begin{array}{c}\text { Desvio } \\
\text { Padrão } \\
\text { para } \\
t_{90 \%} \\
\end{array}$ & $\begin{array}{c}\text { Intervalo } \\
\text { de } \\
\text { Confiança } \\
\text { para } t_{90 \%} \\
\text { (s) } \\
\end{array}$ & $\begin{array}{c}\text { TER } \\
\text { Experimental } \\
\text { da mistura }\end{array}$ \\
\hline \multirow[b]{2}{*}{4.1} & Xileno & 60,0 & \multirow[b]{2}{*}{5} & \multirow[b]{2}{*}{560,4} & \multirow[b]{2}{*}{6,8} & \multirow{2}{*}{$\begin{array}{c}551,9- \\
568,9\end{array}$} & \multirow[b]{2}{*}{84,2} \\
\hline & $\begin{array}{l}\text { Acetato de } \\
\text { n-butila }\end{array}$ & 40,0 & & & & & \\
\hline \multirow{5}{*}{4.2} & $\begin{array}{l}\text { Acetato de } \\
\text { n-butila }\end{array}$ & 10,4 & \multirow{5}{*}{4} & \multirow{5}{*}{220,5} & \multirow{5}{*}{6,6} & \multirow{5}{*}{$\begin{array}{c}210,0- \\
231,0\end{array}$} & \multirow{5}{*}{$\begin{array}{l}211,3 \\
233,8^{*}\end{array}$} \\
\hline & Acetona & 7,4 & & & & & \\
\hline & $\begin{array}{l}\text { Metilisobutil- } \\
\text { cetona }\end{array}$ & 1,9 & & & & & \\
\hline & Isopropanol & 13,9 & & & & & \\
\hline & Tolueno & 66,5 & & & & & \\
\hline
\end{tabular}

Foram feitas algumas repetições das curvas de evaporação para cada mistura, a fim de que fosse possível calcular média, desvio padrão e intervalo de confiança para o tempo em que se tem $90 \%$ da mistura evaporada, e também a TER experimental da mistura. A mistura 4.2 também foi avaliada por Rocklin e Bonner (1980), que apresentaram um resultado de TER da mistura com cerca de $10 \%$ de diferença em relação ao valor observado nas medidas determinadas para este trabalho. Esta diferença foi suficiente para classificar o resultado apresentado por Rocklin e Bonner (1980) como fora do intervalo de confiança dessas medidas, com $95 \%$ de certeza. Esta observação é importante, pois pode ser um indício de que este método do evaporômetro apresenta uma alta variabilidade.

A tabela 4.8 apresenta os resultados obtidos utilizando as quatro opções de modelos para o cálculo do coeficiente de atividade e para os diferentes modelos para a curva de evaporação das misturas. Os parâmetros binários utilizados foram obtidos do banco de dados do software ASPEN Plus 7.1, o qual referencia seus dados ao DECHEMA. Apesar de não apresentar as condições de temperatura e pressão em que estes parâmetros foram obtidos, é dito que em sua maioria estes dados passaram nos testes de consistência termodinâmica. Para os binários em que não havia dados no banco de dados do ASPEN referenciados como de literatura (DECHEMA), foi solicitado que o software calculasse estes parâmetros a partir do modelo UNIFAC, que se baseia no cálculo de equilíbrio líquido-vapor por contribuição de grupos, para as condições de temperatura de $25^{\circ} \mathrm{C}$ e pressão de 760 
mmHg. Estes foram: mistura 4.1 - xileno e acetato de n-butila; mistura 4.2 - acetato de n-butila e tolueno; acetato de n-butila e metilisobutilcetona; metilisobutilcetona e isopropanol; metilisobutilcetona e acetona.

\begin{tabular}{|c|c|c|c|c|c|c|}
\hline Mistura & $\begin{array}{c}\text { Modelo de } \\
\text { coeficiente } \\
\text { de } \\
\text { atividade }\end{array}$ & $\begin{array}{l}\text { Modelo de } \\
\text { evaporação }\end{array}$ & $\begin{array}{c}\text { TER } \\
\text { Calculado } \\
\text { da Mistura }\end{array}$ & RMSE & $\begin{array}{l}\text { Desvio } \\
\text { t }_{90 \%}(\%)\end{array}$ & $\begin{array}{c}\text { intervalo de } \\
\text { confiança }\end{array}$ \\
\hline \multirow{12}{*}{4.1} & \multirow{3}{*}{ Ideal } & WE & 85,1 & 9,1 & $-1,4$ & dentro \\
\hline & & RB & 85,0 & 9,9 & $-1,3$ & dentro \\
\hline & & DS & 85,0 & 9,9 & $-1,3$ & dentro \\
\hline & \multirow{3}{*}{$\begin{array}{l}\text { Solução } \\
\text { Regular }\end{array}$} & WE & 88,5 & 11,5 & $-5,2$ & fora \\
\hline & & $\mathrm{RB}$ & 88,4 & 11,1 & $-5,1$ & fora \\
\hline & & DS & 88,3 & 11,0 & $-5,1$ & fora \\
\hline & \multirow{4}{*}{ UNIQUAC } & WE & 84,1 & 11,8 & $-0,2$ & dentro \\
\hline & & RB & 83,7 & 13,6 & 0,2 & dentro \\
\hline & & DS & 84,0 & 12,7 & $-0,1$ & dentro \\
\hline & & WE & 83,2 & 13,9 & 0,8 & dentro \\
\hline & \multirow[t]{2}{*}{ Wilson } & RB & 83,1 & 15,3 & 1,0 & dentro \\
\hline & & DS & 83,3 & 14,6 & 0,7 & dentro \\
\hline \multirow{13}{*}{4.2} & \multirow{3}{*}{ Ideal } & WE & 186,0 & 25,6 & 14,6 & fora \\
\hline & & RB & 186,7 & 24,6 & 14,1 & fora \\
\hline & & DS & 186,6 & 24,7 & 14,2 & fora \\
\hline & \multirow{3}{*}{$\begin{array}{l}\text { Solução } \\
\text { Regular }\end{array}$} & WE & 195,2 & 18,7 & 9,2 & fora \\
\hline & & RB & 195,9 & 17,7 & 8,8 & fora \\
\hline & & DS & 195,5 & 18,0 & 9,0 & fora \\
\hline & \multirow{3}{*}{ UNIQUAC } & WE & 211,1 & 5,5 & 1,0 & dentro \\
\hline & & $\mathrm{RB}$ & 211,9 & 2,0 & 0,6 & dentro \\
\hline & & DS & 212,1 & 2,4 & 0,5 & dentro \\
\hline & & WE & 208,8 & 10,8 & 2,1 & dentro \\
\hline & \multirow[t]{2}{*}{ Wilson } & RB & 200,9 & 123,0 & 6,1 & fora \\
\hline & & DS & 200,7 & 13,3 & 6,2 & fora \\
\hline & UNIFAC* & RB & 229,3 & 9,7 & $-7,0$ & fora \\
\hline
\end{tabular}

${ }^{*}$ Calculado por Rocklin e Bonner (1980).

A curva de evaporação é determinada principalmente para se obter o tempo necessário para evaporar $90 \%$ da mistura, que é usado para calcular a taxa de evaporação relativa, que é um dado bastante importante para comparação entre solventes puros e misturas. Com base nisso, os desvios apresentados na tabela 4.8 são os valores mais importantes para se avaliar preliminarmente qual o melhor modelo de evaporação. Dessa forma, o modelo de Dillon e Stratta (DS), calculado 
com base no modelo UNIQUAC, apresentou o menor desvio em relação ao t90\% $_{9}$ experimental para as misturas 4.1 e 4.2 .

O RMSE é uma medida também importante para se avaliar qual dos modelos apresenta os resultados de tempo mais ajustados aos dados experimentais. Neste caso, é interessante notar que para a mistura 4.1, o modelo de evaporação e o modelo de coeficiente de atividade que apresentaram o menor RMSE não são os mesmos que apresentaram menor desvio. Neste caso, as diferenças são pequenas e difíceis de serem observadas em gráficos, como o representado pela figura 4.4.

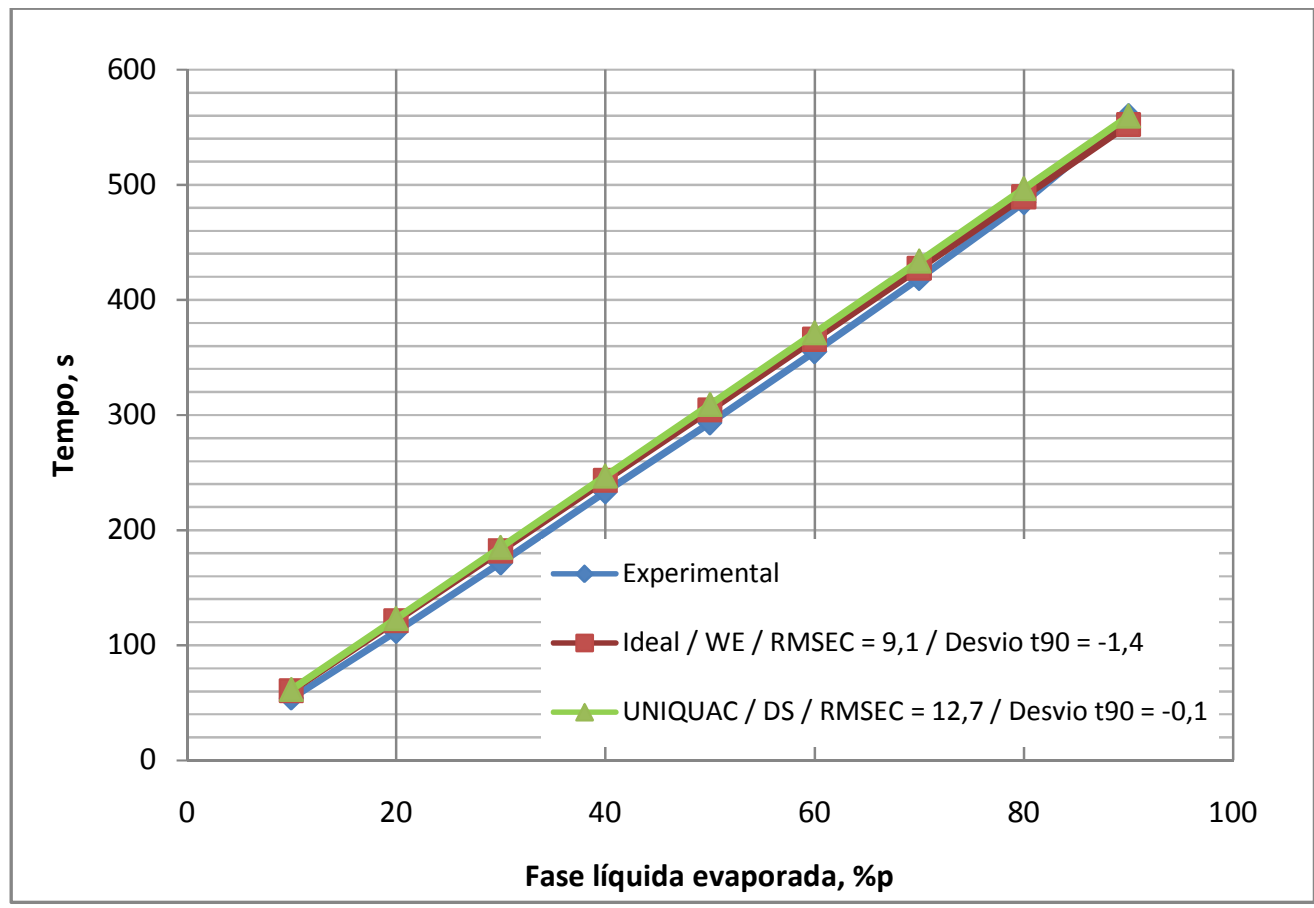

Figura 4.4 - Curvas de evaporação experimental e calculadas pelos modelos Ideal/WE e UNIQUAC/DS para a mistura 4.1.

Em ambos os casos, Ideal / WE e UNIQUAC / DS, o tempo calculado pata t $_{90 \%}$ respeitou os limites calculados para o intervalo de confiança da mistura 4.1. Tanto para esta mistura, como para a mistura 4.2, outros modelos também apresentaram resultados dentro do intervalo de confiança calculado com base nos dados experimentais.

Os resultados apresentados na tabela 4.8 também mostram que as maiores diferenças de RMSE e desvio estão entre os resultados calculados pelos diferentes 
modelos de cálculo de coeficiente de atividade, ou seja, nestes casos os modelos de evaporação são menos influentes nos resultados dos tempos de evaporação do que os modelos para cálculo do coeficiente de atividade. Somando-se o fato de que o modelo de Dillon e Stratta foi o que apresentou o menor desvio para ambas as misturas e a grande dificuldade experimental de se obter a temperatura mínima de evaporação de cada solvente individualmente, o fator de correção de temperaturas de evaporação do modelo de Rocklin e Bonner (RB) não é tão relevante para se garantir melhores resultados nas curvas de evaporação. Vale ressaltar que não há dados ou fontes que apresentem e justifiquem a origem de tal fator de correção nos modelos de mistura.

Para o solvente em que se observa a menor temperatura de evaporação disponível na tabela 4.5, a acetona com temperatura mínima de evaporação de $0^{\circ} \mathrm{C}$, o fator de correção apresentaria um valor máximo de 1,0448, o que representaria para um dado instante e componente uma correção de apenas 4\%. Esta é uma correção que representa pouco impacto ao longo de toda a curva de evaporação, como se pôde observar nos resultados apresentados na tabela 4.8.

\subsubsection{Influência do Fator de Correção de Umidade}

Com base nos resultados observados acima, o modelo de Rocklin e Bonner (RB) pode ser reescrito desconsiderando o fator de correção de temperatura de evaporação. O modelo, portanto, assume a forma da equação 4.7 e 4.8, e será chamado de modelo de Rocklin e Bonner Modificado (RBM).

$$
\begin{aligned}
& \frac{d m_{i}}{d t}=\gamma_{i}(t, T) \cdot x_{i}(t) \cdot r_{i}^{o} \\
& \frac{d m_{\mathrm{H}_{2} \mathrm{O}}}{d t}=\left(1-\frac{R H}{100}\right) \cdot \gamma_{\mathrm{H}_{2} \mathrm{O}}(t, T) \cdot x_{\mathrm{H}_{2} \mathrm{O}}(t) \cdot r_{\mathrm{H}_{2} \mathrm{O}}^{o}
\end{aligned}
$$


A equação 4.7 é exatamente igual a equação 4.5 do modelo de Dillon e Stratta. A diferença entre os modelos DS e RBM passa a ser apenas o fator de correção de umidade das equações associadas à componente água, nas equações 4.6 e 4.8.

Para avaliar o impacto do fator de correção de umidade nos resultados das curvas de evaporação calculadas, foram propostas aleatoriamente misturas que tivessem a água como um dos componentes, conforme apresentadas na tabela 4.9.

Tabela 4.9 - Resultados obtidos a partir dos dados experimentais das curvas de evaporação para as misturas de solventes 4.3 e 4.5 de acordo com a norma ASTM D3539.

\begin{tabular}{|c|c|c|c|c|c|c|c|}
\hline Mistura & Componentes & $\begin{array}{c}\text { Composição } \\
(\% p)\end{array}$ & $\begin{array}{l}\text { Número } \\
\text { de } \\
\text { repetições }\end{array}$ & $\begin{array}{c}\mathbf{t}_{90 \%} \text { médio } \\
\text { experimental } \\
(\mathbf{s})\end{array}$ & $\begin{array}{c}\text { Desvio } \\
\text { Padrão } \\
\text { para } \\
t_{90 \%}\end{array}$ & $\begin{array}{c}\text { Intervalo } \\
\text { de } \\
\text { Confiança } \\
\text { para } t_{90 \%}\end{array}$ & $\begin{array}{c}\text { TER } \\
\text { Experimental } \\
\text { da mistura }\end{array}$ \\
\hline \multirow{4}{*}{4.3} & Metiletilcetona & 47,5 & \multirow{4}{*}{5} & \multirow{4}{*}{1182,4} & \multirow{4}{*}{59,7} & \multirow{4}{*}{$\begin{array}{c}1108,3- \\
1256,5\end{array}$} & \multirow{4}{*}{39,8} \\
\hline & $\begin{array}{l}\text { Acetato de } \\
\text { isopentila }\end{array}$ & 30 & & & & & \\
\hline & Butilglicol & 20 & & & & & \\
\hline & Água & 2,5 & & & & & \\
\hline \multirow{4}{*}{4.4} & Metiletilcetona & 45 & \multirow{4}{*}{5} & \multirow{4}{*}{1224,8} & \multirow{4}{*}{53,2} & \multirow{4}{*}{$\begin{array}{c}1158,7- \\
1290,9\end{array}$} & \multirow{4}{*}{37,9} \\
\hline & $\begin{array}{l}\text { Acetato de } \\
\text { isopentila }\end{array}$ & 30 & & & & & \\
\hline & Butilglicol & 20 & & & & & \\
\hline & Água & 5 & & & & & \\
\hline \multirow{3}{*}{4.5} & Etilglicol & 15 & \multirow{3}{*}{4} & \multirow{3}{*}{1888,0} & \multirow{3}{*}{119,5} & \multirow{3}{*}{$\begin{array}{c}1591,2- \\
2184,8\end{array}$} & \multirow{3}{*}{24,9} \\
\hline & Butilglicol & 15 & & & & & \\
\hline & Água & 70 & & & & & \\
\hline
\end{tabular}

Os resultados de desvio padrão observados na tabela 4.9 são maiores que os observados na tabela 4.7. Para todas as misturas estudadas neste trabalho se observam maiores desvios padrões para misturas com TER menores, ou seja, maiores tempos em $90 \%$ de evaporação da mistura. Misturas que possuem água e componentes de baixa TER tendem a apresentar maiores desvios padrões também, como é o caso da mistura 4.3. Também foi observado um aumento no desvio padrão como tendência à medida que se aumenta o percentual evaporado, como se pode observar na tabela 4.10 . 
Tabela 4.10 - Tempo e desvio padrão para diferentes percentuais de evaporação das misturas 4.1 e 4.2 .

\begin{tabular}{ccccccccccc}
\hline \multirow{2}{*}{ Mistura } & $\begin{array}{c}\text { Fase líquida } \\
\text { evaporada (\%) }\end{array}$ & $\mathbf{1 0}$ & $\mathbf{2 0}$ & $\mathbf{3 0}$ & $\mathbf{4 0}$ & $\mathbf{5 0}$ & $\mathbf{6 0}$ & $\mathbf{7 0}$ & $\mathbf{8 0}$ & $\mathbf{9 0}$ \\
\hline \multirow{2}{*}{$\mathbf{4 . 1}$} & Tempo (s) & 54 & 112 & 171,6 & 233,2 & 293,2 & 355,2 & 418,8 & 484,8 & 560,4 \\
& Desvio Padrão & 4,2 & 5,5 & 3,0 & 2,7 & 3,0 & 1,8 & 3,3 & 5,2 & 6,8 \\
\hline \multirow{2}{*}{$\mathbf{4 . 3}$} & Tempo (s) & 24,0 & 45,6 & 75,2 & 114,4 & 178,4 & 303,2 & 472,0 & 690,4 & 1182,4 \\
& Desvio Padrão & 5,7 & 5,4 & 10,7 & 14,3 & 26,2 & 33,0 & 31,5 & 31,2 & 59,7 \\
\hline
\end{tabular}

$\mathrm{Na}$ tabela 4.9, A mistura 4.5 é a que apresenta maior teor de água na sua composição e menor TER. Como era de se esperar, durante a evaporação desta mistura foi observada uma significativa variação da umidade relativa dentro do evaporômetro, devido à evaporação da água. Esta mistura apresentou o maior desvio padrão, e por conseqüência a faixa mais ampla observada para o intervalo de confiança. A tabela 4.11 apresenta os resultados calculados para os diferentes modelos.

Tabela 4.11 - Resultados obtidos a partir dos dados calculados das curvas de evaporação para as misturas de solventes 4.3 a 4.5 de acordo com diferentes modelos de misturas e modelos para cálculo do coeficiente de atividade.

\begin{tabular}{|c|c|c|c|c|c|c|c|}
\hline Mistura & $\begin{array}{c}\text { Modelo de } \\
\text { coeficiente } \\
\text { de } \\
\text { atividade }\end{array}$ & $\begin{array}{c}\text { Modelo de } \\
\text { evaporação }\end{array}$ & $\begin{array}{l}\text { RH } \\
(\%)\end{array}$ & $\begin{array}{c}\text { TER } \\
\text { Calculado } \\
\text { da Mistura }\end{array}$ & RMSE & $\begin{array}{l}\text { Desvio } \\
t_{90 \%}(\%)\end{array}$ & $\begin{array}{c}\text { intervalo } \\
\text { de } \\
\text { confiança }\end{array}$ \\
\hline \multirow{16}{*}{4.3} & \multirow{4}{*}{ Ideal } & WE & - & 42,7 & 33,2 & $-7,0$ & fora \\
\hline & & RBM/DS & 0 & 42,6 & 31,8 & $-6,8$ & fora \\
\hline & & RBM & 5 & 42,6 & 30,9 & $-6,6$ & fora \\
\hline & & DS & 5 & 40,4 & 13,8 & $-1,5$ & dentro \\
\hline & \multirow{4}{*}{$\begin{array}{l}\text { Solução } \\
\text { Regular }\end{array}$} & WE & - & 43,1 & 36,7 & $-7,8$ & fora \\
\hline & & RBM/DS & 0 & 43,0 & 35,7 & $-7,5$ & fora \\
\hline & & RBM & 5 & 42,9 & 34,8 & $-7,4$ & fora \\
\hline & & DS & 5 & 42,9 & 34,9 & $-7,4$ & fora \\
\hline & \multirow{4}{*}{ UNIQUAC } & WE & - & 49,1 & 108,9 & $-19,0$ & fora \\
\hline & & RBM/DS & 0 & 49,1 & 105,0 & $-19,0$ & fora \\
\hline & & RBM & 5 & 49,1 & 104,8 & $-19,0$ & fora \\
\hline & & DS & 5 & 49,1 & 105,0 & $-19,0$ & fora \\
\hline & \multirow{4}{*}{ Wilson } & WE & - & 137,9 & 356,6 & $-71,2$ & fora \\
\hline & & RBM/DS & 0 & 185,3 & 395,1 & $-78,6$ & fora \\
\hline & & RBM & 5 & 176,0 & 389,6 & $-77,4$ & fora \\
\hline & & DS & 5 & 183,1 & 393,9 & $-78,3$ & fora \\
\hline
\end{tabular}


Continuação da tabela 4.11

\begin{tabular}{|c|c|c|c|c|c|c|c|}
\hline Mistura & $\begin{array}{c}\text { Modelo de } \\
\text { coeficiente } \\
\text { de } \\
\text { atividade }\end{array}$ & $\begin{array}{l}\text { Modelo de } \\
\text { evaporação }\end{array}$ & $\begin{array}{l}\text { RH } \\
(\%)\end{array}$ & $\begin{array}{c}\text { TER } \\
\text { Calculado } \\
\text { da Mistura }\end{array}$ & RMSE & $\begin{array}{l}\text { Desvio } \\
t_{90 \%}(\%)\end{array}$ & $\begin{array}{c}\text { intervalo } \\
\text { de } \\
\text { confiança }\end{array}$ \\
\hline \multirow{16}{*}{4.4} & \multirow{4}{*}{ Ideal } & WE & - & 41,3 & 32,2 & $-7,1$ & fora \\
\hline & & RBM/DS & 0 & 41,3 & 31,0 & $-7,1$ & fora \\
\hline & & RBM & 5 & 41,2 & 29,6 & $-6,8$ & fora \\
\hline & & DS & 5 & 39,1 & 16,8 & $-1,9$ & dentro \\
\hline & \multirow{5}{*}{$\begin{array}{l}\text { Solução } \\
\text { Regular }\end{array}$} & WE & - & 41,8 & 36,4 & $-8,1$ & fora \\
\hline & & RBM/DS & 0 & 41,7 & 35,6 & $-8,0$ & fora \\
\hline & & RBM & 5 & 41,6 & 34,0 & $-7,7$ & fora \\
\hline & & DS & 5 & 41,6 & 34,2 & $-7,8$ & fora \\
\hline & & WE & - & 49,3 & 133,5 & $-22,2$ & fora \\
\hline & \multirow{3}{*}{ UNIQUAC } & RBM/DS & 0 & 48,6 & 119,1 & $-21,0$ & fora \\
\hline & & RBM & 5 & 48,5 & 118,7 & $-21,0$ & fora \\
\hline & & DS & 5 & 48,6 & 119,0 & $-21,0$ & fora \\
\hline & \multirow{4}{*}{ Wilson } & WE & - & 106,8 & 325,4 & $-64,1$ & fora \\
\hline & & RBM/DS & 0 & 166,2 & 395,5 & $-76,9$ & fora \\
\hline & & RBM & 5 & 157,8 & 389,1 & $-75,7$ & fora \\
\hline & & DS & 5 & 164,1 & 394,0 & $-76,6$ & fora \\
\hline \multirow{16}{*}{4.5} & \multirow{4}{*}{ Ideal } & WE & - & 25,1 & 87,7 & $-0,8$ & dentro \\
\hline & & RBM/DS & 0 & 26,7 & 60,5 & $-6,8$ & dentro \\
\hline & & RBM & 5 & 26,7 & 59,8 & $-6,8$ & dentro \\
\hline & & DS & 5 & 26,7 & 59,6 & $-6,7$ & dentro \\
\hline & \multirow{5}{*}{$\begin{array}{l}\text { Solução } \\
\text { Regular }\end{array}$} & WE & - & 27,1 & 63,5 & $-8,3$ & dentro \\
\hline & & RBM/DS & 0 & 27,5 & 88,7 & $-9,6$ & dentro \\
\hline & & RBM & 5 & 27,5 & 88,0 & $-9,6$ & dentro \\
\hline & & DS & 5 & 27,5 & 88,0 & $-9,6$ & dentro \\
\hline & & WE & - & 45,9 & 435,9 & $-45,8$ & fora \\
\hline & \multirow{3}{*}{ UNIQUAC } & RBM/DS & 0 & 38,0 & 294,0 & $-34,5$ & fora \\
\hline & & RBM & 5 & 38,0 & 293,5 & $-34,5$ & fora \\
\hline & & DS & 5 & 38,0 & 293,5 & $-34,5$ & fora \\
\hline & \multirow{4}{*}{ Wilson } & WE & - & 27,8 & 76,5 & $-10,4$ & dentro \\
\hline & & RBM/DS & 0 & 37,5 & 241,9 & $-33,5$ & fora \\
\hline & & RBM & 5 & 37,4 & 241,2 & $-33,5$ & fora \\
\hline & & DS & 5 & 37,4 & 241,3 & $-33,5$ & fora \\
\hline
\end{tabular}

As evaporações realizadas para todas as misturas apresentadas acima respeitaram as condições padrões de umidade relativa do ar, ou seja, menor ou igual a $5 \%$. 0 modelo WE não utiliza fator de correção para a umidade relativa, enquanto que os demais modelos utilizam fator de correção de umidade relativa, porém apenas para 
a componente água. Os modelos RBM e DS apresentam os resultados iguais quando não se leva em consideração o fator de correção da umidade relativa, ou umidade relativa igual a zero.

Em geral, as diferenças entre os resultados relativos ao tempo são mais significativos entre os diferentes modelos de cálculo de coeficiente de atividade e pouco significativos para os tempos de evaporação calculados entre os diferentes modelos de mistura. Porém, observam-se algumas exceções, como: Mistura 4.3 e 4.4 - modelo ideal e modelo DS ( $\mathrm{RH}=5 \%)$; e Mistura 4.5 - modelo Ideal e Wilson e modelo WE. Estes resultados mostram que para baixas umidades relativas, como determina a ASTM D 3539, o fator de correção de umidade relativa não traz resultados expressivamente melhores. Também é possível observar que os modelos do coeficiente de atividade para mistura ideal e solução regular apresentaram os melhores resultados, porém nem sempre dentro do intervalo de confiança. O modelo de Wilson apresentou os maiores desvios em relação aos dados experimentais, o que pode ser um indicativo de que o modelo de Wilson não é adequado para sistemas solventes com água como um componente da mistura. Porém, segundo Wallas (1984), seria esperado que os resultados calculados pelo modelo de Wilson fossem melhores que os resultados observados para o modelo UNIQUAC.

Algumas extrapolações podem ser feitas para se avaliar a influência da umidade relativa na evaporação de misturas de solventes contendo água. Durante este trabalho, não foram feitos testes com umidades relativas acima de $5 \%$, devido a limitações experimentais. Rocklin e Bonner (1980) fizeram estes testes para diferentes umidades relativas evaporando a mistura 4.5, e analisaram a composição da mistura por cromatografia gasosa apenas para $20 \%, 45 \%$ e $70 \%$ da fase líquida evaporada. A tabela 4.12 apresenta os resultados experimentais obtidos. 
Tabela 4.12 - Resultados do tempo de evaporação obtidos a partir dos dados experimentais da curva de evaporação para a mistura de solventes 4.5 , sob diferentes condições de umidade relativa no evaporômetro.

\begin{tabular}{cc}
\hline $\mathbf{R H}$ & $\mathbf{t}_{\mathbf{7 0} \%}(\mathbf{s})$ \\
\hline 15 & 1050,0 \\
40 & 1530,0 \\
65 & 2605,0 \\
\hline \multicolumn{2}{l}{ Fonte: Rocklin e Bonner (1980) }
\end{tabular}

Segundo Rocklin e Bonner (1980), umidades relativas altas tendem a diminuir a taxa de evaporação da água na mistura, prolongando o tempo de evaporação, e este efeito é observado nos resultados da tabela 4.12. A figura 4.5 apresenta a composição da mistura ao longo do processo de evaporação para as diferentes umidades relativas, onde se percebe o efeito da umidade relativa principalmente sobre a componente água. 

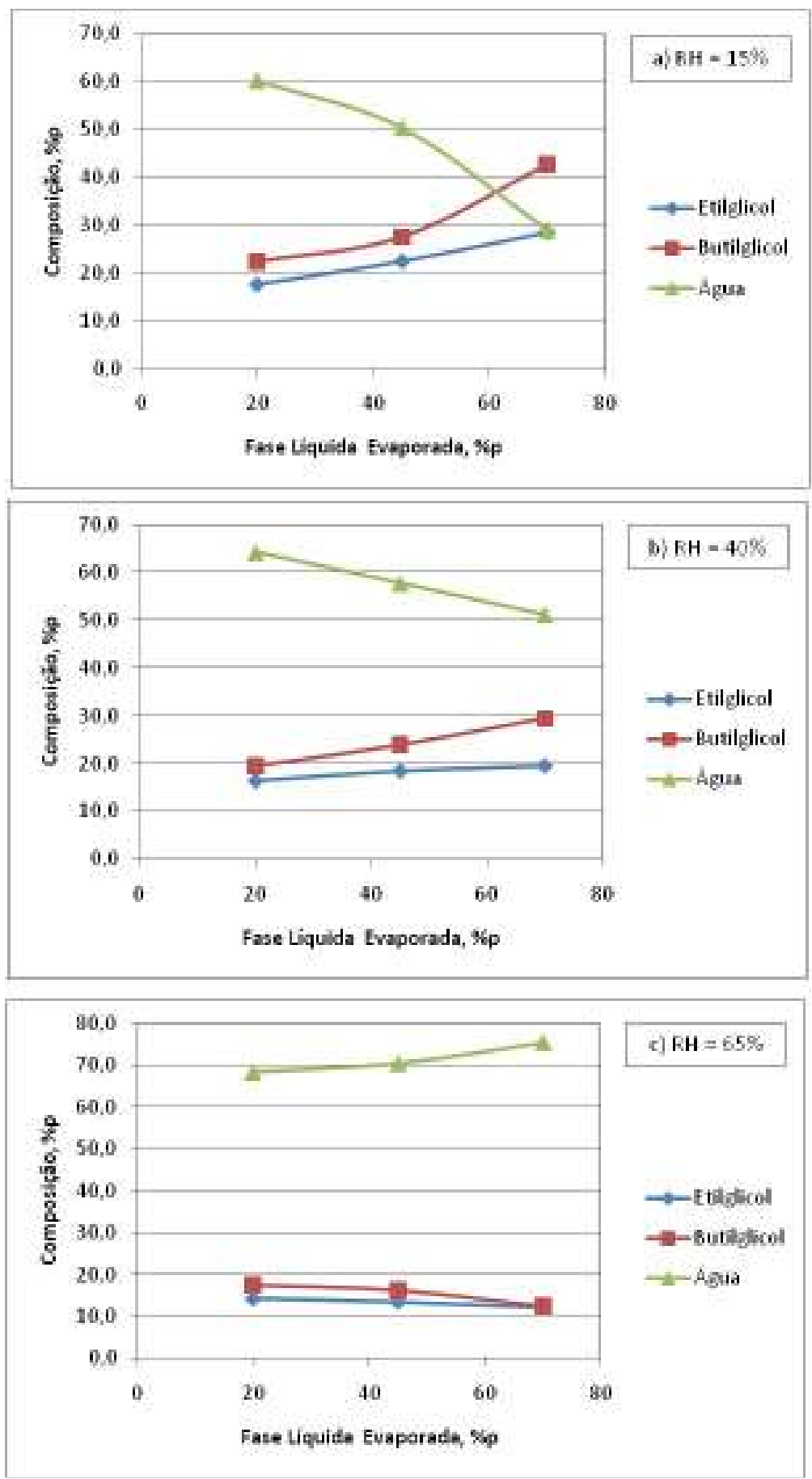

Figura 4.5 - Curvas de evaporação experimental para a mistura 4.5 sob diferentes umidades relativas: a) $\mathrm{RH}=15 \%$; b) $\mathrm{RH}=40 \%$; c) $\mathrm{RH}=65 \%$.

A tabela 4.13 apresenta os resultados de RMSE comparando as composições obtidas pela cromatografia para cada um dos componentes e as composições calculadas pelos diferentes modelos, e o desvio relativo entre o $t_{70 \%}$ experimental e calculado. 
Tabela 4.13 - Resultados de RMSE obtidos a partir dos dados de composição e desvio relativo para o tempo de evaporação em $70 \%$ da mistura evaporada, calculados da curva de evaporação para a mistura de solventes 4.5 de acordo com diferentes modelos de evaporação de misturas e modelos para cálculo do coeficiente de atividade.

\begin{tabular}{|c|c|c|c|c|c|c|c|c|c|c|}
\hline \multirow{2}{*}{$\begin{array}{c}\text { Modelo de } \\
\text { coeficiente } \\
\text { de } \\
\text { atividade }\end{array}$} & \multirow[b]{2}{*}{$\begin{array}{l}\text { Modelo de } \\
\text { evaporação }\end{array}$} & \multicolumn{3}{|c|}{ RH Real $=15 \%$} & \multicolumn{3}{|c|}{ RH Real $=40 \%$} & \multicolumn{3}{|c|}{ RH Real $=65 \%$} \\
\hline & & $\begin{array}{c}\mathrm{RH}- \\
\text { Modelo }\end{array}$ & RMSE & \begin{tabular}{c|} 
Desvio \\
$\mathbf{t}_{70 \%}$ \\
$(\%)$
\end{tabular} & $\begin{array}{c}\mathrm{RH} \text { - } \\
\text { Modelo }\end{array}$ & RMSE & $\begin{array}{c}\text { Desvio } \\
t_{70 \%} \\
(\%)\end{array}$ & $\begin{array}{c}\mathrm{RH}- \\
\text { Modelo }\end{array}$ & RMSE & $\begin{array}{c}\text { Desvio } \\
t_{70 \%} \\
(\%)\end{array}$ \\
\hline \multirow{4}{*}{ Ideal } & WE & - & 11,0 & 26,0 & - & 4,6 & $-13,6$ & - & 12,4 & $-49,2$ \\
\hline & RBM/DS & 0 & 3,5 & 8,2 & 0 & 11,4 & $-25,9$ & 0 & 22,7 & $-56,5$ \\
\hline & RBM & 15 & 2,8 & 25,1 & 40 & 8,5 & 16,0 & 65 & 16,2 & 8,7 \\
\hline & DS & 15 & 2,7 & 28,5 & 40 & 7,7 & 27,6 & 65 & 14,5 & 35,4 \\
\hline \multirow{4}{*}{$\begin{array}{l}\text { Solução } \\
\text { Regular }\end{array}$} & WE & - & 12,9 & 17,8 & - & 5,1 & $-18,6$ & - & 10,8 & $-52,2$ \\
\hline & RBM/DS & 0 & 3,2 & 4,6 & 0 & 10,9 & $-28,3$ & 0 & 22,2 & $-57,9$ \\
\hline & RBM & 15 & 2,7 & 20,9 & 40 & 7,9 & 12,2 & 65 & 15,2 & 5,0 \\
\hline & DS & 15 & 2,7 & 20,5 & 40 & 7,9 & 10,9 & 65 & 15,4 & 2,3 \\
\hline \multirow{3}{*}{ UNIQUAC } & $\begin{array}{c}\text { WE } \\
\text { RBM/DS }\end{array}$ & $\overline{0}$ & $\begin{array}{c}33,1 \\
8,2\end{array}$ & $\begin{array}{l}-31,1 \\
-13,9\end{array}$ & $\overline{0}$ & $\begin{array}{c}23,1 \\
3,6\end{array}$ & $\begin{array}{l}-52,3 \\
-41,4\end{array}$ & $\overline{0}$ & $\begin{array}{l}11,7 \\
13,0\end{array}$ & $\begin{array}{l}-72,0 \\
-65,6\end{array}$ \\
\hline & RBM & 15 & 10,4 & $-1,6$ & 40 & 7,5 & $-11,9$ & 65 & 5,5 & $-22,0$ \\
\hline & DS & 15 & 10,2 & $-2,3$ & 40 & 7,2 & $-13,8$ & 65 & 5,0 & $-24,7$ \\
\hline \multirow{3}{*}{ Wilson } & WE & $\overline{-}$ & $\begin{array}{l}11,0 \\
35\end{array}$ & 18,6 & - & 4,6 & $\begin{array}{l}-18,8 \\
230\end{array}$ & - & $\begin{array}{l}12,4 \\
127\end{array}$ & $-52,3$ \\
\hline & $\begin{array}{c}\text { RBM/DS } \\
\text { RBM }\end{array}$ & $\begin{array}{c}0 \\
15\end{array}$ & $\begin{array}{l}3,5 \\
3,5\end{array}$ & $\begin{array}{l}-2,0 \\
15,3\end{array}$ & $\begin{array}{c}0 \\
40\end{array}$ & $\begin{array}{l}11,4 \\
11,4\end{array}$ & $\begin{array}{c}-33,0 \\
11,6\end{array}$ & $\begin{array}{c}0 \\
65\end{array}$ & $\begin{array}{l}22,1 \\
227\end{array}$ & $\begin{array}{l}-60,7 \\
124\end{array}$ \\
\hline & DS & 15 & 3,5 & 13,5 & 40 & 11,4 & 5,2 & 65 & 22,7 & $-3,4$ \\
\hline UNIFAC* & $\mathrm{RB}$ & 15 & 5,2 & 1,0 & 40 & 2,9 & $-7,7$ & 65 & 2,2 & $-20,5$ \\
\hline
\end{tabular}

Segundo Rocklin e Bonner (1980), os resultados calculados pelos modelos são melhores para maiores umidades relativas. Esta afirmação é verdadeira para os resultados de composição que foram comparados pelo cálculo do RMSE. À medida que se aumenta a umidade relativa do sistema, mais ajustado se apresenta o dado calculado para a composição, ou seja, menor o valor de RMSE. Porém isto não é verdade para o tempo de evaporação calculado com base no modelo RB associado com o modelo UNIFAC, nos modelos WE e RBM/DS associados a qualquer modelo de coeficiente de atividade.

Para os demais resultados calculados neste trabalho, é possível observar na tabela 4.13 que, do ponto de vista de composição observado pelo cálculo do RMSE, os modelos de coeficiente de atividade são responsáveis por apresentar as maiores diferenças entre os resultados. Os modelos UNIFAC e UNIQUAC apresentaram melhores resultados a medida que se aumenta a umidade relativa do sistema, enquanto que as demais apresentaram uma tendência contrária, caracterizado pelo aumento do RMSE. Para a umidade relativa de $65 \%$, os melhores resultados foram 
obtidos para o modelo UNIQUAC e modelos de mistura de RBM e DS, o que mostra a importância do fator de correção de umidade relativa para altas umidades relativas, para cálculo da composição da mistura. Embora o modelo UNIQUAC não tenha apresentado os melhores resultados para as condições de menor umidade relativa como regra, os modelos de RBM e DS foram os que apresentaram melhor resultado.

Observando os resultados obtidos para desvio relativo em $70 \%$ da mistura evaporada, é observada uma tendência entre os resultados obtidos para os diferentes modelos de coeficiente de atividade. Com exceção do modelo de mistura WE, que apresenta os maiores desvios, e os dados calculados por UNIQUAC, os melhores resultados foram calculados com os modelos RBM e DS com umidade relativa igual a zero para a condição real de $15 \%$ de umidade relativa. Para a condição real de umidade relativa de $65 \%$, os melhores resultados foram obtidos com os modelos de DS e RBM associados ao modelo Solução Regular calculados para a umidade relativa de 65\%. Mais uma vez estes resultados confirmam a importância do fator de correção de umidade relativa apenas para condições de umidade relativa alta, muito acima do que determina a norma ASTM D3539.

\subsubsection{Influência dos Diferentes Modelos e parâmetros dos Coeficientes de Atividade}

Com os dados analisados anteriormente foi possível observar a relevância dos fatores de correção de temperatura e umidade, e também a importância dos diferentes modelos de mistura e modelo de coeficiente de atividade. Mas não foi possível definir ainda qual a melhor opção entre os diferentes modelos. A tabela 4.14 apresenta dados experimentais obtidos para outras misturas para as quais se pretende posteriormente avaliar a influência apenas dos diferentes modelos, sem a influência dos fatores descritos anteriormente. 
Tabela 4.14 - Resultados obtidos a partir dos dados experimentais das curvas de evaporação para as misturas de solventes 4.6 a 4.11 de acordo com a norma ASTM D3539.

\begin{tabular}{|c|c|c|c|c|c|c|c|}
\hline Mistura & Componentes & Composição & $\begin{array}{l}\text { Número } \\
\text { de } \\
\text { repetições }\end{array}$ & $\begin{array}{c}t_{90 \%} \text { médio } \\
\text { experimental } \\
\text { (s) }\end{array}$ & $\begin{array}{c}\text { Desvio } \\
\text { Padrão } \\
\text { para } \\
t_{90 \%}\end{array}$ & $\begin{array}{c}\text { Intervalo } \\
\text { de } \\
\text { Confiança } \\
\text { para t } \text { t }_{90 \%}\end{array}$ & $\begin{array}{c}\text { TER } \\
\text { Experimental } \\
\text { da mistura }\end{array}$ \\
\hline \multirow{3}{*}{4.6} & $\begin{array}{l}\text { Acetato de sec- } \\
\text { Butila }\end{array}$ & 9 & \multirow{3}{*}{5} & \multirow{3}{*}{96,8} & \multirow{3}{*}{7,4} & \multirow{3}{*}{$\begin{array}{l}87,57- \\
106,03\end{array}$} & \multirow{3}{*}{486} \\
\hline & Metiletilcetona & 23 & & & & & \\
\hline & Ciclohexano & 68 & & & & & \\
\hline \multirow{3}{*}{4.7} & Metiletilcetona & 50 & \multirow{3}{*}{5} & \multirow{3}{*}{1156,8} & \multirow{3}{*}{79,6} & \multirow{3}{*}{$\begin{array}{c}1058,0- \\
1255,6\end{array}$} & \multirow{3}{*}{40,7} \\
\hline & $\begin{array}{l}\text { Acetato de } \\
\text { isopentila }\end{array}$ & 30 & & & & & \\
\hline & Butilglicol & 20 & & & & & \\
\hline \multirow{3}{*}{4.8} & Ciclohexano & 70 & \multirow{3}{*}{5} & \multirow{3}{*}{93,9} & \multirow{3}{*}{4,8} & \multirow{3}{*}{$\begin{array}{c}87,9- \\
99,9\end{array}$} & \multirow{3}{*}{503,4} \\
\hline & Acetona & 15 & & & & & \\
\hline & Metiletilcetona & 15 & & & & & \\
\hline \multirow{3}{*}{4.9} & Etanol & 60 & \multirow{3}{*}{5} & \multirow{3}{*}{311,2} & \multirow{3}{*}{5,4} & \multirow{3}{*}{$\begin{array}{c}304,5- \\
317,9\end{array}$} & \multirow{3}{*}{151,7} \\
\hline & $\begin{array}{c}\text { Acetato de sec- } \\
\text { Butila }\end{array}$ & 20 & & & & & \\
\hline & sec-Butanol & 20 & & & & & \\
\hline \multirow{4}{*}{4.10} & Etanol & 55 & \multirow{4}{*}{5} & \multirow{4}{*}{324} & \multirow{4}{*}{29,5} & \multirow{4}{*}{$\begin{array}{l}287,3- \\
360,7\end{array}$} & \multirow{4}{*}{144,2} \\
\hline & Metilpropilenoglicol & 2 & & & & & \\
\hline & $\begin{array}{c}\text { Acetato de sec- } \\
\text { Butila }\end{array}$ & 15 & & & & & \\
\hline & sec-Butanol & 28 & & & & & \\
\hline \multirow{3}{*}{4.11} & Acetato de n-Butila & 25 & \multirow{3}{*}{5} & \multirow{3}{*}{485,6} & \multirow{3}{*}{4,8} & \multirow{3}{*}{$\begin{array}{c}479,7- \\
491,5\end{array}$} & \\
\hline & $\begin{array}{c}\text { Acetato de sec- } \\
\text { Butila }\end{array}$ & 25 & & & & & 96,5 \\
\hline & Xileno & 50 & & & & & \\
\hline
\end{tabular}

Os resultados da tabela 4.14 mais uma vez mostram que, quanto maior a TER da

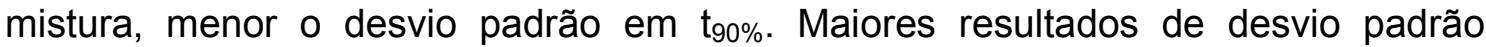
podem também ser observados para misturas que apresentam componentes com TER bastante distintas.

Como anteriormente apresentado, os cálculos para os modelos de Wilson e UNIQUAC foram realizados com os parâmetros binários obtidos do banco de dados do software de simulação ASPEN plus 7.0. Em alguns casos os parâmetros estavam referenciados como de literatura (DECHEMA), e nos casos onde estes não estavam disponíveis, os parâmetros binários foram calculados por meio do método UNIFAC, por contribuição de grupo. 
Tabela 4.15 - Resultados obtidos a partir dos dados calculados das curvas de evaporação para as misturas de solventes 4.6 a 4.11 de acordo com diferentes modelos de misturas para cálculo do

\begin{tabular}{|c|c|c|c|c|c|c|}
\hline Mistura & $\begin{array}{c}\text { Modelo de } \\
\text { coeficiente } \\
\text { de } \\
\text { atividade }\end{array}$ & $\begin{array}{c}\text { Modelo de } \\
\text { evaporação }\end{array}$ & $\begin{array}{c}\text { TER } \\
\text { Calculado } \\
\text { da } \\
\text { Mistura } \\
\end{array}$ & RMSE & $\begin{array}{c}\text { Desvio } \\
\text { t90\% } \\
(\%)\end{array}$ & $\begin{array}{c}\text { intervalo } \\
\text { de } \\
\text { confiança }\end{array}$ \\
\hline \multirow{8}{*}{4.6} & \multirow{2}{*}{ Ideal } & WE & 407,0 & 16,9 & 19,3 & fora \\
\hline & & RBM/DS & 411,1 & 16,1 & 18,1 & fora \\
\hline & \multirow{2}{*}{$\begin{array}{l}\text { Solução } \\
\text { Regular }\end{array}$} & WE & 413,4 & 15,9 & 17,5 & fora \\
\hline & & RBM/DS & 416,9 & 15,3 & 16,5 & fora \\
\hline & \multirow{2}{*}{ UNIQUAC } & WE & 516,6 & 3,8 & $-6,0$ & dentro \\
\hline & & RBM/DS & 520,4 & 3,5 & $-6,7$ & dentro \\
\hline & \multirow{2}{*}{ Wilson } & WE & 479,7 & 7,5 & 1,2 & dentro \\
\hline & & RBM/DS & 479,3 & 7,3 & 1,3 & dentro \\
\hline \multirow{8}{*}{4.7} & \multirow{2}{*}{ Ideal } & WE & 44,2 & 38,7 & $-8,2$ & dentro \\
\hline & & RBM/DS & 44,0 & 36,6 & $-7,7$ & dentro \\
\hline & Solução & WE & 44,5 & 41,0 & $-8,7$ & fora \\
\hline & Regular & RBM/DS & 44,3 & 38,9 & $-8,3$ & dentro \\
\hline & \multirow{2}{*}{ UNIQUAC } & WE & 49,5 & 90,5 & $-17,9$ & fora \\
\hline & & RBM/DS & 49,6 & 90,2 & $-18,0$ & fora \\
\hline & \multirow{2}{*}{ Wilson } & WE & 48,2 & 85,7 & $-15,7$ & fora \\
\hline & & RBM/DS & 47,9 & 84,2 & $-15,2$ & fora \\
\hline \multirow{8}{*}{4.8} & \multirow{2}{*}{ Ideal } & WE & 461,1 & 9,3 & 8,5 & fora \\
\hline & & RBM/DS & 461,4 & 9,1 & 8,5 & fora \\
\hline & \multirow{2}{*}{$\begin{array}{l}\text { Solução } \\
\text { Regular }\end{array}$} & WE & 464,9 & 8,8 & 7,6 & fora \\
\hline & & RBM/DS & 465,2 & 8,6 & 7,6 & fora \\
\hline & \multirow{2}{*}{ UNIQUAC } & WE & 600,3 & 7,3 & $-16,6$ & fora \\
\hline & & RBM/DS & 591,9 & 7,3 & $-15,5$ & fora \\
\hline & \multirow{2}{*}{ Wilson } & WE & 688,5 & 12,2 & $-27,3$ & fora \\
\hline & & RBM/DS & 748,9 & 14,9 & $-33,2$ & fora \\
\hline \multirow{8}{*}{4.9} & \multirow{2}{*}{ Ideal } & WE & 148,5 & 10,4 & 1,7 & dentro \\
\hline & & RBM/DS & 148,7 & 10,6 & 1,5 & dentro \\
\hline & Solução & WE & 149,0 & 9,7 & 1,3 & dentro \\
\hline & Regular & RBM/DS & 149,2 & 10,1 & 1,2 & dentro \\
\hline & \multirow{2}{*}{ UNIQUAC } & WE & 144,3 & 16,6 & 4,7 & fora \\
\hline & & RBM/DS & 156,0 & 17,5 & $-3,6$ & fora \\
\hline & \multirow{2}{*}{ Wilson } & WE & 148,7 & 10,6 & 1,5 & dentro \\
\hline & & RBM/DS & 145,3 & 15,9 & 3,5 & fora \\
\hline
\end{tabular}


Continuação da tabela 4.15.

\begin{tabular}{|c|c|c|c|c|c|c|}
\hline Mistura & $\begin{array}{c}\text { Modelo de } \\
\text { coeficiente } \\
\text { de } \\
\text { atividade }\end{array}$ & $\begin{array}{l}\text { Modelo de } \\
\text { evaporação }\end{array}$ & $\begin{array}{c}\text { TER } \\
\text { Calculado } \\
\text { da } \\
\text { Mistura }\end{array}$ & RMSE & $\begin{array}{c}\text { Desvio } \\
\text { t90\% } \\
(\%)\end{array}$ & $\begin{array}{c}\text { intervalo } \\
\text { de } \\
\text { confiança }\end{array}$ \\
\hline \multirow{8}{*}{4.9} & \multirow{2}{*}{ Ideal } & WE & 148,5 & 10,4 & 1,7 & dentro \\
\hline & & RBM/DS & 148,7 & 10,6 & 1,5 & dentro \\
\hline & Solução & WE & 149,0 & 9,7 & 1,3 & dentro \\
\hline & Regular & RBM/DS & 149,2 & 10,1 & 1,2 & dentro \\
\hline & \multirow{2}{*}{ UNIQUAC } & WE & 144,3 & 16,6 & 4,7 & fora \\
\hline & & RBM/DS & 156,0 & 17,5 & $-3,6$ & fora \\
\hline & \multirow{2}{*}{ Wilson } & WE & 148,7 & 10,6 & 1,5 & dentro \\
\hline & & RBM/DS & 145,3 & 15,9 & 3,5 & fora \\
\hline \multirow{8}{*}{4.10} & \multirow{2}{*}{ Ideal } & WE & 137,2 & 20,5 & 5,8 & dentro \\
\hline & & RBM/DS & 137,9 & 18,6 & 5,2 & dentro \\
\hline & \multirow{2}{*}{$\begin{array}{l}\text { Solução } \\
\text { Regular }\end{array}$} & WE & 137,5 & 19,9 & 5,5 & dentro \\
\hline & & RBM/DS & 138,2 & 18,1 & 5,0 & dentro \\
\hline & \multirow{2}{*}{ UNIQUAC } & WE & 133,0 & 18,6 & 9,1 & dentro \\
\hline & & RBM/DS & 136,8 & 11,1 & 6,0 & dentro \\
\hline & \multirow{2}{*}{ Wilson } & WE & 134,7 & 25,1 & 7,7 & dentro \\
\hline & & RBM/DS & 136,4 & 22,2 & 6,4 & dentro \\
\hline \multirow{8}{*}{4.11} & \multirow{2}{*}{ Ideal } & WE & 99,4 & 10,3 & $-2,6$ & fora \\
\hline & & RBM/DS & 99,2 & 9,6 & $-2,4$ & fora \\
\hline & \multirow{2}{*}{$\begin{array}{l}\text { Solução } \\
\text { Regular }\end{array}$} & WE & 104,8 & 25,1 & $-7,7$ & fora \\
\hline & & RBM/DS & 104,7 & 23,9 & $-7,5$ & fora \\
\hline & \multirow{2}{*}{ UNIQUAC } & WE & 98,1 & 8,0 & $-1,3$ & fora \\
\hline & & RBM/DS & 97,9 & 7,8 & $-1,2$ & dentro \\
\hline & \multirow{2}{*}{ Wilson } & WE & 98,0 & 7,8 & $-1,2$ & dentro \\
\hline & & RBM/DS & 97,7 & 7,9 & $-0,9$ & dentro \\
\hline
\end{tabular}

Os resultados acima não mostram um único modelo e uma única equação de coeficientes de atividade que apresentem os melhores resultados para todas e quaisquer misturas. Entre os diversos modelos de evaporação para misturas, podem-se destacar os modelos de RBM e DS como os que apresentaram os melhores resultados com maior freqüência entre os resultados da tabela 4.15. Era esperado também que as curvas de evaporação calculadas pelos modelos UNIQUAC e de Wilson apresentassem os melhores resultados, pois estes são modelos muito mais robustos para representar o equilíbrio líquido vapor, mas isto não foi observado. 
É possível que os resultados calculados com base nos modelos de UNIQUAC e Wilson não tenham sido melhores, porque os parâmetros utilizados não representam adequadamente o equilíbrio líquido-vapor das misturas em questão. Assim, a fim de tentar solucionar esta dúvida, foram selecionadas outras misturas de solventes para as quais fossem conhecidas a origem e validade dos seus parâmetros binários. $A$ tabela 4.16 apresenta as misturas selecionadas.

Tabela 4.16 - Resultados obtidos a partir dos dados experimentais das curvas de evaporação para as misturas de solventes 4.12 e 4.18 de acordo com a norma ASTM D3539.

\begin{tabular}{|c|c|c|c|c|c|c|c|}
\hline Mistura & Componentes & Composição & $\begin{array}{c}\text { Número } \\
\text { de } \\
\text { repetições }\end{array}$ & $\begin{array}{c}t_{90 \%} \text { médio } \\
\text { experimental } \\
\text { (s) }\end{array}$ & $\begin{array}{c}\text { Desvio } \\
\text { Padrão } \\
\text { para } \\
\text { t9o\% }_{9}\end{array}$ & $\begin{array}{c}\text { Intervalo } \\
\text { de } \\
\text { Confiança } \\
\text { para } t_{90 \%}\end{array}$ & $\begin{array}{c}\text { TER } \\
\text { Experimental } \\
\text { da mistura }\end{array}$ \\
\hline \multirow{2}{*}{4.12} & Metileticetona & 71,4 & \multirow{2}{*}{3} & \multirow{2}{*}{1684,0} & \multirow{2}{*}{27,7} & 1615,2 - & \multirow{2}{*}{28,4} \\
\hline & Butilglicol & 28,6 & & & & 1752,8 & \\
\hline \multirow{3}{*}{4.13} & Metileticetona & 67,8 & \multirow{3}{*}{3} & \multirow{3}{*}{1802,0} & \multirow{3}{*}{117,2} & & \multirow{3}{*}{26,3} \\
\hline & Butilglicol & 28,6 & & & & $\begin{array}{l}1510,9- \\
20931\end{array}$ & \\
\hline & Água & 3,6 & & & & & \\
\hline \multirow{2}{*}{4.14} & Etilglicol & 30 & \multirow{2}{*}{3} & \multirow{2}{*}{1306,7} & \multirow{2}{*}{64,2} & 1147,3 - & \multirow{2}{*}{35,7} \\
\hline & Água & 70 & & & & 1466,1 & \\
\hline \multirow{2}{*}{4.15} & Butilglicol & 30 & \multirow{2}{*}{3} & \multirow{2}{*}{3065,3} & \multirow{2}{*}{82,6} & 2860,2 - & \multirow{2}{*}{15,3} \\
\hline & Água & 70 & & & & 3270,5 & \\
\hline \multirow[b]{2}{*}{4.16} & Acetato de n- & 40 & \multirow[b]{2}{*}{3} & \multirow{2}{*}{334,0} & \multirow[b]{2}{*}{5,3} & 320.9 - & \multirow[b]{2}{*}{141,3} \\
\hline & Tolueno & 60 & & & & 347,1 & \\
\hline \multirow{3}{*}{4.17} & Etanol & 60 & \multirow{3}{*}{3} & \multirow{3}{*}{382,7} & \multirow{3}{*}{8,3} & \multirow{3}{*}{$\begin{array}{c}362,0- \\
403,4\end{array}$} & \multirow{3}{*}{123,0} \\
\hline & Butanol & 20 & & & & & \\
\hline & $\begin{array}{c}\text { Acetato de n- } \\
\text { Butila }\end{array}$ & 20 & & & & & \\
\hline \multirow{3}{*}{4.18} & Acetato de n- & 20 & \multirow{3}{*}{3} & \multirow{3}{*}{1040,0} & \multirow{3}{*}{3,5} & & \multirow{3}{*}{45,8} \\
\hline & Butila & 20 & & & & $\begin{array}{l}1031,4- \\
1048,6\end{array}$ & \\
\hline & Etilglicol & 80 & & & & & \\
\hline
\end{tabular}

Os dados apresentados pelo DECHEMA são bastante confiáveis para cálculos de equilíbrio líquido-vapor. A maioria dos parâmetros selecionados atende aos dois testes de consistência termodinamicamente mais conhecidos. A tabela 4.17 apresenta informações sobre os parâmetros selecionados para as misturas da tabela 4.16. 
Tabela 4.17 - Informações sobre as condições de determinação dos parâmetros binários dos modelos UNIQUAC e de Wilson para cálculo do coeficiente de atividade de acordo com a base de dados DECHEMA.

\begin{tabular}{|c|c|c|c|c|}
\hline Mistura & Componentes & $\begin{array}{c}\text { Consistência } \\
\text { Termodinamica }\end{array}$ & $\begin{array}{c}\text { Temperatura } \\
\left({ }^{\circ} \mathrm{C}\right)\end{array}$ & $\begin{array}{l}\text { Pressão } \\
(\mathrm{mmHg})\end{array}$ \\
\hline 4.12 & Metileticetona/Butilglicol & -+ & $79,7-171,2$ & 760,0 \\
\hline \multirow{3}{*}{4.13} & Metileticetona/Butilglicol & -+ & $79,7-171,2$ & 760,0 \\
\hline & Metileticetona/Água & ++ & $75,3-77,0$ & 760,0 \\
\hline & Butilglicol/Água & ++ & 110,0 & $97,7-1074,6$ \\
\hline 4.14 & Etilglicol/Água & -- & $99,8-103,4$ & 740,0 \\
\hline 4.15 & Butilglicol/Água & ++ & 110,0 & $97,7-1074,6$ \\
\hline 4.16 & $\begin{array}{l}\text { Acetato de } n- \\
\text { Butila/Tolueno }\end{array}$ & ++ & $109,9-123,4$ & 728,4 \\
\hline \multirow{3}{*}{4.17} & Etanol/Butanol & -+ & 70,0 & $\begin{array}{c}140,0- \\
527,0\end{array}$ \\
\hline & Etanol/Acetato de n-Butila & ++ & $79,1-118,1$ & 760,0 \\
\hline & Butanol/Acetato de n-Butila & ++ & $117,0-121,7$ & 760,0 \\
\hline 4.18 & $\begin{array}{l}\text { Acetato de n- } \\
\text { Butila/Etillgicol }\end{array}$ & ++ & $126,1-135,0$ & 760,0 \\
\hline
\end{tabular}

O DECHEMA apresenta e avalia dois testes de consistência termodinâmica. O sinal positivo indica que os parâmetros utilizados passaram naquele determinado teste, $\mathrm{e}$ o sinal negativo indica que os parâmetros não foram válidos para aquele teste de consistência.

A tabela 4.18 apresenta os resultados calculados para as misturas 4.12 a 4.18 , com base nos diferentes modelos e parâmetros binários relacionados com a tabela 4.17.

Tabela 4.18 - Resultados obtidos a partir dos dados calculados das curvas de evaporação para as misturas de solventes 4.12 a 4.18 de acordo com diferentes modelos de misturas e para cálculo do coeficiente de atividade.

\begin{tabular}{|c|c|c|c|c|c|c|c|}
\hline Mistura & $\begin{array}{c}\text { Modelo de } \\
\text { coeficiente } \\
\text { de } \\
\text { atividade } \\
\end{array}$ & $\begin{array}{l}\text { Modelo de } \\
\text { evaporação }\end{array}$ & $\mathbf{R H}$ & $\begin{array}{c}\text { TER } \\
\text { Calculado } \\
\text { da } \\
\text { Mistura } \\
\end{array}$ & RMSE & $\begin{array}{c}\text { Desvio } \\
\text { t }_{90 \%} \\
(\%)\end{array}$ & $\begin{array}{c}\text { intervalo } \\
\text { de } \\
\text { confiança }\end{array}$ \\
\hline \multirow{8}{*}{4.12} & \multirow{2}{*}{ Ideal } & WE & - & 34,2 & 145,1 & $-18,3$ & fora \\
\hline & & RBM/DS & - & 34,2 & 147,2 & $-18,3$ & fora \\
\hline & \multirow{2}{*}{$\begin{array}{l}\text { Solução } \\
\text { Regular }\end{array}$} & WE & - & 34,2 & 145,1 & $-18,3$ & fora \\
\hline & & RBM/DS & - & 34,2 & 147,2 & $-18,3$ & fora \\
\hline & \multirow{2}{*}{ UNIQUAC } & WE & - & 34,9 & 159,4 & $-20,0$ & fora \\
\hline & & RBM/DS & - & 34,7 & 159,7 & $-19,6$ & fora \\
\hline & \multirow{2}{*}{ Wilson } & WE & - & 34,9 & 159,0 & $-20,0$ & fora \\
\hline & & RBM/DS & - & 34,8 & 160,0 & $-19,7$ & fora \\
\hline
\end{tabular}


Continua

Continuação da tabela 4.18

\begin{tabular}{|c|c|c|c|c|c|c|c|}
\hline Mistura & $\begin{array}{c}\text { Modelo de } \\
\text { coeficiente } \\
\text { de } \\
\text { atividade }\end{array}$ & $\begin{array}{l}\text { Modelo de } \\
\text { evaporação }\end{array}$ & RH & $\begin{array}{c}\text { TER } \\
\text { Calculado } \\
\text { da } \\
\text { Mistura }\end{array}$ & RMSE & $\begin{array}{c}\text { Desvio } \\
\text { t }_{90 \%} \\
(\%)\end{array}$ & $\begin{array}{c}\text { intervalo } \\
\text { de } \\
\text { confiança }\end{array}$ \\
\hline \multirow{16}{*}{4.13} & \multirow{4}{*}{ Ideal } & WE & - & 32,9 & 176,1 & $-20,7$ & fora \\
\hline & & RBM/DS & - & 32,9 & 187,3 & $-20,7$ & fora \\
\hline & & RBM & 5 & 32,9 & 186,0 & $-20,6$ & fora \\
\hline & & DS & 5 & 31,2 & 158,6 & $-16,3$ & fora \\
\hline & \multirow{5}{*}{$\begin{array}{l}\text { Solução } \\
\text { Regular }\end{array}$} & WE & - & 33,0 & 179,4 & $-21,0$ & fora \\
\hline & & RBM/DS & - & 33,0 & 189,6 & $-21,0$ & fora \\
\hline & & RBM & 5 & 33,0 & 188,4 & $-20,9$ & fora \\
\hline & & DS & 5 & 33,0 & 188,5 & $-20,9$ & fora \\
\hline & & WE & - & 34,4 & 218,5 & $-24,3$ & fora \\
\hline & \multirow{4}{*}{ UNIQUAC } & RBM/DS & - & 34,3 & 220,9 & $-23,9$ & fora \\
\hline & & RBM & 5 & 34,3 & 220,6 & $-23,9$ & fora \\
\hline & & DS & 5 & 34,3 & 220,8 & $-23,9$ & fora \\
\hline & & WE & - & 114,9 & 554,6 & $-77,3$ & fora \\
\hline & \multirow{3}{*}{ Wilson } & RBM/DS & - & 158,0 & 604,3 & $-83,5$ & fora \\
\hline & & RBM & 5 & 150,1 & 598,3 & $-82,6$ & fora \\
\hline & & DS & 5 & 156,4 & 603,0 & $-83,3$ & fora \\
\hline \multirow{16}{*}{4.14} & \multirow{5}{*}{ Ideal } & WE & - & 33,6 & 138,1 & 7,0 & dentro \\
\hline & & RBM/DS & - & 33,7 & 132,3 & 6,6 & dentro \\
\hline & & RBM & 5 & 32,4 & 169,2 & 10,9 & dentro \\
\hline & & DS & 5 & 32,0 & 176,0 & 12,2 & fora \\
\hline & & WE & - & 36,4 & 78,5 & $-1,3$ & dentro \\
\hline & \multirow{4}{*}{$\begin{array}{l}\text { Solução } \\
\text { Regular }\end{array}$} & RBM/DS & - & 35,0 & 104,6 & 2,8 & dentro \\
\hline & & RBM & 5 & 33,6 & 138,9 & 6,9 & dentro \\
\hline & & DS & 5 & 33,7 & 138,2 & 6,8 & dentro \\
\hline & & WE & - & 45,7 & 151,2 & $-21,3$ & fora \\
\hline & \multirow{3}{*}{ UNIQUAC } & RBM/DS & - & 41,9 & 64,7 & $-14,1$ & fora \\
\hline & & RBM & 5 & 40,2 & 53,5 & $-10,6$ & dentro \\
\hline & & DS & 5 & 40,3 & 53,9 & $-10,8$ & dentro \\
\hline & \multirow{4}{*}{ Wilson } & WE & - & 34,7 & 113,8 & 3,7 & dentro \\
\hline & & RBM/DS & - & 39,6 & 90,6 & $-9,1$ & dentro \\
\hline & & RBM & 5 & 37,6 & 117,2 & $-4,3$ & dentro \\
\hline & & DS & 5 & 37,8 & 115,3 & $-4,9$ & dentro \\
\hline
\end{tabular}


Continuação da tabela 4.18

\begin{tabular}{|c|c|c|c|c|c|c|c|}
\hline Mistura & $\begin{array}{c}\text { Modelo de } \\
\text { coeficiente } \\
\text { de } \\
\text { atividade } \\
\end{array}$ & $\begin{array}{c}\text { Modelo de } \\
\text { evaporação }\end{array}$ & $\mathbf{R H}$ & $\begin{array}{c}\text { TER } \\
\text { Calculado } \\
\text { da } \\
\text { Mistura } \\
\end{array}$ & RMSE & $\begin{array}{c}\text { Desvio } \\
\text { t }_{90 \%} \\
(\%)\end{array}$ & $\begin{array}{c}\text { intervalo } \\
\text { de } \\
\text { confiança }\end{array}$ \\
\hline \multirow{16}{*}{4.15} & \multirow{4}{*}{ Ideal } & WE & - & 17,3 & 411,3 & $-11,6$ & fora \\
\hline & & RBM/DS & - & 17,4 & 208,3 & $-11,9$ & fora \\
\hline & & RBM & 5 & 17,1 & 229,8 & $-10,1$ & fora \\
\hline & & DS & 5 & 16,5 & 234,1 & $-7,1$ & fora \\
\hline & \multirow{5}{*}{$\begin{array}{l}\text { Solução } \\
\text { Regular }\end{array}$} & WE & - & 18,7 & 372,0 & $-17,8$ & fora \\
\hline & & RBM/DS & - & 17,8 & 199,9 & $-13,8$ & fora \\
\hline & & RBM & 5 & 17,4 & 215,4 & $-12,1$ & fora \\
\hline & & DS & 5 & 17,5 & 214,9 & $-12,1$ & fora \\
\hline & & WE & - & 45,4 & 722,1 & $-66,2$ & fora \\
\hline & \multirow{3}{*}{ UNIQUAC } & RBM/DS & - & 23,9 & 385,8 & $-35,9$ & fora \\
\hline & & RBM & 5 & 23,7 & 377,7 & $-35,4$ & fora \\
\hline & & DS & 5 & 23,8 & 379,0 & $-35,4$ & fora \\
\hline & \multirow{4}{*}{ Wilson } & WE & - & 23,4 & 440,7 & $-34,4$ & fora \\
\hline & & RBM/DS & - & 35,0 & 584,8 & $-56,2$ & fora \\
\hline & & RBM & 5 & 33,3 & 560,5 & $-53,9$ & fora \\
\hline & & DS & 5 & 33,8 & 567,9 & $-54,6$ & fora \\
\hline \multirow{8}{*}{4.16} & \multirow{2}{*}{ Ideal } & WE & - & 147,4 & 5,3 & $-4,5$ & fora \\
\hline & & RBM/DS & - & 148,6 & 7,0 & $-5,3$ & fora \\
\hline & \multirow{2}{*}{$\begin{array}{l}\text { Solução } \\
\text { Regular }\end{array}$} & WE & - & 156,1 & 14,3 & $-9,8$ & fora \\
\hline & & RBM/DS & - & 157,0 & 16,9 & $-10,4$ & fora \\
\hline & \multirow{2}{*}{ UNIQUAC } & WE & - & 139,3 & 9,1 & 1,0 & dentro \\
\hline & & RBM/DS & - & 140,7 & 5,3 & 0,0 & dentro \\
\hline & \multirow{2}{*}{ Wilson } & WE & - & 144,3 & 3,9 & $-2,5$ & dentro \\
\hline & & RBM/DS & - & 144,8 & 3,3 & $-2,8$ & dentro \\
\hline \multirow{8}{*}{4.17} & \multirow{2}{*}{ Ideal } & WE & - & 110,0 & 41,7 & 11,6 & fora \\
\hline & & RBM/DS & - & 109,6 & 32,9 & 12,0 & fora \\
\hline & \multirow{2}{*}{$\begin{array}{l}\text { Solução } \\
\text { Regular }\end{array}$} & WE & - & 110,1 & 41,6 & 11,6 & fora \\
\hline & & RBM/DS & - & 109,7 & 32,8 & 12,0 & fora \\
\hline & \multirow{2}{*}{ UNIQUAC } & WE & - & 132,1 & 9,6 & $-7,0$ & fora \\
\hline & & RBM/DS & - & 131,8 & 9,6 & $-6,8$ & fora \\
\hline & \multirow{2}{*}{ Wilson } & WE & - & 241,8 & 100,1 & $-49,2$ & fora \\
\hline & & RBM/DS & - & 198,8 & 87,5 & $-38,2$ & fora \\
\hline \multirow{8}{*}{4.18} & \multirow{2}{*}{ Ideal } & WE & - & 41,1 & 84,9 & 9,9 & fora \\
\hline & & RBM/DS & - & 41,1 & 93,1 & 10,0 & fora \\
\hline & \multirow{2}{*}{$\begin{array}{l}\text { Solução } \\
\text { Regular }\end{array}$} & WE & - & 41,1 & 84,8 & 9,9 & fora \\
\hline & & RBM/DS & - & 41,1 & 93,1 & 10,0 & fora \\
\hline & \multirow{2}{*}{ UNIQUAC } & WE & - & 42,7 & 41,5 & 5,8 & fora \\
\hline & & RBM/DS & - & 42,7 & 47,5 & 5,8 & fora \\
\hline & \multirow{2}{*}{ Wilson } & WE & - & 34,9 & 345,9 & 29,6 & fora \\
\hline & & RBM/DS & - & 34,8 & 359,3 & 30,0 & fora \\
\hline
\end{tabular}


Os resultados apresentados na tabela 4.18 mostram que os modelos de mistura RBM e DS apresentam os melhores resultados mais freqüentemente. Já não é possível afirmar mais uma vez que existe uma única equação de coeficientes de atividade melhor que as demais. Porém observa-se uma boa freqüência em que os resultados com UNIQUAC e Solução Regular são melhores. É interessante observar também que, embora os parâmetros binários da mistura 4.14 (etilglicol + água) não tenham sido positivos nos dois testes de consistência termodinâmica, os resultados obtidos para os modelos de UNIQUAC e Wilson apresentaram menores valores de RMSE e desvio relativo em módulo que os resultados obtidos para a mistura 4.15 (butilglicol + água), para os quais seus parâmetros binários são termodinamicamente consistentes. Os resultados calculados para o tempo de evaporação da mistura 4.15 para os diversos modelos estão todos fora do intervalo de confiança.

\subsubsection{Influência das Variações nos Parâmetros Binários}

A fim de avaliar apenas a influência da origem, ou seja, das condições em que foram determinados os parâmetros binários e sua influência sobre os resultados da curva de evaporação, foram utilizados diferentes parâmetros binários para calcular a curva de evaporação da mistura 4.15, como apresentado na tabela 4.19.

Tabela 4.19 - Resultados obtidos a partir dos dados calculados das curvas de evaporação para a mistura de solvente 4.15 de acordo com diferentes modelos de misturas e para cálculo do coeficiente de atividade, variando os parâmetros binários obtidos sob diferentes condições.

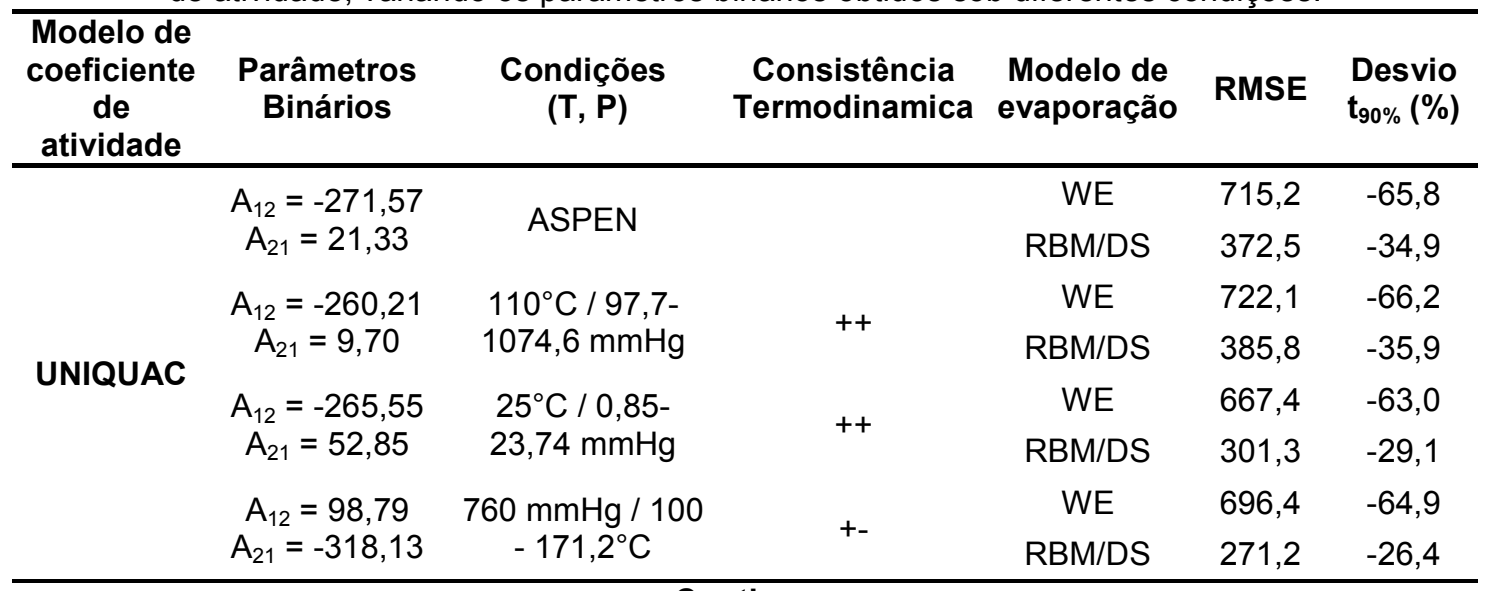


Continuação da tabela 4.19

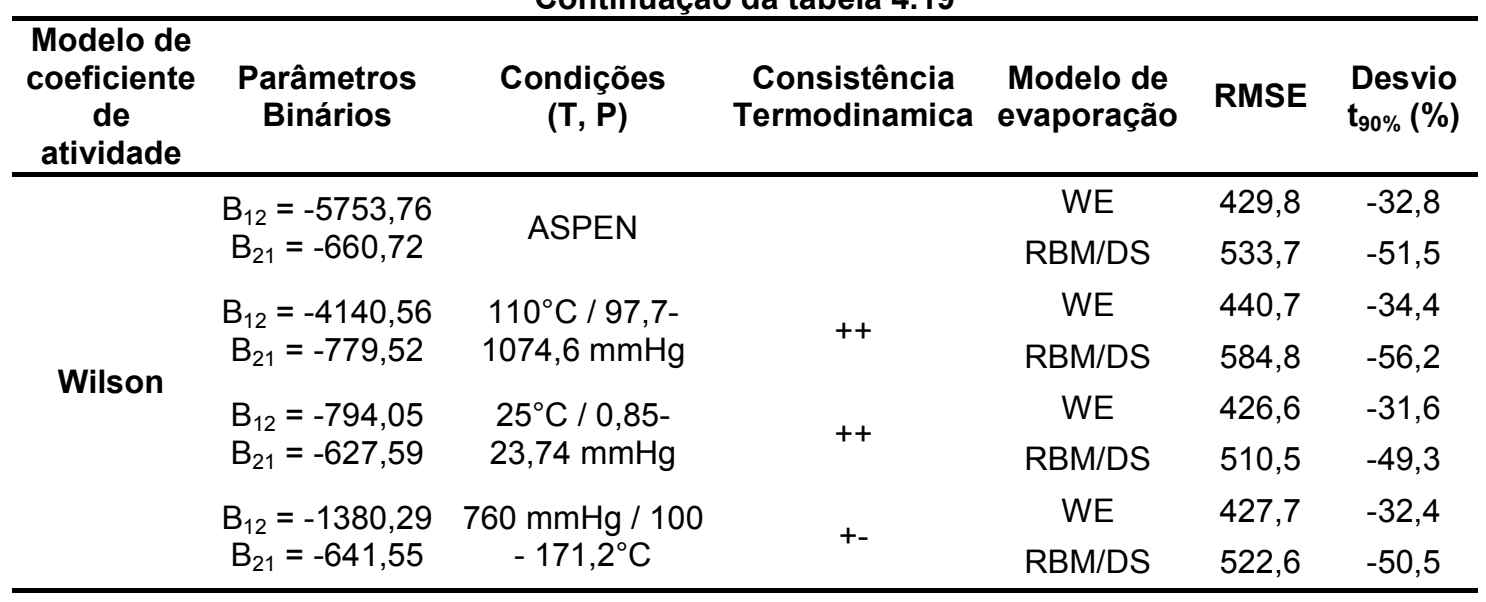

A ASTM D 3539 determina que a curva de evaporação seja determinada a $25^{\circ} \mathrm{C}$ e $760 \mathrm{mmHg}$. Infelizmente, nem sempre é possível encontrar em literatura parâmetros binários que satisfaçam estas condições. Como se pode observar na tabela 4.19, mudando-se a fonte dos parâmetros binários, os resultados obtidos para um mesmo modelo de mistura não apresenta grandes variações nos resultados de desvio relativo para o tempo de evaporação em $90 \%$ de evaporado. As maiores variações são observadas quando se comparam os resultados entre as diferentes modelos para cálculo do coeficiente de atividade.

Utilizando-se UNIQUAC para cálculo do coeficiente de atividade, são obtidos melhores resultados para a curva de evaporação quando se utiliza os modelos RBM e DS. Quando se utiliza o modelo de Wilson, os melhores resultados são observados para o modelo de evaporação de mistura WE.

De acordo com a raiz do erro médio quadrático (RMSE), os modelos de evaporação de mistura RBM e DS, e o modelo UNIQUAC e Solução Regular apresentam os melhores resultados. Embora os modelos de evaporação de mistura representem a maior influencia nos resultados das curvas de evaporação, é também importante que os parâmetros binários utilizados nos modelos sejam confiáveis.

\subsection{Chemical Product Design e Otimização}


Conforme apresentado no capítulo de Revisão Bibliográfica, Wu, Klein e Gani (1992) propuseram um modelo com base em Chemical Product Design bastante semelhante com o modelo aqui proposto. A principal diferença é que eles utilizaram a temperatura de ebulição como uma de suas restrições, enquanto que neste trabalho serão utilizados modelos para cálculo da taxa de evaporação.

Como visto anteriormente, embora não se tenha encontrado um modelo de mistura e de coeficiente de atividade únicos para cálculo da taxa de evaporação de toda e qualquer mistura de solventes, qualquer desses modelos será suficiente para servir de guia ao usuário, e associado aos parâmetros de solubilidade, reduzir o tempo que seria gasto apenas no processo de tentativa e erro para encontrar uma mistura adequada.

Para mostrar a aplicabilidade e efetividade do modelo com base na teoria do Chemical Product Design, mais especificamente do Computer-Aided Mixture/Blend Design $\left(C A M^{b} D\right)$, será apresentado um exemplo de um estudo de substituição de uma mistura de solventes. Os preços e nomes dos solventes utilizados foram descaracterizados devido ao sigilo industrial e comercial, e por isso apenas algumas propriedades serão apresentadas. Os preços reais dos solventes que serão apresentados foram divididos pelo preço do solvente de maior valor.

A tabela 4.20 apresenta a mistura de solventes original utilizada para solubilização da Resina X. Sua substituição foi solicitada para redução de preço da mistura e eliminação do solvente A que apresenta graves problemas de toxicidade.

Tabela 4.20 - Mistura de Solventes Original para ser substituída

\begin{tabular}{lcc}
\hline \multicolumn{1}{c}{ Componente } & $\begin{array}{c}\text { Composição } \\
(\% \mathrm{p})\end{array}$ & $\begin{array}{c}\text { Custo } \\
\text { (US\$/US\$) }\end{array}$ \\
\hline Solvente A & 54,70 & 0,46 \\
Solvente B & 32,13 & 0,88 \\
Solvente C & 13,17 & 0,57 \\
\hline Mistura & $\mathbf{1 0 0 , 0 0}$ & $\mathbf{0 , 6 1}$ \\
\hline
\end{tabular}

De acordo com o modelo de parâmetros de solubilidade de Hansen, a resina $X$ apresenta raio $\left(R^{k}\right)$ de 10,02 , enquanto que a mistura de solventes original apresenta 
raio de $\left(R^{\mathrm{ijk}}\right)$ de 9,80 . Isso mostra que, segundo a teoria de Hansen, é esperado que esta mistura de solventes seja eficiente na solubilização da resina, já que $R^{\mathrm{ijk}}<R^{\mathrm{k}}$.

A taxa de evaporação relativa da mistura foi determinada pelos modelos de evaporação e modelos de coeficiente de atividade estudados anteriormente, e apresentou resultados de TER que variam de 22,09 a 22,40.

Com base nestas informações, o modelo de otimização foi construído tendo o custo da mistura como função objetivo, o volume e somatório da composição da mistura como equações de restrição, e as equações para cálculo da taxa de evaporação de misturas (RBM/DS) e os raios de solubilidade como inequações de restrição. Foi utilizado o modelo de mistura ideal para cálculo do coeficiente de atividade, ou seja, $\gamma_{i}=1$, já que não se conhece todos os parâmetros binários dos solventes selecionados para os modelos de Wilson e UNIQUAC. A resposta dada pelo modelo de otimização é a composição da mistura de menor custo.

Para o exemplo apresentado a seguir e com base na TER prevista, foi definido para este modelo de otimização a faixa de TER de 20 a 25 como restrição.

O modelo construído não possui variáveis binárias, e o modelo para taxa de evaporação e para cálculo do raio de solubilidade da mistura não são equações lineares.

Esta programação foi escrita para ser calculada pelo software Matlab R2007b, e é necessário que seja informada uma composição inicial para os solventes selecionados, que será chamado de "estimativa inicial".

A tabela 4.21 apresenta os preços dos solventes tanto da mistura original, quanto os demais solventes disponíveis para substituição. 
Tabela 4.21 - Solventes e seus preços disponíveis para otimização da mistura Original

\begin{tabular}{lc}
\hline Solvente & $\begin{array}{c}\text { Custo } \\
\text { (US\$/US\$) }\end{array}$ \\
\hline Solvente A & 0,46 \\
Solvente B & 0,88 \\
Solvente C & 0,57 \\
Solvente D & 0,59 \\
Solvente E & 0,54 \\
Solvente F & 0,88 \\
Solvente G & 0,68 \\
Solvente H & 0,93 \\
Solvente I & 0,64 \\
Solvente J & 1,00 \\
\hline
\end{tabular}

Os primeiros testes realizados mostraram que a convergência e o resultado final de composição dependem dos valores iniciais de composição informados, a estimativa inicial. Segundo Pinto e Gut (2005), as soluções ótimas globais para problemas do tipo NLP são garantidas no caso em que a função objetivo $f(x)$ e as restrições $g(x)$ sejam convexas, e as funções $h(x)$ sejam lineares. Eles ainda comentam que, dada a hipótese de convexidade das funções, aliada ao fato de que na maioria dos casos não é possível caracterizar a curvatura da função e principalmente da região viável, os algoritmos garantem apenas uma solução ótima local. Por outro lado, o algoritmo pode convergir para soluções que não são necessariamente mínimos locais ou globais.

Gani (2004b) também comenta que o CPD pode apresentar algumas desvantagens, e estas estão associadas ao tempo, aos recursos, e mais à sorte do que a habilidade do projetista em encontrar uma alternativa viável, embora o conhecimento de um especialista possa ser importante. Por isso, ter um conhecimento prévio auxilia na escolha de uma estimativa inicial, o que pode facilitar que a otimização encontre uma alternativa viável mais facilmente.

Inicialmente foram selecionados dois grupos de solventes, o grupo 1 composto dos solventes D, E, F, G, H, I e J, e o grupo 2, composto pelos solventes $\mathrm{G}, \mathrm{H}, \mathrm{I}$ e J. Várias "estimativas iniciais" foram dadas, sem obter garantia de que o ponto de convergência conrresponde a um ótimo. A tabela 4.22 apresenta os melhores 
resultados obtidos de acordo com as estimativas iniciais dadas para o Grupo 1 e 2, respectivamente.

Tabela 4.22 - Solventes e seus preços disponíveis para otimização da mistura Original

\begin{tabular}{lcc}
\hline \multicolumn{1}{c}{ Solvente } & $\begin{array}{c}\text { Alternativa 1 } \\
(\% \mathbf{\%})\end{array}$ & $\begin{array}{c}\text { Alternativa 2 } \\
(\% \mathbf{\%})\end{array}$ \\
\hline Solvente D & 49,63 & - \\
Solvente E & 23,93 & - \\
Solvente F & 0,00 & - \\
Solvente G & 0,00 & 0,00 \\
Solvente H & 0,00 & 0,00 \\
Solvente I & 13,75 & 86,76 \\
Solvente J & 12,69 & 13,24 \\
\hline
\end{tabular}

Segundo os critérios de convergência utilizados, a Alternativa 1 atendeu todas as equações de restrições, mas o processo iterativo foi finalizado, porque o algoritmo não conseguiu melhorar o critério. A alternativa 2 satisfez todas as restrições e tolerâncias. Porém, nenhuma das alternativas apresentou menor custo que a mistura original, pois os solventes A, B e C não fazem parte das opções de solventes para estas misturas, e como o solvente A apresenta o de menor custo, não é possível obter uma mistura sem ele, com um custo menor.

Tabela 4.23 - Resultados obtidos para as Alternativas 1 e 2

\begin{tabular}{lcc}
\hline \multicolumn{1}{c}{ Variáveis } & Alternativa 1 & Alternativa 2 \\
\hline TER & 25 & 25 \\
$\mathrm{R}^{\mathrm{ijk}}$ & 9,02 & 9,68 \\
Custo (US $\$ / U S \$)$ & 0,64 & 0,67 \\
\hline
\end{tabular}

Outras tentativas foram feitas com um grupo composto apenas pelos solventes de $D$ a I, já que o solvente $\mathrm{J}$ é o mais caro. Mas nenhuma apresentou um resultado viável que tenha atendido todas as restrições satisfatoriamente. Ao se observar os parâmetros de solubilidade do solvente A, pode-se concluir que nenhum solvente ou suas misturas conseguiriam satisfazer a restrição associada aos parâmetros de solubilidade com a resina $X$. O solvente $\mathrm{J}$ era o único que conseguiria satisfazer esta necessidade, e que não apresentava problemas toxicológicos como o solvente $A$.

Para validar os resultados calculados pelos modelos, foram determinadas experimentalmente a taxa de evaporação da mistura original e das duas alternativas, 
e a capacidade destas em solubilizar a resina $X$, com base no teor de resina determinado para a mistura original, de $36,5 \%$ p.

Todas as misturas solubilizaram a resina satisfatoriamente. Porém as duas misturas alternativas solubilizaram a resina $X$ mais rapidamente que a mistura original, devido ao raio de solubilidade calculado para essas serem menores, como observado na tabela 4.23. O resultado experimental obtido para a taxa de evaporação é dado na tabela 4.24 .

\begin{tabular}{|c|c|}
\hline Solvente & TER \\
\hline Mistura Original & $21,67 \pm 0,58$ \\
\hline Alternativa 1 & $27,33 \pm 1,53$ \\
\hline Alternativa 2 & $32,67 \pm 1,15$ \\
\hline
\end{tabular}

Os resultados experimentais de TER para as alternativas 1 e 2 , principalmente a alternativa 2, apresentam resultados diferentes do resultado calculado (tabela 4.23). A alternativa 2 é composta por dois solventes de taxa de evaporação relativa bastante diferentes. Um dos componentes é um solvente de rápida evaporação, enquanto que o outro é de lenta evaporação, e esta grande diferença entre as taxas de evaporação dos solventes pode ser a razão para tal desvio observado no cálculo da taxa de evaporação da mistura.

Como não se conhecem todos os parâmetros binários para calculo dos modelos de Wilson e UNIQUAC, não será possível avaliar a influência destes modelos no cálculo da taxa de evaporação das misturas. Considerar que tais misturas tenham comportamento ideal pode também ter sido a causa dos desvios observados entre os valores calculados e experimentais para a taxa de evaporação.

A tabela 4.25 apresenta os resultados obtidos para os cálculos realizados a partir de variações das restrições, servido assim como base para analisar a sensibilidade da mistura original quanto à sua otimalidade. 
Tabela 4.25 - Resultados obtidos para otimização da mistura original mantendo os mesmos componentes da mistura

\begin{tabular}{|c|c|c|c|c|c|}
\hline \multicolumn{2}{|c|}{ Variáveis } & \multirow{2}{*}{$\begin{array}{l}\text { Mistura } \\
\text { Original } \\
54,70 \% p \\
32,13 \% p \\
13,17 \% p\end{array}$} & \multirow{2}{*}{$\begin{array}{c}\text { Resultado } 1 \\
57,29 \% p \\
28,31 \% p \\
14,39 \% p\end{array}$} & \multirow{2}{*}{$\begin{array}{c}\text { Resultado } 2 \\
43,59 \% p \\
27,55 \% p \\
28,87 \% p\end{array}$} & \multirow{2}{*}{$\begin{array}{c}\text { Resultado } 3 \\
54,76 \% p \\
30,78 \% p \\
14,46 \% p\end{array}$} \\
\hline Composição & $\begin{array}{c}\text { Solvente A } \\
\text { Solvente B } \\
\text { Solvente C }\end{array}$ & & & & \\
\hline Restrições & & - & $\begin{array}{c}20 \leq \text { TER } \leq 25 \\
\mathrm{R}^{\mathrm{ijk}} \leq \mathrm{R}^{\mathrm{k}}\end{array}$ & $\begin{array}{c}20 \leq \mathrm{TER} \leq 25 \\
\mathrm{R}^{\mathrm{ijk}} \leq 0,95 \mathrm{R}^{\mathrm{k}}\end{array}$ & $\begin{array}{c}21 \leq \text { TER } \leq 23 \\
R^{i j k} \leq R^{k}\end{array}$ \\
\hline \multirow[t]{2}{*}{ Resultados } & $\begin{array}{l}\text { TER } \\
\text { (modelo } \\
\text { Ideal) } \\
\mathrm{R}^{\mathrm{IJk}}\end{array}$ & 22,10 & 25,00 & 25,00 & 23,00 \\
\hline & $\begin{array}{l}\mathrm{R}^{\mathrm{Jn}} \\
\text { Custo } \\
\text { (US\$/US\$) }\end{array}$ & $\begin{array}{l}9,80 \\
0,61\end{array}$ & $\begin{array}{c}10,02 \\
0,60\end{array}$ & $\begin{array}{l}9,52 \\
0,61\end{array}$ & $\begin{array}{l}9,93 \\
0,61\end{array}$ \\
\hline Convergência & & - & Não & Sim & Sim \\
\hline
\end{tabular}

A mistura original foi utilizada como estimativa inicial para realização dos cálculos da otimização, variando os limites das restrições. O resultado 1 atende a todas as restrições, embora não possa se garantir que a solução corresponda a um ótimo. Os resultados 2 e 3 atendem a todas as restrições e tolerâncias da programação nãolinear. A diferença entre os cálculos para obtenção dos resultados 1 e os demais está nas pequenas mudanças realizadas nos limites das restrições, comprovando a afirmativa acima.

É notório que o modelo de otimização apresentado é uma ferramenta importante no auxílio de formulação de misturas de solventes para solubilização de resinas que serão empregadas na formulação de tintas e vernizes. Porém, este tipo de modelo não exclui a necessidade de se avaliar posteriormente os resultados experimentalmente, tendo em mente que, principalmente, os modelos de evaporação não representam a realidade em todo e qualquer caso.

Devido a isso, é sugerida a seguir uma metodologia para uso do modelo de otimização de misturas de solventes. 


\subsection{Metodologia para Otimização de Misturas de Solventes}

Segue uma proposta de metodologia para substituição e identificação de misturas de solventes com base no modelo de otimização e modelos de evaporação estudados anteriormente.

- Determinar a taxa de evaporação da mistura que se quer substituir, experimentalmente ou pelos modelos de mistura RBM/DS, e diferentes modelos de coeficiente de atividade. Com base no valor encontrado, calcular a taxa de evaporação relativa da mistura (TER) e determinar uma faixa de TER que seja aceitável para a nova mistura;

- Identificar os parâmetros e raio de solubilidade da resina ou polímero que se pretende solubilizar com a mistura de solventes;

- Selecionar um grupo de solventes que apresente características de evaporação e solubilidade variadas a fim de satisfazer as restrições impostas com base no solvente ou na mistura que se quer substituir;

- Conhecer as seguintes propriedades dos solventes selecionados: preço ou custo, densidade, taxa de evaporação relativa, parâmetros de solubilidade e peso molecular;

- A escolha do modelo para cálculo do coeficiente de atividade das misturas está diretamente ligada com a disponibilidade dos parâmetros binários dos solventes. Caso não sejam conhecidos os parâmetros binários para cálculo dos modelos UNIFAC e de Wilson, calcular a taxa de evaporação com coeficiente de mistura ideal $\left(\gamma_{i}=1\right)$;

- Inserir os solventes e suas propriedades, e as restrições de TER e parâmetros de solubilidade no código fonte da programação de otimização;

- Com base no conhecimento prévio, estimar uma composição inicial, para cálculo da composição otimizada. Rodar a programação.

- Se houver solução viável e todas as restrições forem satisfeitas, validar os resultados experimentalmente, confirmando a taxa de evaporação pela taxa de evaporação experimental determinada de acordo com a norma ASTM D3539 e a solubilização da resina ou polímero; 
- Se não houver solução viável, realimentar o programa com uma nova composição inicial ou com a composição final que foi obtida, e seguir passos anteriores, até que se confirme convergência do programa de otimização.

- Caso a taxa de evaporação determinada experimentalmente seja muito diferente da que foi calculada, verificar qual dos modelos de taxa de evaporação de mistura (WE, RBM, DS) e qual modelo de coeficiente de atividade (Solução Regular, UNIQUAC e Wilson) melhor representam a mistura obtida, e recalcular a mistura otimizada com base nestes modelos, tendo como estimativa inicial a própria composição otimizada. Se houver variações significativas entre as duas composições avaliadas, reavaliar experimentalmente a taxa de evaporação e capacidade de solubilização da resina ou polímero pela mistura de solventes otimizada. 


\section{CONCLUSÕES E SUGESTÕES}

O processo de evaporação que ocorre no evaporômetro está diretamente relacionado com a pressão de vapor do solvente. Devido a isso, a equação de De Heen (2.16) apresentou o melhor resultado para os diversos solventes avaliados, principalmente para aqueles com pressão de vapor entre $0,136 \mathrm{mmHg}$ e 28,456 $\mathrm{mmHg}$. Os solventes considerados de mais rápida evaporação, que são aqueles de maior pressão de vapor, são os que apresentaram maior desvio, embora também se observem grandes variações para solventes dentro da faixa de pressão de vapor apresentada. Isso mostra que estas equações para cálculo da taxa de evaporação relativa não substituem o método experimental e devem ser utilizadas com muito cuidado, pois podem incorrer em grandes erros.

Como não há uma equação ou modelo capaz de prever adequadamente a taxa de evaporação de um solvente, as taxas de evaporação das misturas são então dependentes das taxas de evaporação dos solventes determinadas experimentalmente, de acordo com o método do evaporômetro, a ASTM D3539. Três foram os modelos avaliados com apenas algumas pequenas diferenças entre eles. O fator de correção de temperatura apresentado pelo modelo de Rocklin e Bonner não garantiu melhores resultados quando comparado com os outros dois modelos.

Os modelos de evaporação de misturas de Rocklin e Bonner (RB) e Dillon e Stratta (DS) também possuem diferentes fatores de correção de umidade relativa para a componente água na composição da mistura de solventes. Foi observado que, para baixas condições de umidade relativa pela norma ASTM D3539, ou seja, abaixo de $5 \%$, ambos os fatores não resultam em melhora significativa. Porém, à medida que se aumenta a umidade relativa do ambiente, estes fatores de correção se tornam importantes - não se podendo afirmar, entretanto, que um dos modelos seja superior ao outro. Também foi observado que as curvas de evaporação de misturas contendo água como componente e calculadas com o modelo de Wilson apresentaram os resultados mais distantes dos valores observados experimentalmente. Isso mostra 
que, este modelo de coeficiente de atividade não é adequado para prever a nãoidealidade da mistura no processo de evaporação contendo água, pois em algum momento durante a evaporação, a mistura líquida água-solventes apresentará problemas de imiscibilidade, para tal situação a equação de Wilson não é adequada (REID; PRAUSNITZ; POLING, 1987).

Para as condições determinadas de acordo com a ASTM D3539, portanto não são necessários os fatores de correção de temperatura e umidade.

Os principais desvios observados entre as taxas de evaporação determinadas experimentalmente e calculadas foram encontrados nas misturas onde seus componentes apresentam taxas de evaporação relativas (TER) muito distintas. Para estes casos, tanto os modelos de evaporação de mistura como os diferentes modelos de coeficiente de atividade falharam em tentar representar a curva de evaporação obtida experimentalmente.

Em geral, os modelos de evaporação de misturas RBM e DS, que são idênticos quando desprovidos dos fatores de correção de temperatura e umidade, são os que apresentaram os melhores resultados mais freqüentemente, quando associados também à equação UNIQUAC para cálculo do coeficiente de atividade. Vale ressaltar que este é um dos únicos trabalhos em que foram avaliados simultaneamente diferentes modelos de evaporação de mistura e modelos de coeficiente de atividade.

A programação não-linear utilizada para cálculo da mistura de solventes otimizada, por meio do Computer-Aided Mixture/Blend Design, mostrou-se uma importante ferramenta para uso do dia-a-dia na substituição de solventes e misturas, garantindo economia de tempo e recursos. A principal deficiência nesta ferramenta é o modelo para cálculo da taxa de evaporação, que pode apresentar resultados diferentes do que se obtém experimentalmente.

Para trabalhos futuros, pode-se avaliar melhor a influência de outros modelos para cálculo dos coeficientes de atividade, bem como a influência dos parâmetros destas 
equações determinados para as condições de equilíbrio líquido-vapor de acordo com a ASTM D3539, no cálculo da taxa de evaporação de misturas.

Outras variáveis também podem ser incorporadas no modelo para cálculo otimizado de mistura, como a viscosidade final da mistura solventes e resina (ou polímero), que é também informação importante para a formulação de tintas e vernizes.

É interessante também definir concentrações mínimas admissíveis de cada solvente da mistura como uma restrição, com o auxílio de variáveis binárias. Assim, evita-se que sejam apresentados valores de composição muito baixos para um determinado componente.

Além disso, pode-se incorporar ou substituir a função objetivo Custo, com outras funções referentes a periculosidade do solvente ao homem e ao meio ambiente, como VOC - Volatile Organic Compound, coeficiente de partição, TLV - Threshold Limit Value, biodegradabilidade, etc. 


\section{REFERÊNCIAS BIBLIOGRÁFICAS}

ACHENIE, L. E. K.; SINHA, M. The design of blanket wash solvents with environmental considerations. Advances in Environmental Research, v. 8, p. 213227, 2003.

AMERICAN SOCIETY FOR TESTING AND MATERIALS. ASTM D3539: Standard Test Methods for Evaporation Rates of Volatile Liquids by Shell Thin-Film Evaporometer, 1981.

$\mathrm{AVCl}, \mathrm{A}$.; CAN, M. The analysis of the drying process on unsteady forced convection in thin films of ink. Applied Thermal Engineering, v. 19, p. 641-657, 1999.

AVCI, A.; CAN, M.; ETEMOGLU, A. B. A theoretical approach to the drying process of thin film layers. Applied Thermal Engineering, v. 21, p. 465-479, 2001.

BARRY, J. Estimating rates of spreading and evaporation of volatile liquids. Chemical Engineering Progress, v. 101, n. 1, p. 32-39, 2005.

BARTON, A. F. M. Handbook of solubility parameters and other cohesion parameters. Boca Raton: CRC Press, 1983.

CARY, J. D.; GUTOFF, E. B. Analyze the dying of aqueous coatings. Chemical Engineering Progress, Feb., p. 73-79, 1991.

CASTELLS, R. C.; CASELLA, M. L. Evaporation rates of solvent blends measured by gas chromatography. Journal of Chromatography, v. 402, p. 65-72, 1987.

CASTELLS, R. C.; CASELLA, M. L.; NARDILLO, A. M. Gas chromatographic study of the evaporation from films composed of a volatile solvent plus a nonvolatile, nonpolymeric liquid. Industrial \& Engineering Chemical Research, v. 28, n.8, p. 1236-41, 1989.

CREMASSO, M. A. Fundamentos de transferência de massa. Campinas: Editora da Unicamp, 2002. 
CUSSLER, E. L.; MOGGRIDE, G. D. Chemical product design. USA: Cambridge University Press, 2001.

DEAN, J. A. Lange's handbook of chemistry. New York: McGraw-Hill, 1985.

DILLON, P. W. Application of critical relative humidity, an evaporation analog of azeotropy, to the drying of water-borne coatings. Journal of Coatings Technology, v.49, n. 634, p. 38-49, 1977.

GMEHLING, J.; ONKEN, U.; ARLT, W. Vapor-Liquid Equilibrium Data Collection. Frankfurt/Main: Dechema,1979-.

DOOLITTLE, A. K. Lacquer solvents in commercial use. Industrial and Engineering Chemistry, v. 27, p. 1169, 1935.

ESBENSEN, K.H. Multivariate data analysis: in practice. 5th ed. Oslo: CAMO Software AS, 2006.

ETEMOGLU, A. B.; CAN, M.; AVCl, A.; PULAT, E. Theoretical study of combined heat and mass transfer process during paper drying. Heat Mass Transfer, v. 41, p. 419-427, 2005.

FULLER, E. N.; SCHETTLER, P. D.; GIDDINGS, J. C. A new method for prediction of binary gas-phase diffusion coefficients. Industrial and Engineering Chemistry, v. 58, p. 18-27, 1966.

GANI, R. Chemical Product Design: challenges and opportunities. Computers and Chemical Engineering, v. 28, p. 2441-2457, $2004 a$.

GANI, R. Computer-aided methods and tools for chemical product design. Chemical Engineering Research and Design, v. 82, p.1494-1504, 2004b.

GARBELOTTO, P.; RIZZATO, A.; LEITE, A. C.; SCHUCH, C. M.; ZIM, D.; VICENTIM, D. J.; RODRIGUES, E. L.; MARRA, F.; ZANATTA, F.; SANTOS, H.; SANTOS, L.; COUTO, M. L. T.; DE NADAI, R.; MARTINS, S. Solventes Industriais: seleção, formulação e aplicação. São Paulo: Editora Blucher, 2007.

GARDNER, G. S. Evaporative index. Industrial and Engineering Chemistry, v. 32, n. 2, p. 226-231, 1940. 
GILBERT, T. E. Rate of evaporation of liquids into air. Jounal of Paint Technology, v. 43 n. 562, p. 93-97, 1971.

GILLILAND, E. R.; SHERWOOD, T. K. Diffusion of vapors into air streams. Industrial and Engineering Chemistry, v. 26, n. 5, p. 516-523, 1934.

GILLILAND, E. R. Diffusion coefficients in gaseous system. Industrial and Engineering Chemistry, v. 26 (6), p. 681-685, 1934.

GUTOFF, E. B. Modeling the Drying of Solvent Coatings on Continuous Webs. Journal of Imaging Science and Technology, v. 38, n. 2, p. 184 - 192, 1994.

HANSEN, C. M. $\mathbf{5 0}$ years with solubility parameters - past and future. Progress in Organic Coatings, v. 51, p. 77-84, 2004.

HARDISTY, H. Analysis of the constant-rate period of ink drying. Journal of Oil and Colour Chemists' Association, v. 60, p. 479-487, 1977.

HIRSCHFELDER, J. O.;BIRD, R. B.; SPOTZ, E. L. The transport properties of gases and gaseous mixtures. Chemical Reviews, v. 44, p. 205, 1949.

KLEIN, J. A.; WU, D. T.; GANI, R. Computer aided mixture design with specified property constraints. Computers \& Chemical Engineering, v. 16, p. 229-236, 1992.

LINAK, E. Green Solvents - Safe \& Sustainable Chemicals Report. SRI Consulting, 2006.

MARTIN, $\mathrm{H}$. Heat and mass transfer between impinging gas jets and solid surfaces. Advanced Heat Transfer, v. 13, p. 1-60, 1977.

OLIVEIRA, S. A. Evaporação de mistura de solventes. Dissertação de Mestrado. Campinas, SP: UNICAMP, 1992.

PERRY, R. H.; CHILTON, C. H. Manual de engenharia química. 5a Edição. Rio de Janeiro: Guanabara Dois, 1980. 
PIEROTTI, G. J.; DEAL, C. A.; DERR, E. L. Activity coefficients and molecular structure. Industrial \& Engineering Chemistry, 51, p. 95-102, 1959.

PINTO, J.M.; GUT, J.A.W. Otimização de processos químicos.: Apostila do curso PQI5779 - Otimização de Processos Químicos I. Universidade de São Paulo, São Paulo, 2005.

PRAUSNITZ, J. M.; LICHTENTHALER, R. N.; AZEVEDO, E. G. Molecular thermodynamics of fluid-phase equilibria. Prentice Hall PTR, 1999.

REID, R. C.; PRAUSNITZ, J. M.; SHERWOOD, T. K. The properties of gases \& liquids. $3^{\text {a }}$ Edição. Nova York: McGraw-Hill, 1977.

REID, R. C.; PRAUSNITZ, J. M.; POLING, B. The properties of gases \& liquids. $4^{a}$ Edição. Nova York: McGraw-Hill, 1988.

ROCKLIN, A. L.. Evaporation Phenomena: precise comparison of solvent evaporation rates from different substrates. Journal of Coatings Technology, $v$. 48, n. 622, p. 45-57, 1976.

ROCKLIN, A. L.. Effect of humidity and other ambient conditions on evaporation of ternary aqueous solvent blends. Journal of Coatings Technology, v. 50 (646), p. 46-55, 1978.

ROCKLIN, A. L.. Computer methods for finding solvent blend replacements and for predicting water/cosolvent evaporation at any humidity. ACS Symposium Series, p. 427-437, 1982.

ROCKLIN, A. L.; BONNER, D. C.. A computer method for predicting evaporation of multicomponent aqueous solvent blends at any humidity. Journal of Coatings Technology, v.52, n. 670, p. 27-36, 1980.

SAARY, Z.; GOFF, P. L. New instrument to measure solvent evaporation. Journal of Paint Technology, v. 45, n. 583, p. 45-55, 1973.

SANDLER, S. I. Chemical and Engineering Thermodynamics. $3^{\text {a }}$ Edição. New York: John Wiley \& Sons, Inc., 1999. 
SHERWOOD, T. K. The drying of solids. Industrial and Engineering Chemistry, v. 21, n. 1, p. 12-16, 1929.

SLETMOE, G. M. The calculation of mixed hydrocarbon-oxygenated solvent evaporation. Journal of Paint Technology, v. 42, n. 543, p. 246-259, 1970.

SLETMOE, G. M.. The evaporation of nonhydrogen-bonding solvents from resin films. Journal of Paint Technology, v. 38, n. 502, p. 642-655, 1966.

STRATA, J. J.; DILLON, P. W.; SEMP, R. H. Evaporation of organic cosolvents from water-borne formulations. Journal of Coatings Technology, v.50, n. 647, p. 39-47, 1978.

VENCESLAU, E. B.; PESSOA FILHO, P. A.; LE ROUX, G. A. Estudo de modelos de evaporação para misturas de solventes. In: XVIII Congresso Brasileiro de Engenharia Química e V Congresso Brasileiro de Termodinâmica Aplicada, 2010, Foz do Iguaçu. Anais, 2010. v. 1. p. 1-10.

WALAS, S. M. Phase equilibria in chemical engineering. Stoneham: Butterworth Publishers, 1984.

WALSHAM, J. G., EDWARDS, G. D. A model of evaporation from solvent blends. Journal of Paint Technology, v.43, n. 554, p. 64-70, 1971.

WEAST, R. C. CRC Handbook of chemistry and physics. Boca Raton, Florida: CRC Press, 1983-1984.

WISE, B.M.; GALLAGHER, N.B.; BRO, R.; SHAVER, J.M. PLS toolbox 3.0. Manson: Eigenvector Research, Inc., 2003.

$<$ http://www.abiquim.com.br >. Acesso em: 2009.

YAWS, C. L. Chemical properties handbook. New York: McGraw-Hill, 1999. 


\title{
APÊNDICE A - Artigo publicado no XVIII Congresso Brasileiro de Engenharia Química
}

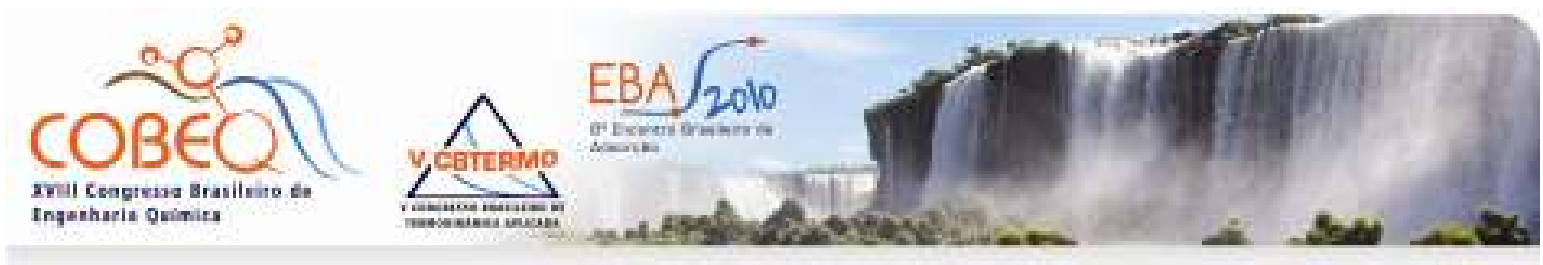

\section{ESTUDO DE MODELOS DE EVAPORAÇÃO PARA MISTURA DE SOLVENTES}

\author{
E. B. VENCESLAU ${ }^{1,2}$, P. A. PESSÔA FILHO ${ }^{2}$ e G. A. C. LE ROUX ${ }^{2}$ \\ ${ }^{1}$ Oxiteno S/A Ind. e Comércio \\ e-mail: emerson.venceslau@oxiteno.com.br \\ ${ }^{2}$ Escola Politécnica da Universidade de São Paulo, Departamento de Engenharia \\ Química \\ e-mail: galoroux@usp.br
}

RESUMO - O mercado de tintas e vernizes é um dos maiores demandantes de solventes. Dentre as várias propriedades necessárias de um solvente para estas aplicações, a taxa de evaporação é de extrema importância no mecanismo de formação de filme, que se reflete no aspecto final do revestimento. Durante a etapa de secagem de um filme, a taxa de evaporação tem um dos papéis mais importantes, e pode ser descrita em dois estágios. No primeiro estágio a resistência à evaporação se deve à difusão das moléculas de solventes através de uma fina camada de ar acima da superfície do filme, que responde por cerca de $80-90 \%$ de todo o solvente evaporado do sistema. No segundo estágio, quando a concentração da resina é maior, a taxa de evaporação é controlada pela taxa de difusão das moléculas do solvente através do filme. Como simplificação, em geral, mede-se a taxa de evaporação apenas para o primeiro estágio, que é determinada experimentalmente através do método do evaporômetro de filme fino (ASTM D 3539). Neste trabalho apresentamos um modelo para determinação da taxa de evaporação, que permite o cálculo, além da variação da massa total evaporada, da variação de composição da mistura. O modelo foi validado para vários sistemas de interesse industrial.

PALAVRAS-CHAVE: modelagem matemática, solvente, taxa de evaporação 


\section{INTRODUÇÃO}

Atualmente, o mercado de solventes cresce, em média, nas mesmas taxas do PIB mundial. Os solventes oxigenados crescem a taxas duas vezes maiores do que o PIB, e os chamados "verdes", quatro vezes. Entre os anos de 2005 e 2007, a demanda global de solventes foi da ordem de 20 milhões de toneladas por ano, tendo a América do Norte e Europa como líderes no consumo (cerca de 4-5 milhões de toneladas por ano, cada), seguido por China (4 milhões de toneladas) e Japão (2 milhões de toneladas) (Linak, 2006). Estas quantidades apresentadas são apenas uma estimativa do mercado, tendo em vista a magnitude e pulverização desta indústria, que possui diversos produtos, produtores e usuários. Dentre os produtores, as multinacionais respondem por mais de $50 \%$ em volume da produção mundial de solventes (Linak, 2006). Dos solventes produzidos mundialmente, $70 \%$ são oxigenados. No Brasil, os principais produtores são: Oxiteno, Rhodia, Cloroetil, Butilamil, Elekeiroz e usinas de álcool (Abiquim, 2009). Segundo Linak (2006), cerca de 40$50 \%$ do mercado de solvente é utilizado na formulação de tintas e vernizes.

Embora o mercado de solventes se mostre crescente, de forma contraditória, o mesmo apresenta uma tendência de redução, explicada pela pressão das regulamentações para redução das emissões. Como agravante, a maioria dos solventes é considerada como composto orgânico volátil (VOC - volatile organic compound), que contribui para formação da névoa atmosférica mais baixa em áreas urbanas, conhecida como smog. Além de muitos deles serem potencias causadores de problemas de saúde, se não manipulados corretamente. Com isso, tem-se estudado novos compostos considerados "verdes" (solventes "verdes"), para substituição dos solventes tradicionais.

Ao se escolher os solventes, algumas propriedades precisam ser levadas em consideração para as suas várias aplicações. Na aplicação em tintas e vernizes base-solvente, os solventes apresentam algumas funções específicas (Linak, 2006):

- Solubilização da resina ou do polímero, formando a fase contínua do revestimento;

- Molhabilidade do pigmento, que possibilita o revestimento das partículas de pigmento pela resina;

- Redução/ajuste da viscosidade para facilitar a aplicação e fornecimento;

- Controle do processo de secagem por meio da evaporação, e auxilia na formação do filme (alastramento);

- $\quad$ Promoção de adesão;

- Realce de brilho.

Os revestimentos base-água também possuem solventes orgânicos em sua formulação, pois estes desenvolvem algumas funções importantes: coalescência e estabilização em estocagem sob baixas temperaturas.

Nestas aplicações, o solvente possui papel importante na qualidade do filme formado, e sua taxa de evaporação é uma propriedade extremamente importante para o balanceamento correto da formulação de tintas e vernizes. É dessa propriedade que depende a velocidade de secagem, determinando o ponto de equilíbrio na aplicação, para evitar o 
escorrimento da tinta se muito lento, porém o suficiente para garantir 0 nivelamento e adesão do filme formado ao substrato. Além disso, pode-se evitar o esbranquiçamento da superfície da tinta, efeito conhecido como blushing, que é causado pela absorção de água, devido ao resfriamento pronunciado na evaporação de solventes mais voláteis.

A taxa de evaporação relativa é definida experimentalmente de acordo com a norma ASTM D 3539, que é a metodologia mais empregada. $A$ utilização desta norma não é complexa, porém para determinação da curva de evaporação, é necessário condicionar um equipamento específico chamado de evaporômetro, que exige um longo período de preparação, seguido do tratamento dos dados. Além disso, no uso de misturas de solventes (blends), obtémse apenas a curva de evaporação total, de toda a mistura, desconhecendo a variação da concentração dos componentes da mistura ao longo do período de evaporação. Estas informações são essenciais para entender o mecanismo de formação do filme e solubilidade da resina ao longo da secagem.

Este trabalho tem como objetivo estudar modelos matemáticos para a evaporação de mistura de solventes, simulando então a curva de evaporação e predizendo a concentração dos componentes da mistura ao longo do tempo de evaporação, permitindo predizer o processo experimental determinado pela norma ASTM D 3539.

\section{MATERIAIS E MÉTODOS}

\subsection{Materiais}

Para obtenção das curvas de evaporação experimentais foi utilizado o método ASTM D 3539, que faz uso do equipamento conhecido como evaporômetro ou ainda Shell Thin Film Evaporometer (Figura 1). O evaporômetro consiste de um sistema de duas cabines, interna e externa, para a determinação da curva de evaporação. Esta estrutura visa proporcionar o controle das variáveis: temperatura $-25,0 \pm 0,5^{\circ} \mathrm{C}$, umidade (fluxo de nitrogênio ou ar seco) - 0$5 \%$, e fluxo de ar -21 L. $\mathrm{min}^{-1}$. A amostra de solvente ou mistura de solventes é aplicada sobre um papel de filtro que fica suspenso em uma estrutura de arame preso a uma balança. Depois de atingida as condições determinadas pelo método, $0,7 \mathrm{~mL}$ de amostra (condicionada a $25 \pm 0,50^{\circ} \mathrm{C}$ ) é aplicada com auxílio de uma seringa sob o papel de filtro, através de um orifício de borracha na lateral direita do equipamento. A perda de massa é então medida e registrada no registrador para posterior avaliação e tratamento dos dados.

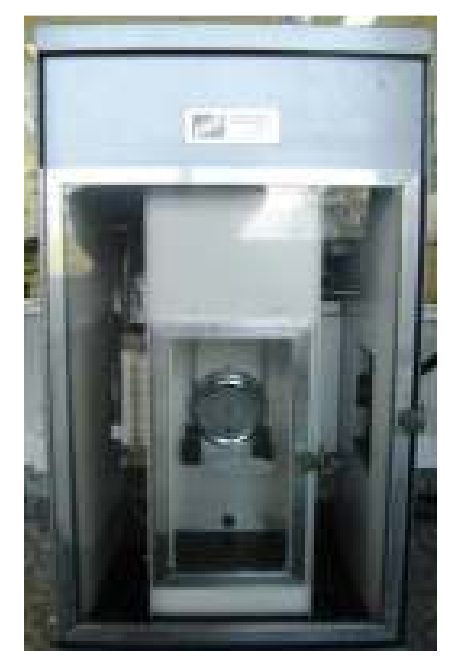

Figura 1 - Evaporômetro de Filme Fino

Antes de qualquer medição, o evaporômetro precisa ser padronizado com acetato de n-butila (99\%), e este deve apresentar uma taxa de 
evaporação em $90 \%$ de $470 \pm 10 \mathrm{seg}$. Se o tempo de evaporação estiver fora desta faixa, alguns ajustes podem ser feitos na injeção de ar. $O$ resultado final deste teste é apresentado em um gráfico onde se apresenta a perda de massa líquida em relação ao tempo. A taxa de evaporação relativa (TER) é calculada pela razão entre o tempo necessário para evaporar $90 \%$ do acetato de n-butila e o tempo necessário para evaporar $90 \%$ do solvente em avaliação, multiplicado por 100. Desta forma, o acetato de nbutila possui taxa de evaporação relativa de 100 , enquanto que os mais voláteis possuem valores maiores que 100 , e os menos voláteis, valores menores que 100.

Para este estudo, foram escolhidas aleatoriamente misturas de solventes que pudessem representar algumas opções utilizadas industrialmente no mercado de tintas e vernizes. As curvas de evaporação experimentais foram todas realizadas em duplicata. Com base nos dados experimentais e calculados, foram construídos gráficos comparativos. Às curvas obtidas experimentalmente foram adicionadas barras de erro, com base no valor de um desvio padrão para cima e para baixo a partir do valor médio do tempo de cada medida.

Para desenvolvimento deste trabalho, foram utilizados solventes de grau industrial, com baixo teor de umidade. A tabela 1 apresenta a composição das misturas de solventes realizadas.
Tabela 1 - Composição mássica (\%p) das misturas de solventes

\begin{tabular}{|l|c|c|c|c|c|c|}
\hline \multirow{2}{*}{ Componentes } & \multicolumn{7}{|c|}{ Misturas } \\
\cline { 2 - 7 } & $\mathbf{1}$ & $\mathbf{2}$ & $\mathbf{3}$ & $\mathbf{4}$ & $\mathbf{5}$ & $\mathbf{6}$ \\
\hline Acetato de n-butila & & & 25 & & & \\
\hline Acetato de sec-Butila & 20 & 15 & $\mathbf{2 5}$ & $\mathbf{9}$ & & \\
\hline Acetato Isopentila & & & & & 30 & 30 \\
\hline Água & & & & & & 2,5 \\
\hline Butilglicol & & & & & 20 & 20 \\
\hline Ciclohexano & & & & 68 & & \\
\hline Etanol & 60 & 55 & & & & \\
\hline Metiletilcetona & & & & 23 & 50 & 47,5 \\
\hline Metilpropilenoglicol & & 2 & & & & \\
\hline Sec-butanol & 20 & 28 & & & & \\
\hline Xileno & & & 50 & & & \\
\hline
\end{tabular}

Os modelos foram avaliados em Matlab R2007b, da Mathworks, Inc.

A taxa de evaporação relativa de cada solvente foi determinada de acordo com a metodologia da norma ASTM D 3539. As demais propriedades foram obtidas a partir de dados de literatura referenciados.

\subsection{Modelos de mistura}

Conforme apresentado na introdução, a escolha do solvente ou da mistura de solventes adequada para a formulação de tintas e vernizes é de extrema importância, visando sua melhor compatibilidade com a(s) resina(s) a serem utilizadas. Dentre as importantes propriedades a serem avaliadas, a taxa de evaporação possui um papel de grande importância na aparência final do revestimento aplicado, pois contribui para o mecanismo de formação de filme.

O processo de formação de um filme leva em consideração três etapas fundamentais (Garbelotto et al., 2007):

- $\quad$ Aplicação: nesta etapa o solvente regula a viscosidade da solução 
de resina, que determina o tipo de aplicação a ser empregada;

- Fixação: o solvente possui a função de garantir uma boa aderência da resina na superfície e também a formação de uma camada uniforme;

- Secagem: é nesta etapa que a taxa de evaporação parece ter um dos papéis mais importantes. O solvente precisa evaporar completamente após a solubilização da resina de tal forma que as cadeias poliméricas formem uma camada homogênea, uniforme e durável, garantindo a formação de um filme de boa aparência.

Esta etapa de secagem ocorre em dois estágios (Garbelotto et al., 2007; Saary e Goff, 1973):

- Inicialmente, a perda de solvente do filme ocorre devido à pressão parcial do solvente. O solvente consegue passar através da barreira sólida (resina) rapidamente, mantendo a condição de equilíbrio livre na superfície, e assim evapora a uma taxa constante. Neste caso, a resistência à evaporação se deve à difusão das moléculas de solventes através de uma fina camada de ar acima da superfície do filme. Assim, a taxa de evaporação nesta etapa é controlada pelo que foi conhecido de mecanismo de barreira de superfície (Surface Barrier) - (Sletmoe, 1970).

- No segundo estágio, quando a concentração da resina é maior, a taxa de evaporação é controlada pela taxa de difusão das moléculas do solvente através do filme, até a superfície. Este estágio é reportado como o mais lento, e muitos autores reportam que este só é alcançado quando cerca de $80 \%$ do solvente foi evaporado. Para Sletmoe (1970), os efeitos da resina se tornam importantes, ou seja, a difusão através do filme da resina, durante a evaporação dos últimos $10 \%$ de solvente. Neste estágio, segundo Garbelotto et al. (2007), a predição dos coeficientes de difusão é muito mais difícil, e por isso os modelos de evaporação desconsideram este estágio numa primeira aproximação.

A taxa de evaporação é também bastante dependente da área superficial, da transferência de massa e de calor disponível para a evaporação, inclusive do método de aplicação da tinta ou verniz, o qual é difícil de estimar. Assim, parâmetros como temperatura, umidade e fluxo de ar desempenham um papel importante na determinação da taxa de evaporação. Estimar o caso real de evaporação na aplicação de uma tinta, como se pode observar, é extremamente complexo. Por isso, os formuladores caracterizam a evaporação de um solvente por meio do método do evaporador de um filme fino (ASTM D 3539).

Um fator importante para a taxa de evaporação é o meio, ou a superfície de onde se evapora o líquido em questão. De acordo com um trabalho apresentado por Sletmoe em 1966, para um determinado grupo de solventes estudado, a taxa de evaporação média foi $6 \%$ mais rápida quando determinada a partir de uma superfície metálica em relação àquela determinada a partir de um papel de filtro. Rocklin (1980 e 1982) também 
observou que a umidade prolongava o tempo de secagem e distorcia a ordem de evaporação para sistemas baseágua. Já as pequenas variações no fluxo de ar eram consideradas de pouca significância.

Segundo John G. Walsham e Granville D. Edwards (1971), e conforme se pode observar experimentalmente, para a maioria dos solventes puros a evaporação é um processo linear ao longo de quase todo o tempo de evaporação. Contudo, para misturas de solventes o processo de evaporação possui uma curvatura evidente. Assumindo que a evaporação de um solvente puro apresenta linearidade nos $90 \%$ em massa iniciais evaporados.

Com base nisso, Walsham e Edwards (1971) descreveram que a força motriz para evaporação é o gradiente de pressão parcial que existe entre as fases líquido e vapor, e portanto, a taxa de evaporação deve ser assumida como proporcional à pressão de vapor do solvente.

Para misturas de solventes, a taxa de evaporação total é igual à soma das taxas de evaporação dos componentes individuais. Todavia, como comentado acima, para mistura de solventes não se observa um comportamento ideal, linear, apenas em caso onde os componentes da mistura sejam similares em tamanho molecular e estrutura. Assim, para uma mistura de $\mathrm{n}$ componentes, ideal ou não, a taxa de evaporação é definida como apresentado abaixo: $\gamma_{\mathrm{n}} \mathrm{w}_{\mathrm{n}} \mathrm{r}_{\mathrm{n}}^{\mathrm{o}}$

$$
\mathrm{R}=\gamma_{1} \mathrm{w}_{1} \mathrm{r}_{1}^{\mathrm{o}}+\gamma_{2} \mathrm{w}_{2} \mathrm{r}_{2}^{\mathrm{o}}+\cdots+
$$

Nesta equação, a fração molar foi substituída pela fração mássica por conveniência numérica.
Rocklin e Bonner (1980), e Rocklin (1982) publicaram trabalhos para a predição do comportamento de evaporação para sistemas de solventes onde a água estivesse presente como um componente, e onde a umidade fosse levada em consideração, pois em trabalhos anteriores já se falava da sua relevância. Segundo eles, o trabalho apresentado por Walsham e Edwards (1971) foi bem sucedido para misturas de solventes orgânicos, mas não para misturas aquosas.

O modelo proposto acima parte da premissa de que todas as taxas de evaporação para o solvente puro foram determinadas experimentalmente respeitando as condições de umidade, temperatura e fluxo de ar definidas pela metodologia da ASTM D 3539.

Neles também não se considera eventuais variações na temperatura da superfície relacionadas ao fenômeno de secagem.

\subsection{Coeficiente de Atividade}

Nos modelos apresentados acima, quanto mais a mistura de solventes se aproxima da idealidade, mais o valor de gama $\left(\gamma_{i}\right)$, coeficiente de atividade, se aproxima do valor 1 . Existe uma grande variedade de modelos para calcular o coeficiente de atividade. Um dos modelos mais simples é conhecido como solução regular e foi desenvolvido por Hildebrand e Scatchard a partir da teoria de soluções de Van Laar (Prausnitz et al., 1999). O coeficiente de atividade é definido de acordo com a equação 2 :

$$
R T \ln \gamma_{\mathrm{i}}=v_{i}\left(\delta_{i}-\sum_{j}^{m} \Phi_{\mathrm{j}} \delta_{j}\right)
$$


Este é um modelo bastante interessante para se estudar devido à sua simplicidade, já que depende apenas de parâmetros disponíveis: volume molar, fração molar e parâmetro de solubilidade dos solventes (Barton, 1983).

\section{RESULTADOS DISCUSSÕES}

Com base nas equações 1 e 2, foi elaborada uma programação utilizando o software Matlab para calcular a evaporação das misturas de solventes propostas. Basicamente, 0 programa consiste na resolução de um sistema de equações diferenciais, de acordo com a equação 3 :

$$
\frac{d m_{i}}{d t}=-\mathrm{w}_{\mathrm{i}}\left(\mathrm{m}_{\mathrm{i}}, \mathrm{t}\right) \gamma_{\mathrm{i}}(\mathrm{t}, \mathrm{T}) \mathrm{r}_{\mathrm{i}}^{0}
$$

Quando a água é um dos componentes da mistura, a equação 3 apenas para a componente água é multiplicada por um fator de correção linear dependente da umidade relativa: (1-RH/100), seguindo 0 que foi proposto por Walsham e Edwards (1971).

Para cada mistura foi calculado o RMSE - root mean square error, ou seja, o erro médio quadrado, de acordo com a equação 4.

RMSE

$=\sqrt{\sum \frac{\left(\% m_{\text {evap }}(t)^{\text {exper. }}-\% m_{\text {evap }}(t)^{c a l c .}\right)^{2}}{n}}$

A seguir são apresentadas as curvas elaboradas a partir de resultados experimentais e calculados a partir dos modelos para cada mistura. As misturas estão listadas na tabela 1.

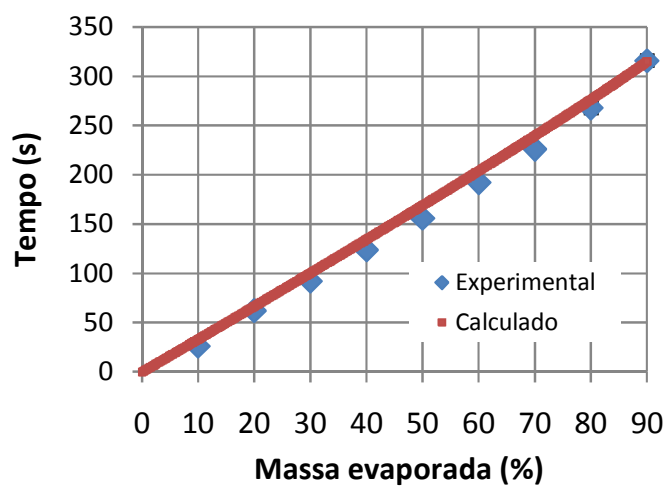

Figura 2 - Curva de Evaporação da mistura 1

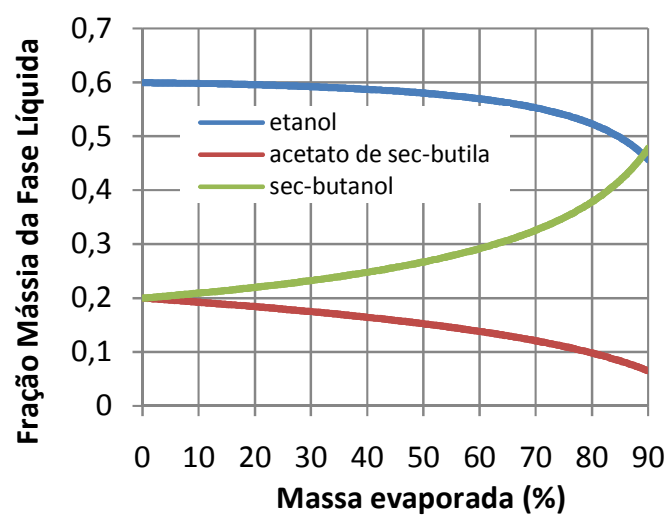

Figura 3 - Curva de composição predita para a evaporação da mistura 1

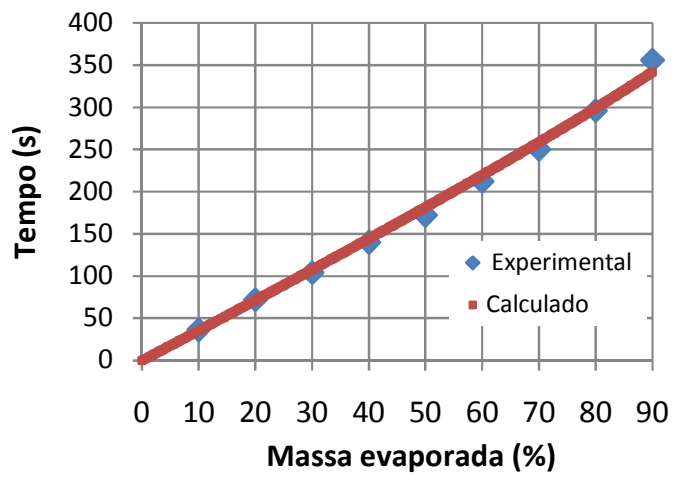

Figura 4 - Curva de evaporação da mistura 2 


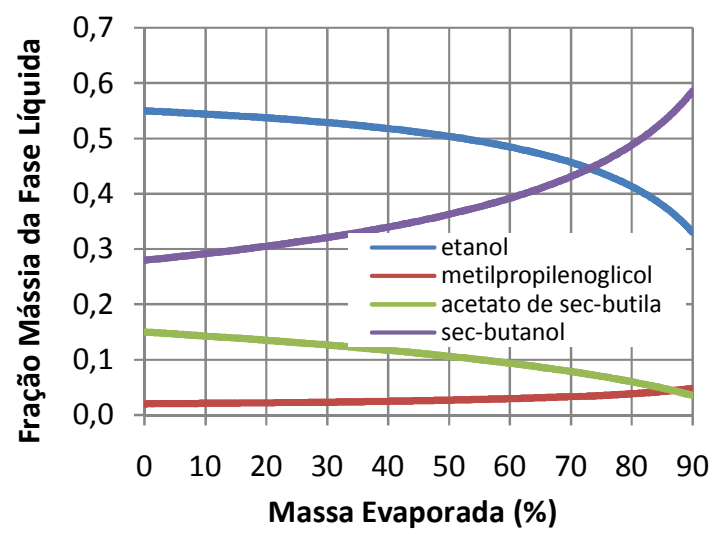

Figura 5 - Curva de composição predita para a evaporação da mistura 2

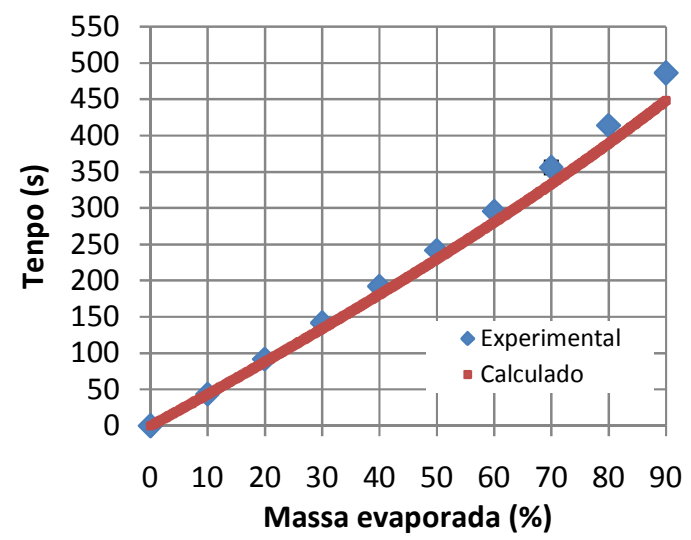

Figura 6 - Curva de evaporação da mistura 3

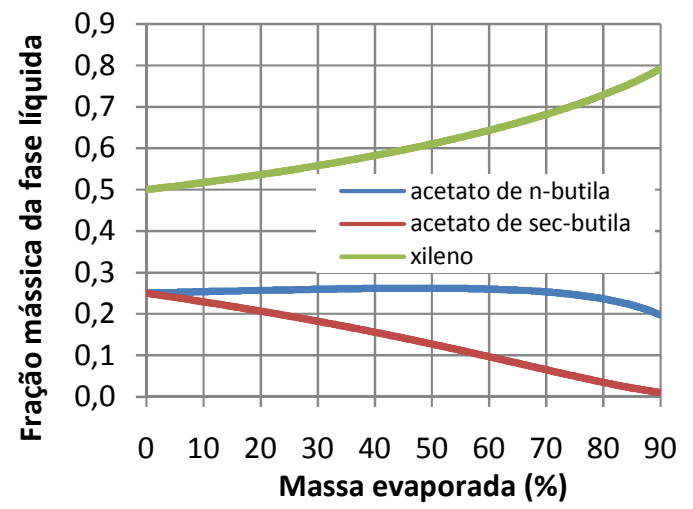

Figura 7 - Curva de composição predita para a evaporação da mistura

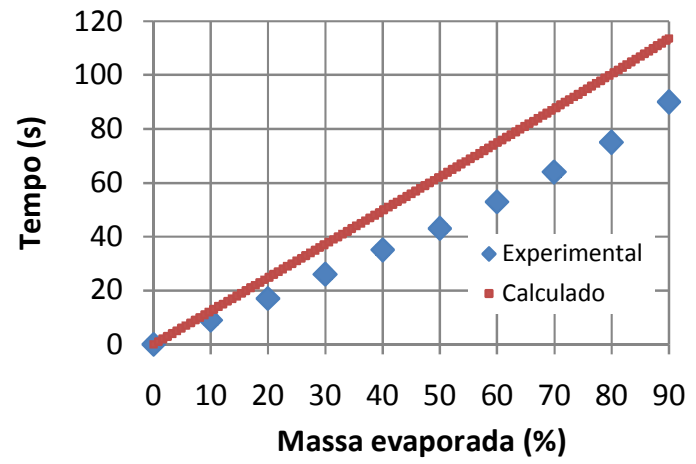

Figura 8 - Curva de evaporação da mistura 4

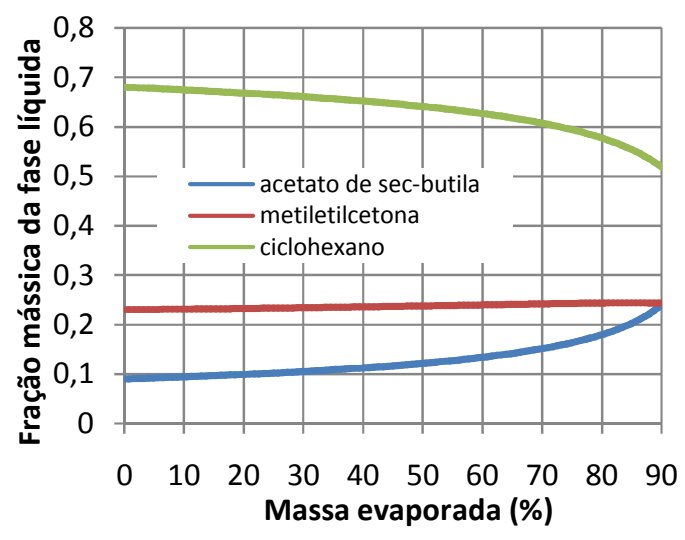

Figura 9 - Curva de composição predita para a evaporação da mistura 4

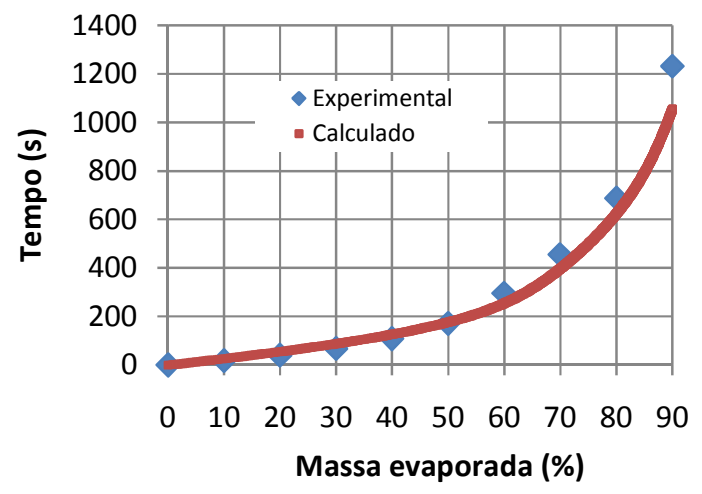

Figura 10 - Curva de evaporação da mistura 5 


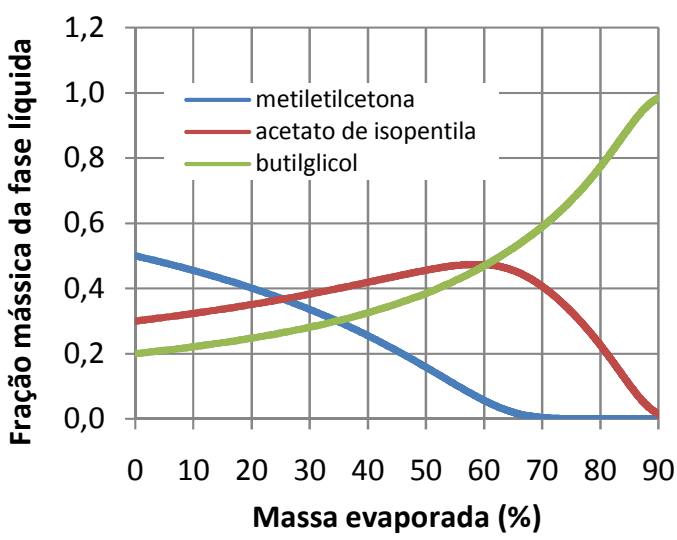

Figura 11 - Curva de composição predita para a evaporação da mistura

5

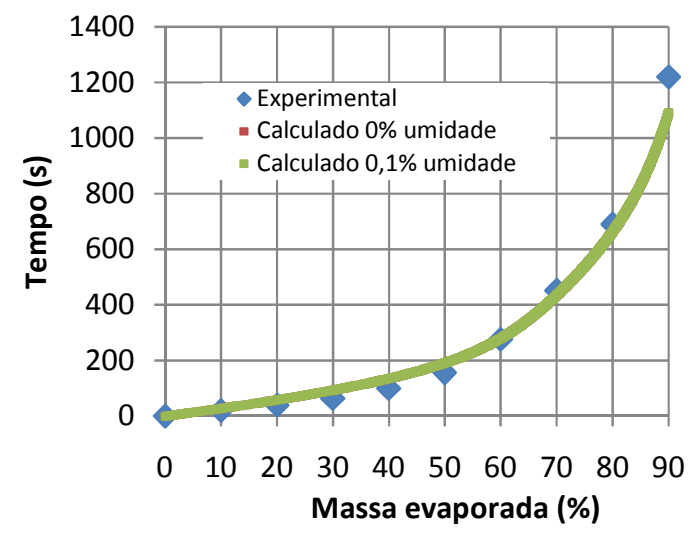

Figura 12 - Curva de evaporação da mistura 6

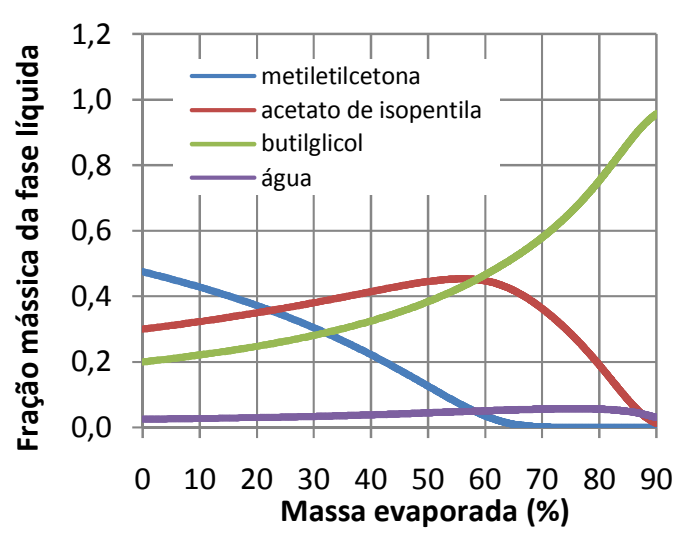

Figura 13 - Curva de composição predita para a evaporação da mistura 6
Para cada mistura foi calculado o RMSE entre 10 e $80 \%$ de evaporado, e também o erro relativo para o tempo de evaporação em $90 \%$ de evaporado entre a curva experimental e a teórica. Estes resultados estão listados na tabela 2.

Tabela 2 - Resultados de RMSE e

Erro Relativo para as misturas de solventes

\begin{tabular}{|l|c|c|}
\hline Mistura & $\begin{array}{c}\text { RMSE } \\
(\mathbf{1 0 - 8 0 \%} \text { evaporado) }\end{array}$ & $\begin{array}{c}\text { Erro Relativo } \\
\text { (\%) } \mathbf{( 9 0 \%} \\
\text { evaporado) }\end{array}$ \\
\hline Mistura 1 & 2,96 & 0,21 \\
\hline Mistura 2 & 1,53 & 3,99 \\
\hline Mistura 3 & 2,69 & 7,76 \\
\hline Mistura 4 & 15,35 & $-26,33$ \\
\hline Mistura 5 & 3,89 & 14,26 \\
\hline Mistura 6 & 5,19 & 10,56 \\
\hline
\end{tabular}

Os valores de RMSE dão uma noção de quão ajustados estão os valores experimentais e calculado. Assim, é possível observar um bom ajuste para quase todas as curvas geradas. A mistura 4 foi a que apresentou o maior desvio, que pode ser explicado pela grande diferença de propriedades químicas e estruturais do ciclohexano com os demais solventes da mistura. Esta mesma mistura foi a que apresentou maior desvio no tempo final de evaporação, em $90 \%$ evaporado. É possível que estas diferenças possam ser minimizadas se forem utilizadas melhores correlações, mais complexas, para o cálculo do coeficiente de atividade. Também é possível que, para algumas misturas, nos instantes finais haja uma mudança de regime, verificada pelas diferenças entre os valores calculados e observados experimentalmente.

Todos os experimentos realizados seguiram a metodologia sugerida pela ASTM D 3539. A umidade relativa observada para todas estas curvas foi da ordem de $0,1 \%$. O valor de umidade relativa foi utilizado 
apenas no cálculo para a mistura 6, que possui água em sua composição, e foi observado que não há diferença significativa nos resultados. Ou seja, para este nível de umidade relativa, esta tem pouca ou nenhuma influência no resultado de evaporação obtido pelo modelo.

Embora não tenha sido possível determinar valores experimentais que consigam validar o perfil observado nas curvas de composição durante a evaporação, é possível observar que estes modelos são coerentes do ponto de vista de volatilidade relativa entre os solventes de cada mistura.

\section{CONCLUSÕES}

O modelo estudado apresenta um bom ajuste com os resultados experimentais, em geral, para os solventes que apresentam propriedades e estrutura química semelhantes. Porém, é necessário avaliar outras equações para o cálculo do coeficiente de atividade que garantam um melhor ajuste para diferentes perfis moleculares, e avaliar o impacto que estes terão no tempo de evaporação em $90 \%$ de evaporado.

Para os níveis de umidade admitidos pela norma, o termo de correção da taxa de evaporação do componente água nas misturas com base na umidade relativa não é significativo. Porém, pode ser importante se a taxa de evaporação for extrapolada para condições de umidade relativa alta.

Para o modelo estudado ainda se faz necessário conhecer a taxa de evaporação do solvente puro determinado a partir da metodologia da ASTM D 3539. É de extrema valia estudar o mecanismo de evaporação dos solventes puros e encontrar modelos para estes, que dependam apenas de correlações de propriedades e de transporte comuns para os solventes. Além de poder avaliar 0 comportamento da evaporação para condições de temperatura diferentes àquelas às quais a norma se limita.

\section{NOMENCLATURA}

$\% m_{\text {evap }}(t)^{\text {exper. }}$ - Porcentagem da massa total da mistura de solventes evaporada para $o$ tempo $t$, determinada a partir dos dados experimentais.

$\% m_{\text {evap }}(t)^{\text {calc. }}$ - Porcentagem da massa total da mistura de solventes evaporada para o tempo $t$, determinada a partir dos dados calculados do modelo de mistura.

$r_{i}^{o}$ - taxa de evaporação do solvente i puro $(\mathrm{g} / \mathrm{s})$.

$R$ - taxa total de evaporação da mistura (g/s).

$\mathrm{RH}$ - umidade relativa do ar ambiente em volta da mistura em evaporação (\%).

RMSE - root mean square error, ou seja, erro médio quadrático.

$\mathrm{t}$ - tempo (s).

$v_{i}$ - volume molar do solvente $\mathrm{i}$ $\left(\mathrm{cm}^{3} / \mathrm{mol}\right)$.

$\mathrm{w}_{\mathrm{i}}$ - fração mássica do solvente $\mathrm{i}$ na mistura.

$x_{i}$ - fração molar do solvente i na mistura.

$\delta_{i}$ - parâmetro de solubilidade de Hildebrand do solvente i $\left(\mathrm{MPa}^{1 / 2}\right)$.

$\Phi_{\mathrm{i}}$ - fração volumétrica do solvente i na mistura. 
$\gamma_{\mathrm{i}}$ - coeficiente de atividade do solvente i.

\section{REFERÊNCIAS}

ASTM D 3539. Standard Test Methods for Evaporation Rates of Volatile Liquids by Shell Thin-Film Evaporometer.

BARTON, A. F. M. Handbook of Solubility Parameters and Other Cohesion Parameters. Boca Raton, Florida: Editora CRC Press, 1983.

GARBELOTTO, P.; RIZZATO, A.; LEITE, A. C.; SCHUCH, C. M.; ZIM, D.; VICENTIM, D. J.; RODRIGUES, E. L.; MARRA, F.; ZANATTA, F.; SANTOS, H.; SANTOS, L.; COUTO, M. L. T.; DE NADAI, R.; MARTINS, S. Solventes Industriais: seleção, formulação e aplicação. São Paulo: Editora Blucher, 2007.

LINAK, E. Green Solvents - Safe \& Sustainable Chemicals Report. SRI Consulting, 2006.

PRAUSNITZ, $\quad$ J. $\quad M . ;$ LICHTENTHALER, R. N.; AZEVEDO, E. G. Molecular Thermodynamics of Fluid-Phase Equilibria. Prentice Hall PTR, 1999.

ROCKLIN, A. L.. Computer Methods for Finding Solvent Blend Replacements and for Predicting
Water/Cosolvent Evaporation at Any Humidity. ACS Symposium Series, p. 427-437, 1982.

ROCKLIN, A. L.. Effect of Humidity and Other Ambient Conditions On Evaporation of Ternary Aqueous Solvent Blends. J. Coat. Technol., v. 50 (646), p. 46-55, 1978.

ROCKLIN, A. L.; BONNER, D. C.. A Computer Method for Predicting Evaporation of Multicomponent Aqueous Solvent Blends at Any Humidity. J. Coat. Technol., v.52 (670), p. 27-36, 1980.

SAARY, Z.; GOFF, P. L. New Instrument to Measure Solvent Evaporation. J. Paint Technol., v. 45 (583), p. 45-55, 1973

SLETMOE, G. M. The Calculation of Mixed Hydrocarbon-Oxygenated Solvent Evaporation. J. Paint Technol., v. 42 (543), p. 246-259, 1970.

SLETMOE, G. M.. The Evaporation of Nonhydrogen-Bonding Solvents from Resin Films. J. Paint Technol., v. 38 (502), p. 642-655, 1966.

WALSHAM, J. G., EDWARDS, G. D. A Model of Evaporation from Solvent Blends. J. Paint Technol., v.43 (554), p. 64-70, 1971.

www.abiquim.com.br, 2009 